\title{
Molten Salt Reactor Campaign Modeling and Simulation Program Plan
}

Nuclear Technology

Research and Development

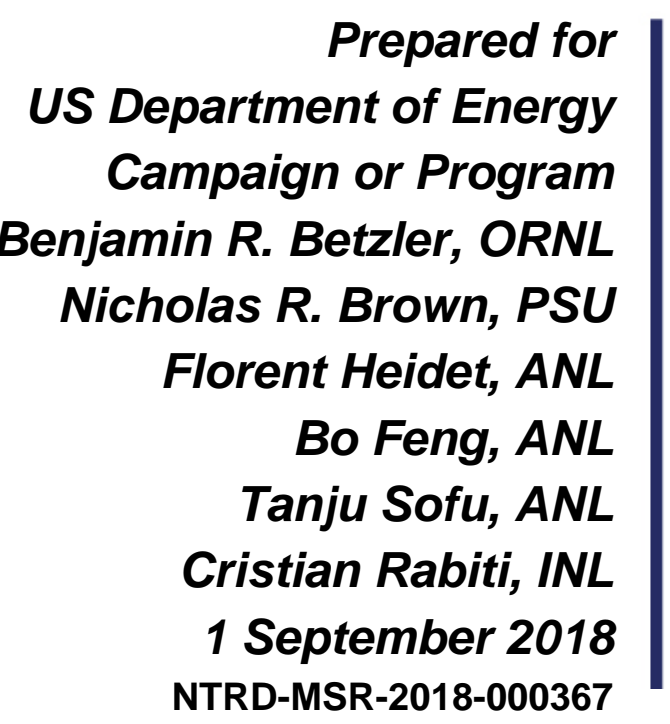





\section{DISCLAIMER}

This information was prepared as an account of work sponsored by an agency of the U.S. Government. Neither the U.S. Government nor any agency thereof, nor any of their employees, makes any warranty, expressed or implied, or assumes any legal liability or responsibility for the accuracy, completeness, or usefulness, of any information, apparatus, product, or process disclosed, or represents that its use would not infringe privately owned rights. References herein to any specific commercial product, process, or service by trade name, trade mark, manufacturer, or otherwise, does not necessarily constitute or imply its endorsement, recommendation, or favoring by the U.S. Government or any agency thereof. The views and opinions of authors expressed herein do not necessarily state or reflect those of the U.S. Government or any agency thereof. 



\section{SUMMARY}

The modeling and simulation activities within the Molten Salt Reactor Research and Development Campaign of the US Department of Energy Office of Nuclear Energy Advanced Reactor Technologies Program facilitate the development and application of analysis tools for the licensing and design of molten salt reactors.

This document describes the modeling and simulation focus areas, goals, and activities of the Molten Salt Reactor campaign. This includes an assessment of the modeling and simulation functional needs for molten salt reactors for licensing and design. This assessment is generated using a licensing-focused approach considering the modeling and simulation components that contribute to a molten salt reactor safety analysis report. These functional needs are prioritized by identifying the relationships between functional needs and using a weighting scheme to identify the most critical components to build a licensing case. In addition, functional need inputs are ranked to reveal those that feed the most modeling and simulation components. The modeling and simulation objectives of the Molten Salt Reactor campaign are drawn directly from the findings of this prioritization effort, with some additional expert judgement.

The identified modeling and simulation needs fall into three focus areas:

(1) source term definition, material accountancy, and radiological consequences, (2) safety analysis, and (3) steady-state neutronics and thermal hydraulics. Five near-term goals were identified among these focus areas that add value and draw on current Department of Energy capabilities: (1) deploying a systems and safeguards analysis computational tool, (2) defining source term analysis and interfacing with the US Nuclear Regulatory Commission on accident progression analysis, (3) developing point designs for liquid-fueled thermal-spectrum and fast-spectrum molten salt reactors, (4) building safety analysis specifications and reference solutions for Molten Salt Reactor Experiment transients, and (5) interfacing with the thermophysical and thermodynamic salt chemistry databases. The intent is to accomplish these goals over the course of four years beginning fiscal year 2019, provided that resources are adequate and changes to these objectives are not significant. 


\section{CONTENTS}

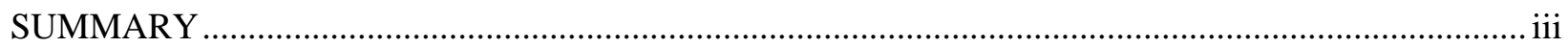

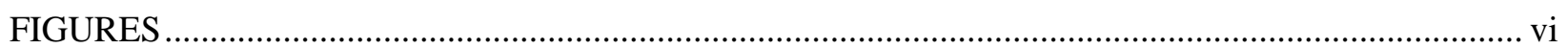

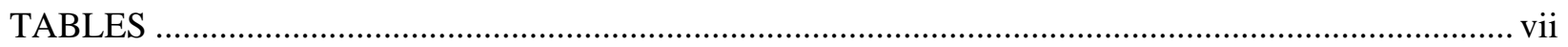

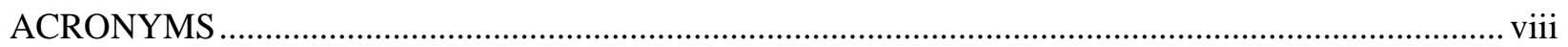

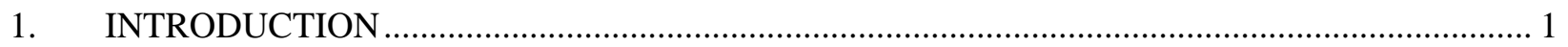

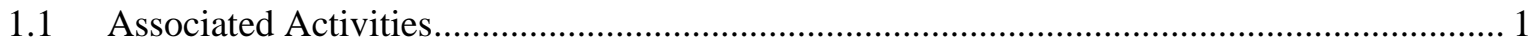

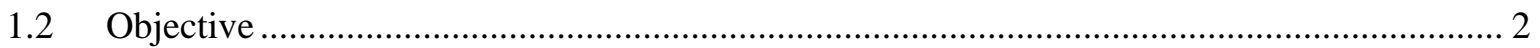

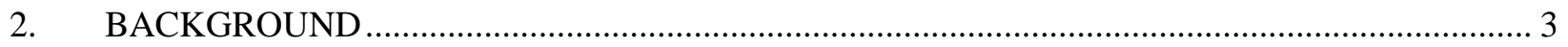

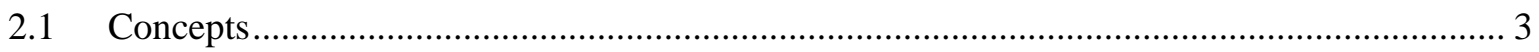

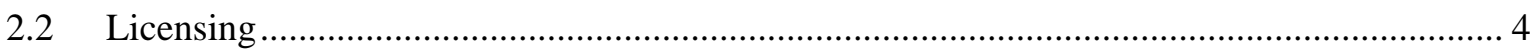

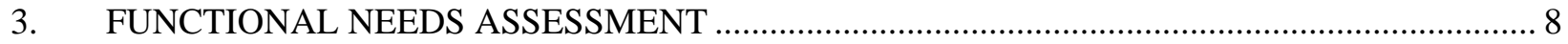

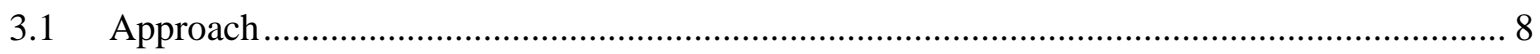

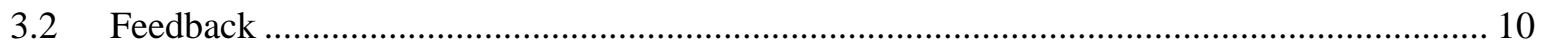

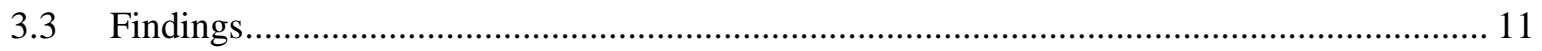

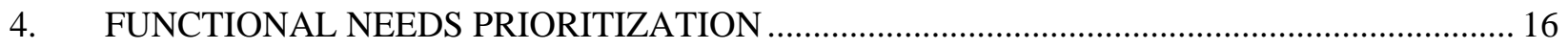

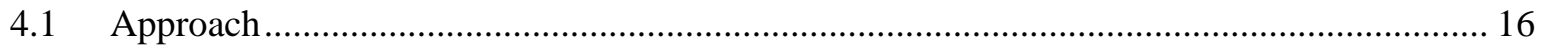

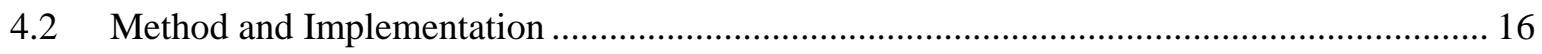

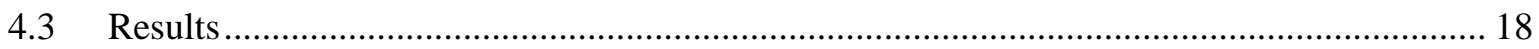

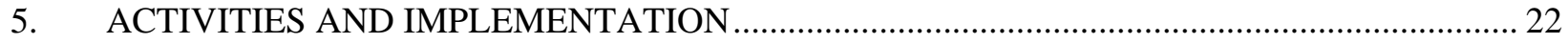

5.1 Timeliness and Non-Licensing Functional Needs .......................................................... 22

5.2 Program Focus Areas and Objectives …........................................................................ 22

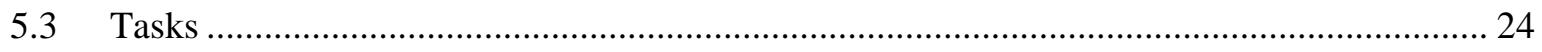

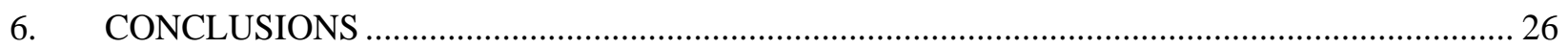

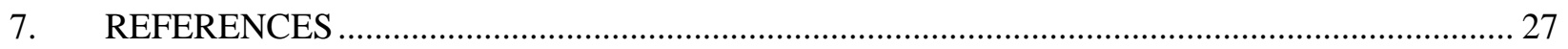

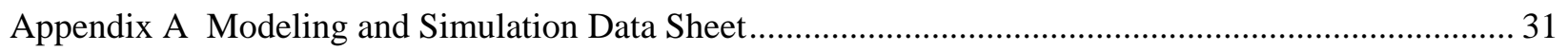

Appendix B Functional Needs Assessment Feedback .......................................................................... 34

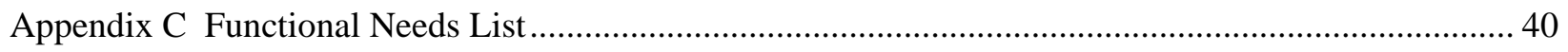




\section{FIGURES}

Figure 1. Modeling and simulation focus areas in the MSR campaign. 3

Figure 2. Neutron flux spectrum in some MSR concepts representing the different focus area within the MSR campaign (Brown et al. 2015, Brown et al. 2017, Taube and Ligou 1974). . .4

Figure 3. Visual depiction of MSR modeling and simulation functionalities............................................ 5

Figure 4. Parallel paths for power reactor licensing (Petti et al. 2016) …................................................. 5

Figure 5. Parallel paths for software quality assurance (Brown et al. 2016, Brunett et al. 2017)................ 6

Figure 6. Inputs to the reactor licensing process (Petti et al. 2016) ...................................................... 7

Figure 7. Dose estimation functionality diagram showing identified input and outputs. .......................... 9

Figure 8. Expanded source term accountability functionality diagram showing linkages to other

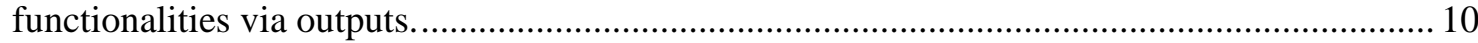

Figure 9. Expanded predict atmospheric transport of radioactive plume segments functionality diagram showing linkages to other functionalities via inputs.................................................. 10

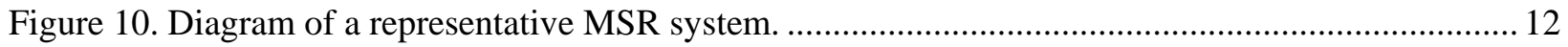

Figure 11. Diagram of a representative MSR system highlighting isotopic composition of in-core fuel salt. 13

Figure 12. Diagram of a representative MSR system highlighting isotopic composition of in-core fuel salt and processing tanks. 14

Figure 13. Diagram of a representative MSR system highlighting isotopic composition of in-core fuel salt, processing tanks, and all pipes and components within the primary system. 14

Figure 14. Diagram of a representative MSR system highlighting isotopic composition of in-core fuel salt, processing tanks, all pipes and components within the primary system and cover gas system. 15

Figure 15. Fuel depletion functionality diagram showing input, output, and function weights. 17

Figure 16. Iterative scoring method to generating and converge weights of inputs, outputs, and functionalities. 17

Figure 17. Prioritized functionalities with relative scores. 19

Figure 18. Highest priority inputs ordered by relative scores. 21 


\section{TABLES}

Table 1. List of modeling and simulation functional needs. ............................................................... 11 


\section{ACRONYMS}

$\begin{array}{ll}\text { AFC } & \text { Advanced Fuels Campaign } \\ \text { AHTR } & \text { advanced high-temperature reactor } \\ \text { CASL } & \text { Consortium for Advanced Simulation of Light Water Reactors } \\ \text { DOE } & \text { US Department of Energy } \\ \text { FHR } & \text { fluoride salt-cooled high-temperature reactor } \\ \text { HTGR } & \text { high-temperature gas-cooled reactor } \\ \text { IS MSR } & \text { Intermediate Spectrum Molten Salt Reactor } \\ \text { LWR } & \text { light water reactor } \\ \text { LWRS } & \text { Light Water Reactor Sustainability } \\ \text { MCFR } & \text { Molten Chloride Fast Reactor } \\ \text { MPACT } & \text { Material Protection, Accounting and Control Technologies } \\ \text { mHTGR } & \text { modular high temperature gas-cooled reactors } \\ \text { MSR } & \text { molten salt reactor } \\ \text { MSRE } & \text { Molten Salt Reactor Experiment } \\ \text { MW } & \text { megawatt } \\ \text { NBSR } & \text { National Bureau of Standards Reactor } \\ \text { NEAMS } & \text { Nuclear Energy Advanced Modeling and Simulation } \\ \text { NEUP } & \text { Nuclear Energy University Program } \\ \text { NIST } & \text { National Institute of Standards and Technology } \\ \text { NRC } & \text { US Nuclear Regulatory Commission } \\ \text { PIRT } & \text { phenomena identification ranking table } \\ \text { PRA } & \text { probabilistic risk assessment } \\ \text { R\&D } & \text { research and development } \\ \text { SFR } & \text { sodium-cooled fast reactor } \\ & \end{array}$





\section{MOLTEN SALT REACTOR CAMPAIGN MODELING AND SIMULATION PROGRAM PLAN}

\section{INTRODUCTION}

The objective of the Molten Salt Reactor (MSR) Research and Development Campaign within the US Department of Energy (DOE) Office of Nuclear Energy Advanced Reactor Technologies Program is to enable the licensing and deployment of MSR concepts by developing capability and providing expertise to molten salt reactor vendors, license applicants, and the regulator. As part of this campaign, modeling and simulation activities facilitate the development and application of analysis tools for licensing and design. The following phased approach for Fiscal Year 2018 has been used to determine the activities to be undertaken in coming years:

1. Identification of functional needs for modeling and simulation tools;

2. Prioritization of modeling and simulation development needs to deliver software tools that enable design optimization and licensing;

3. Development of a five-year modeling and simulation plan; and

4. Integration of development efforts within DOE programs, including Nuclear Energy Advanced Modeling and Simulation (NEAMS), the Consortium for Advanced Simulation of Light Water Reactors (CASL), Light Water Reactor Sustainability (LWRS), the Advanced Fuels Campaign (AFC), the Systems Analysis and Integration Campaign, and the Material Protection, Accounting and Control Technologies (MPACT) Campaign.

These efforts are independent of any specific toolset or application to any specific MSR concept. The objective is to identify the important capabilities necessary to build a licensing case and establish the path to close existing knowledge gaps. The resulting five-year modeling and simulation plan must be flexible enough to adapt to timeline and/or scope changes due to fluctuations in technology developer schedules, tool developer capabilities, and funding availability. Each of these factors may impact the relative prioritization of the activities identified in this plan. It is crucial to ensure effective communication and integration with other DOE programs to identify and leverage existing or emerging capabilities and knowledge. There is a broad interest across these programs to develop the capabilities needed to analyze and study MSRs. Effective communication with MSR technology developers is necessary to ensure that the activities are relevant to industry needs.

\subsection{Associated Activities}

Relevant MSR campaign planning activities include licensing (Belles et al. 2018), chemistry modeling, chemistry database development (McMurray et al. 2018), and corrosion modeling. Due to the focus on building a licensing case, this modeling and simulation plan is integral to license planning.

Relevant activities outside the MSR campaign have yielded important resources to enable licensing of MSRs. The US Nuclear Regulatory Commission (NRC) has defined specific readiness (NRC 2016) and near- and long-term implementation action plans (NRC 2017a, NRC 2017b) for non-light water reactor (LWR) technologies. Regulator and university activities have funded expert elicitations to develop phenomena identification and ranking tables (PIRT) on fluoride salt-cooled high-temperature reactors (FHRs) (Rahnema et al. 2016, Sun et al. 2017) and fluid-fueled MSRs (Diamond et al. 2018). Increased interest in MSRs has resulted in funding for activities across multiple DOE programs, regulator funding for R\&D activities, relevant Nuclear Energy University Program (NEUP) awards, internally funded laboratory research and development (R\&D) activities, and MSR developer funding awards (i.e., publicprivate partnerships). These activities include support funded by the Gateway for Accelerated Innovation 
in Nuclear (GAIN) awards, NRC-funded accident progression analysis, safeguards analysis within the MPACT campaign, and development activities within NEAMS.

While full coordination between these various activities may not be practical, a broader awareness of ongoing activities within these programs is important, as some underlying methodologies and models may be shared, and activities that are impactful on MSR licensing and operation must be known.

\subsection{Objective}

This document provides a high-level overview of MSR technology, discusses the MSR modeling and simulation functional needs assessment and prioritization approaches, and provides a prioritized modeling and simulation activity plan to facilitate near-term MSR deployment. 


\section{BACKGROUND}

A broader definition of MSR includes any reactor using molten salt to serve a major function. Most often, this molten salt is used as the primary system coolant for both solid- and liquid-fueled concepts. Graphitemoderated plate (Greene et al. 2010), stringer (Szakaly et al. 2007), compact (Qualls et al. 2017), and pebble (Andreades et al. 2016) solid fuel forms have been studied with or without microsphere particle fuels. These systems (FHRs) often use more technically mature fluoride coolant salts. In liquid-fueled concepts, fissile and fertile fuel compounds are dissolved in fluoride or chloride carrier salts. Fluoride carrier salts have been used or proposed for thermal spectrum systems (Bettis and Robertson 1970, Robertson et al. 1971, Engel et al. 1980, Betzler et al. 2018a), but in a few cases, they have been proposed in systems without moderator materials (Ignatiev et al. 2009, EVOL 2015). Chloride carrier salts are often considered for deployment in fast spectrum reactor systems (Smith and Simmons 1974, Taube and Ligou 1974, Mourogov and Bokov 2006) due to their potential for achieving a harder spectrum (Holcomb et al. 2011). Liquid-fueled concepts have drawn the bulk of private industry focus due to their potential for improving fuel cycle metrics (Betzler et al. 2017) and passive safety (Elsheikh 2013). Liquid-fueled concepts also present more significant challenges in reactor modeling and simulation with respect to solid-fueled systems.

\subsection{Concepts}

There are three main types of salt reactor concepts under active development in the United States: (1) fluoride salt-cooled reactor concepts, (2) fluoride salt-fueled reactor concepts, and (3) chloride saltfueled fast spectrum reactor concepts (Figure 1). Each of these concepts represents a focus area for the MSR campaign modeling and simulation activities. While each concept has unique needs (e.g., pebble bed flow models for salt-cooled reactor concepts), there is common R\&D required to enable licensing that benefits all concepts. Cross-cutting items that are significant for accelerating reactor deployment are the most critical components of these modeling and simulation activities. These advanced reactor concepts also have functional needs that differ from established nuclear reactor modeling and simulation capabilities (e.g., coupling to chemistry models).

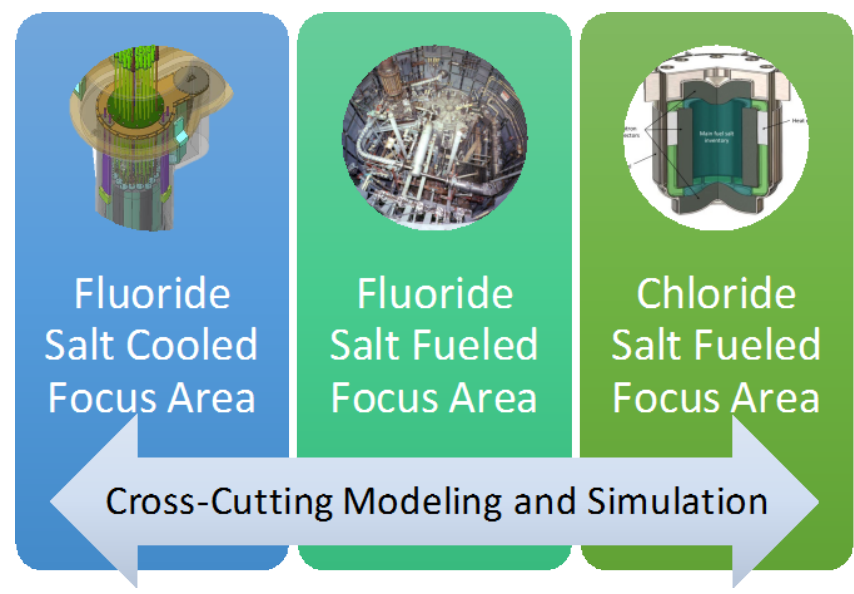

Figure 1. Modeling and simulation focus areas in the MSR campaign.

Design missions and commercial objectives for current MSR concepts include nuclear waste incineration, electricity generation, process heat, and hybrid energy systems. These varied objectives are made possible due to the design flexibility of MSR technology: different carrier salts and fuel forms provide a flexibility in temperature, neutron spectrum, and power density (Figure 2). Likewise, the possible licensing approaches and the modeling and simulation needs to support these designs vary considerably from one concept to another. 
With this broad application space and aggressive development timelines, it is important to gain a focused understanding of MSR modeling and simulation needs to (1) generate the most impact from MSR campaign activities and (2) to ensure the efficient use of computational development resources.

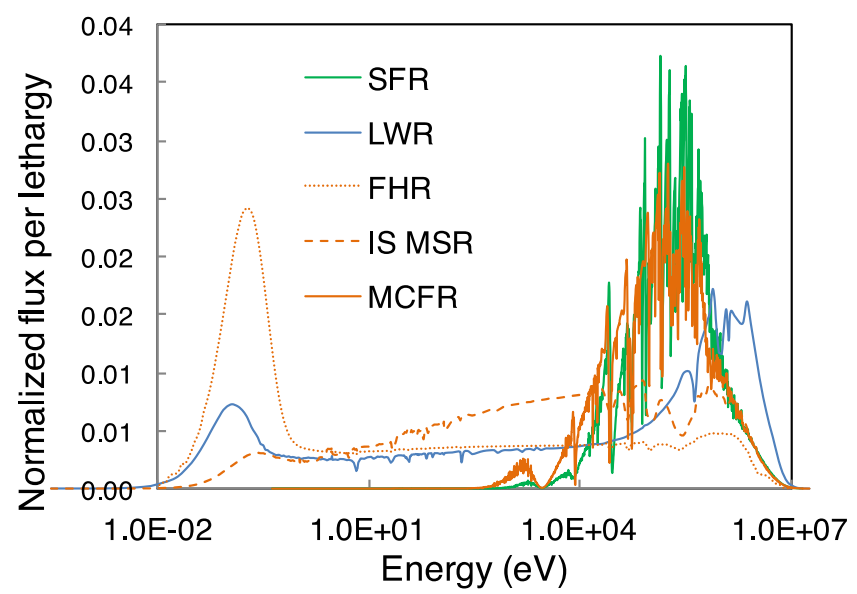

Figure 2. Neutron flux spectrum in some MSR concepts representing the different focus area within the MSR campaign (Brown et al. 2015, Brown et al. 2017, Taube and Ligou 1974).

\subsection{Licensing}

The key question in prioritizing the modeling and simulation activities as part of the MSR campaign is, what is the priority ranking of the identified functionalities, and how will those priorities be addressed? The overall high-level goal to accelerate design, licensing, deployment, and operation of MSR concepts within the United States requires a thorough understanding of each concept's functional requirements, as well as the potential licensing approaches. There are three tool functionality categories that support licensing approaches considered as part of the development of the modeling and simulation plan:

1. Test reactor licensing tool functionalities are the foundational elements of the modeling and simulation needed to design and license a molten salt test reactor; they represent the basic building blocks: defining the source term of a maximum hypothetical accident in a molten salt test reactor. This maximum hypothetical accident approach is only relevant for test reactor licensing; generating a mechanistic source term would be the approach for an engineering demonstration or commercial demonstration reactors.

2. Demonstration reactor licensing tool functionalities are necessary to license a commercial demonstration plant using a "license-by-prototype" approach. These tools must fulfill software quality assurance requirements for commercial dedication or regulator's requirements for confirmatory analysis tools.

3. Exemplary reactor design tool functionalities are those that enable high-fidelity design optimization of MSRs and inform lower order models used in licensing. If they are intended to support establishing the design envelope for Chapter 4, then these tools must fulfill software quality assurance requirements for commercial dedication. Specific directed application of these tools, including informing lower fidelity models and quantifying/reducing uncertainties, will be conducted as part of the MSR campaign.

Each of these sets of functionalities requires software quality assurance support activities that are relevant for either DOE licensing (test reactor), NRC confirmatory analysis, or commercial dedication. There is overlap in these functionalities, and the exemplary reactor design tools' functionalities provide the detailed design information that feeds the licensing process (Figure 3). 


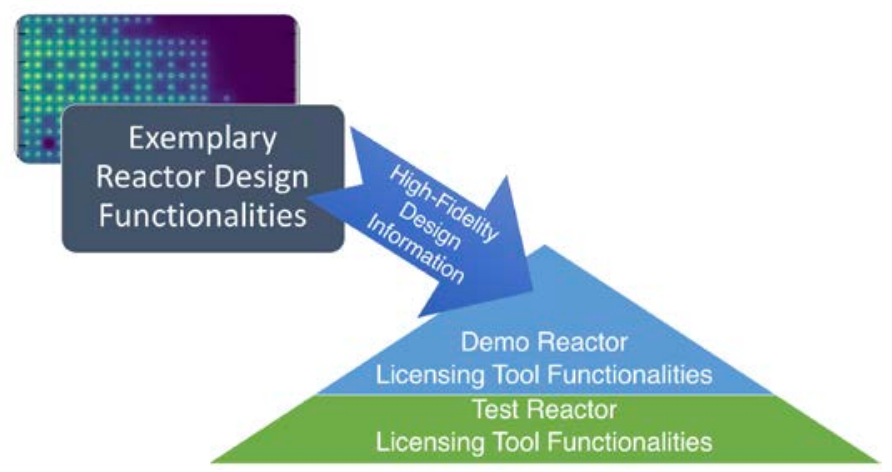

Figure 3. Visual depiction of MSR modeling and simulation functionalities.

The main licensing pathways for MSRs are the test reactor licensing pathway (non-power reactor) and the power reactor licensing pathway. These two approaches are reviewed here. The test reactor licensing pathway is for a test facility licensed under Subsection 104(c) of the Atomic Energy Act (AEA) and is defined as a nuclear reactor of the type described in § 10 CFR 50.21(c) for operation at:

- A thermal power level in excess of 10 megawatts; or

- A thermal power level in excess of 1 megawatt, if the reactor is to contain:

o A circulating loop through the core in which the applicant proposes to conduct fuel experiments; or

o A liquid fuel loading.

It is notable that there is currently one NRC-licensed test reactor, also a non-LWR, the 20 megawatt (MW) National Institute of Standards and Technology (NIST) reactor, known as the National Bureau of Standards Reactor (NBSR) in Gaithersburg, Maryland. The key requirement of such a facility is that it is to be used so that no more than $50 \%$ of the annual cost of owning and operating the facility is devoted to the production of materials, products, or energy for sale or commercial distribution or to the sale of services other than $R \& D$, education, or training. The functionalities required for this licensing pathway are classified as "test reactor licensing tool functionalities" in this document.

There are two relevant power reactor licensing pathways: the conventional two-step class 103 license, and the license-by-prototype approach (Figure 4). Each reactor developer may be pursuing a different approach to licensing a commercial unit. Both approaches have similar modeling and simulation requirements, which are referred to herein as "demonstration reactor licensing tool functionalities.”

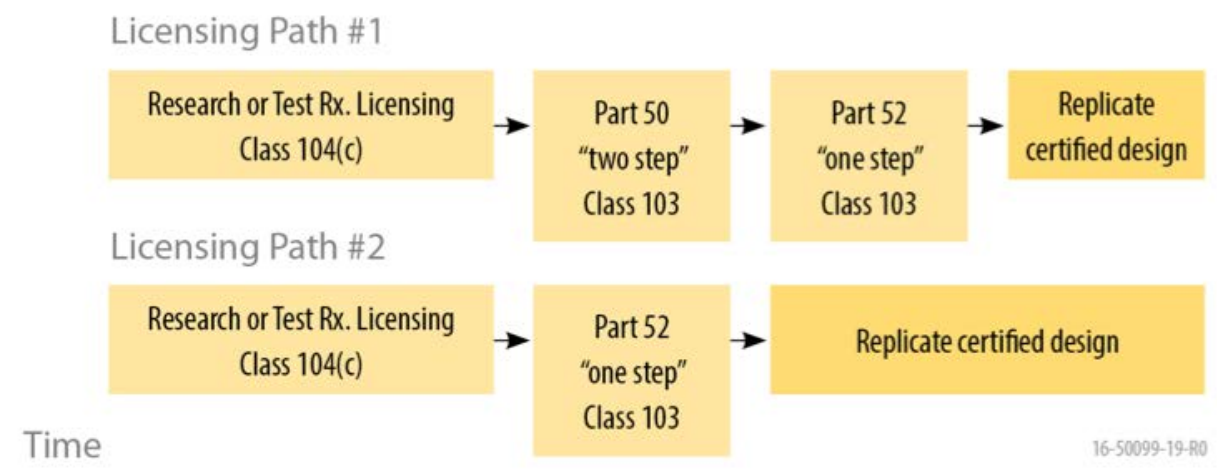

Figure 4. Parallel paths for power reactor licensing (Petti et al. 2016). 
Regardless of the licensing pathway selected, there are some commonalities for the development of a safety analysis report or a design control document. Below are the common chapters of a licensing application:

- Chapter 3: modeling and simulation tools required to study the design of structures, components, equipment, systems, and seismic events;

- Chapter 4: modeling and simulation tools that define the nuclear design, fuel design, thermal hydraulic design, reactor materials, and reactor control;

- Chapter 15: modeling and simulation tools for anticipated operational occurrences, design basis events; and

- Chapter 19: accident progression modeling and simulation tools, including probabilistic risk assessment (PRA) and severe accident analysis.

This ranking is focused on establishing credible source term, operating conditions, and accident analysis. Specifically, the ranking is focused on Chapter 4 and Chapter 15, with emphasis on answering the question, how do transient and accident events progress and what are the consequences? The functional requirements for the analysis of beyond-design-basis-accidents in Chapter 19 are similar to those in Chapter 15, but they also include PRA. Chapter 4 and Chapter 15 are considered to be the most crosscutting areas for near-term functional needs over the next several years because they are a necessary precursor to licensing.

Recent guidance from the $\mathrm{NRC}^{\mathrm{a}}$ suggests that the most important factor in confirmatory analysis is not necessarily the requirement for entirely independent tools, but rather is the requirement for independent users and applications of those tools. In addition, although the initial condition for NRC confirmatory tools and commercially dedicated license application tools might be similar for MSRs, the parallel paths for quality assurance are different (Figure 5).
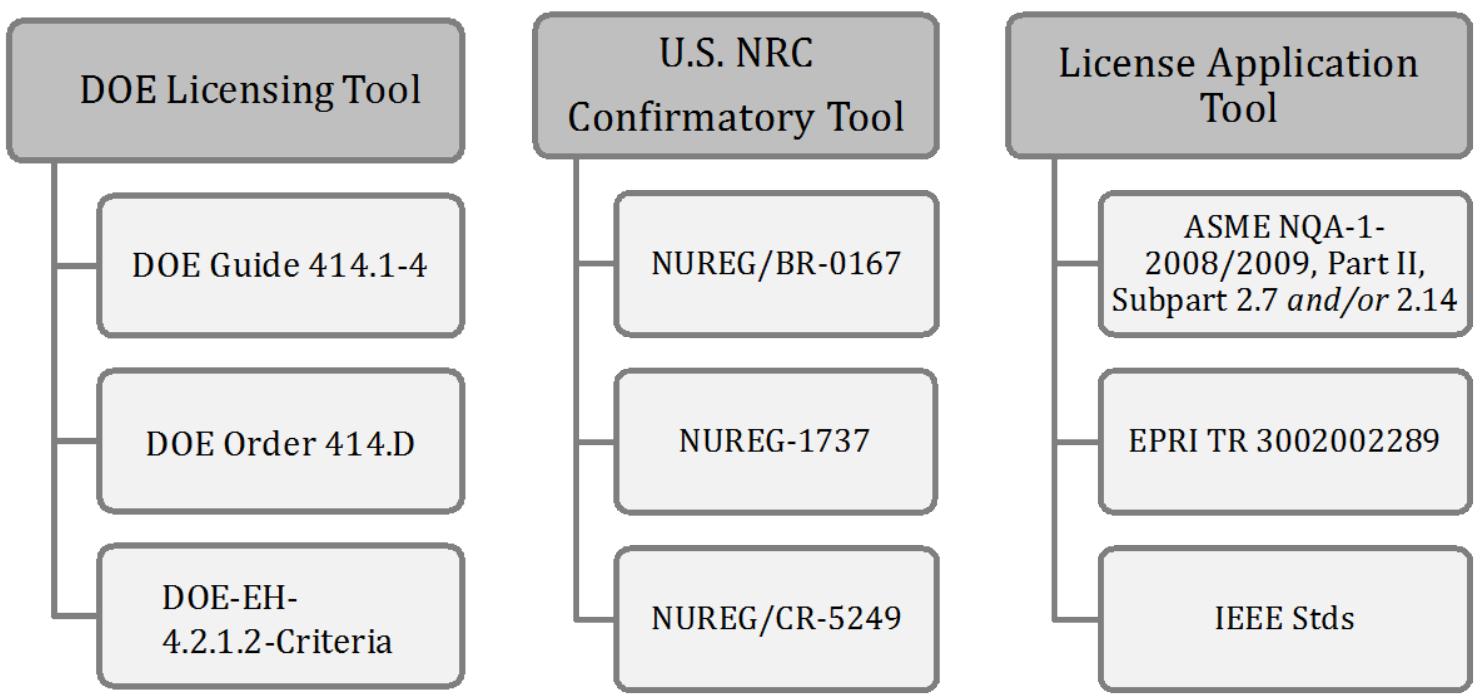

Figure 5. Parallel paths for software quality assurance (Brown et al. 2016, Brunett et al. 2017).

A depiction of the licensing process is shown in Figure 6. This visual depiction cross-cuts all licensing pathways and guides the ranking process of functional needs. The objective is to establish the

\footnotetext{
a S. M. Bajorek, Molten Salt Reactor Workshop 2017, October 3-4.
} 
functionalities required for accident analysis, consequences analysis, and source term assessments. The major interfaces between the modeling and simulation activities and the modeling process is the development of analytical codes and methods. Secondary interfaces to licensing activities that are directly supported by modeling and simulation activities within the MSR campaign include core design and heat removal, accident sequences and initiators, fuel qualification, and eventually dose calculation.

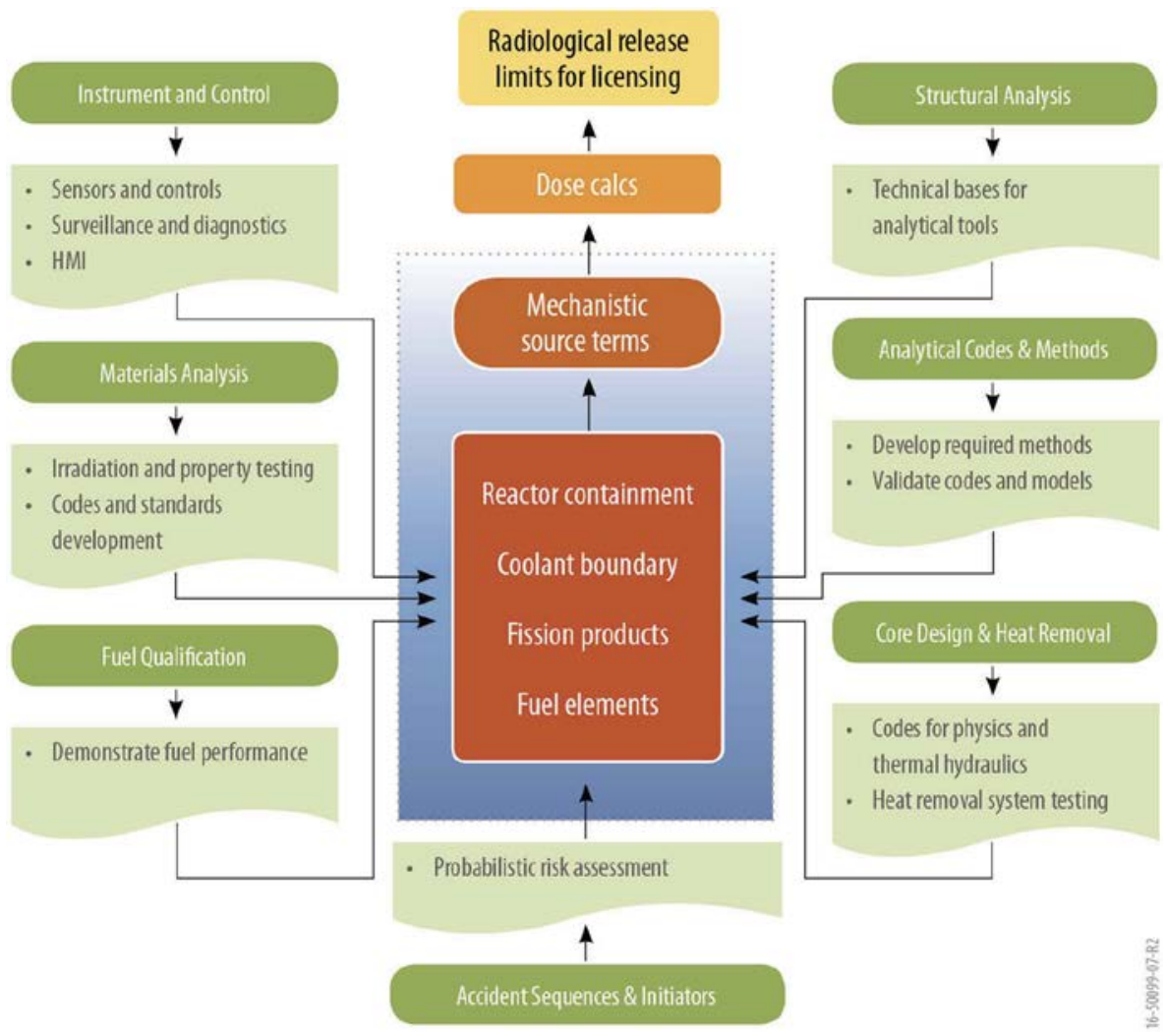

Figure 6. Inputs to the reactor licensing process (Petti et al. 2016). 


\section{FUNCTIONAL NEEDS ASSESSMENT}

The overall high-level goal of accelerating the design, licensing, and deployment of MSR concepts within the United States requires an understanding of the functional modeling and simulation requirements for each of the concepts, as well as the potential licensing approaches. The first steps in the functional needs assessment are to (1) identify the components of a reactor licensing case supported by modeling and simulation and (2) identify the associated safety analysis report or design control document chapter where the components appear: structural and seismic (Ch. 3); fuel, nuclear, and thermal hydraulic design (Ch. 4); accident analyses (Ch. 15); accident progression and consequences analysis (Ch. 19); and other fuel and component surveillance programs (multiple chapters). Once the chapters are identified, the modeling and simulation functionalities applicable for those licensing components must be identified. Therefore, each identified modeling and simulation functional need herein either directly or indirectly supports a licensing requirement.

The licensing requirements are outlined for LWRs in 10 CFR 50, Appendix A, "General Design Criteria," and review of these requirements is governed by the Standard Review Plan (NUREG-0800, or NUREG-1537 for non-power reactors). Generic advanced reactor design criteria (Holbrook and Kinsey 2015) are supplied in Regulatory Guide 1.232 (Mazza 2018), and a draft revision of the Standard Review Plan (Belles et al. 2017) for advanced reactors are also available. The proposed revision of the Standard Review Plan is focused on modular high temperature gas-cooled reactors (mHTGRs) and sodium-cooled fast reactors (SFRs), but not MSRs.

\subsection{Approach}

Each functionality is defined by modeled physical phenomena and associated inputs and outputs. This facilitates linking the functionalities and determining which functionalities apply to others in a reactor licensing case. Each functionality does not necessarily represent a single modeling and simulation tool, but it may have different requirements, depending on desired outputs (e.g., steady-state vs. timedependent analysis tools). A high-level approach to defining these functionalities was chosen to provide a more communicable format favoring inclusive generic definitions (e.g., isotopic composition) over specific quantifications (e.g., Xe concentrations). Because this generic approach covers three reactor types, some identified inputs and outputs apply to only one or two of these types, while some inputs and outputs carry different levels of importance for each type.

These functionalities were captured in modeling and simulation functionality datasheets designed to succinctly communicate each functional need, including capabilities and requirements, for MSR modeling and simulation that supports reactor licensing. These data sheets also provide a means to add and integrate modeling and simulation capabilities that may come to light in the future. The following definitions outline the expectations for each field that must be populated in the datasheet. The datasheet defines each functionality, the underlying physical phenomena that must be modeled, the required inputs and outputs to the functionality, and the links to other functionalities. These links define the dependence of each individual modeling and simulation functionality on other functionalities.

1. Modeling and simulation functionality: defines the functionality being described. The functionalities are described at a high level, and they support specific licensing objectives. For example, a high-level functionality that supports safety analysis in Chapter 15 is "modeling of active and passive safety systems and components.” This functionality includes many supporting physical phenomena that must be modeled; these phenomena are described in the "definitions and phenomena" field. Functionalities should be linked to the chapter and sections of a typical safety analysis report or to the design control document that they support.

2. Inputs required: defines the input requirements of the functionality. This includes data flow and derived requirements directly linked to input requirements. Derived requirements are not defined explicitly, but they are required to carry out the functionality. Clarity and completeness are ideal; 
input requirements must be defined consistently, as links between functionalities will be established.

3. Definitions and phenomena: defines the technical performance details of the functionality. Specifically, this field identifies the fundamental physical phenomena that must be modeled to generate the output of the functionality. This field also identifies the other operations that must be performed to translate the input requirements into outputs and derived requirements for other functionalities.

4. Outputs obtained: communicates key outputs of the functionality that directly support the licensing process and are needed for a safety analysis report or design control document. These outputs must be defined clearly, comprehensively, and consistently with the input requirements, as links will be established between functionalities (i.e., some outputs are used as inputs for other functionalities).

5. Additional comments: identifies direct links between outputs of the functionality and input requirements or derived requirements of other functionalities. Identification of these links describes the intended end use of the output of the functionality. Additionally, this field serves to capture other important information such as comments on the existence of the functionality, key sources of uncertainty in the modeling of specific phenomena, and important proposed approaches to help obtain the functionality.

Additional tools were developed to take in these functional needs and their associated inputs and outputs and generate useful visualizations for review (Figure 7). With some additional information linking inputs and outputs, these tools can track and visualize interdependencies between functional needs (Figure 8 and Figure 9). These interdependencies are used in follow-on prioritization and ranking efforts.

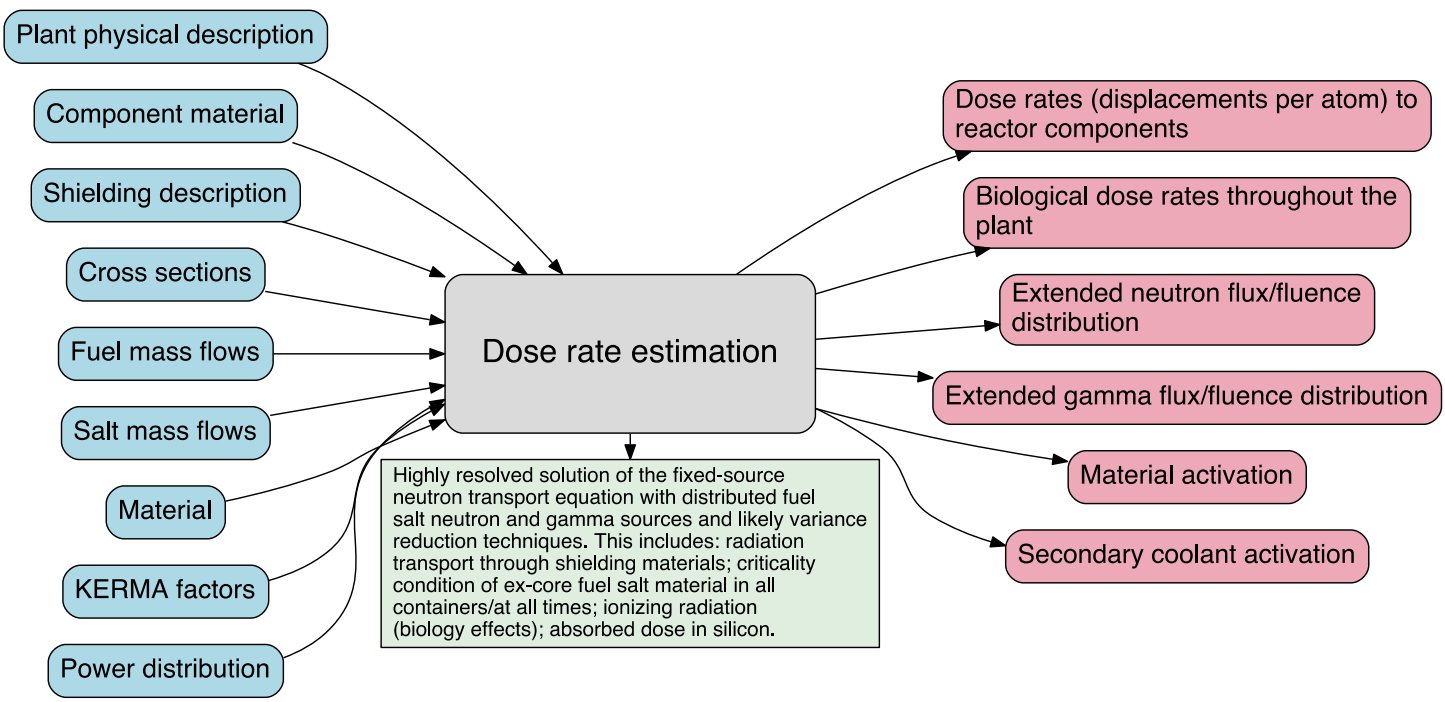

Figure 7. Dose estimation functionality diagram showing identified input and outputs. 


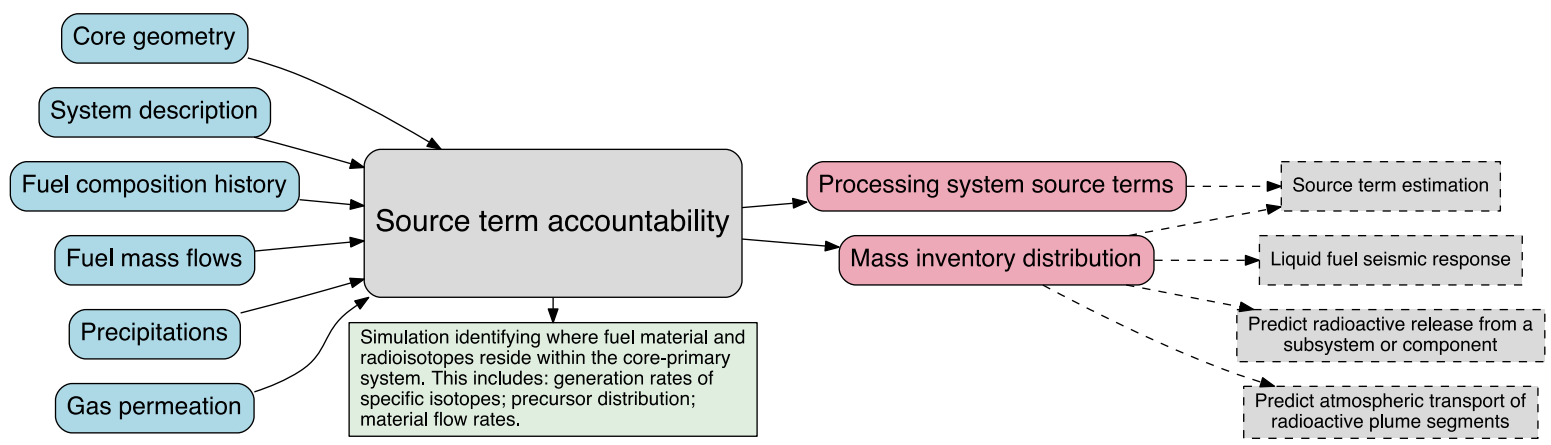

Figure 8. Expanded source term accountability functionality diagram showing linkages to other functionalities via outputs.

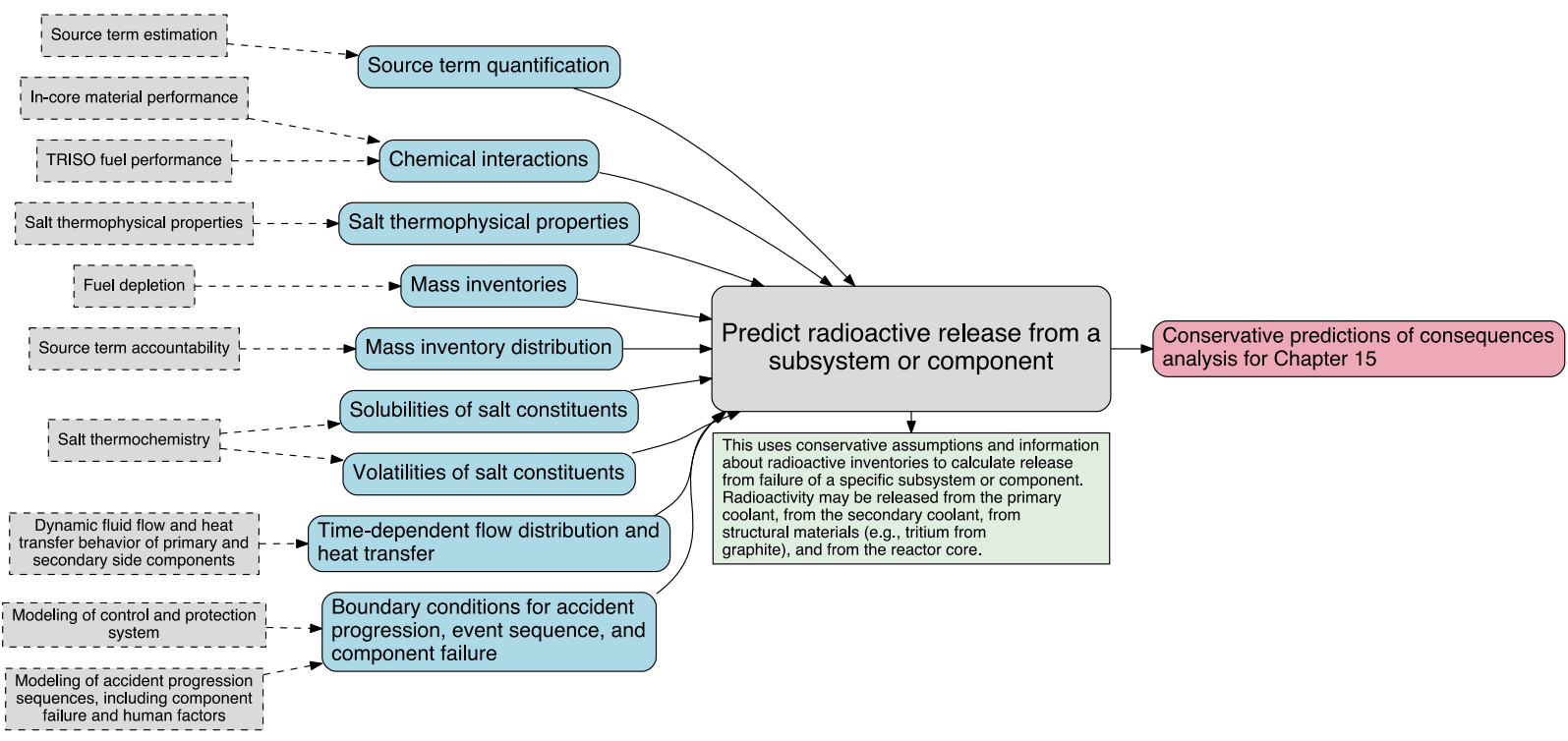

Figure 9. Expanded predict atmospheric transport of radioactive plume segments functionality diagram showing linkages to other functionalities via inputs.

While this high-level approach determines interdependencies between functional needs, the level of fidelity and tightness of coupling necessary for licensing are undefined. These are dictated by the level of uncertainty in the parameter of interest and the available safety margin. Currently, determining these is difficult with insufficient data available for validation.

\subsection{Feedback}

A limited-distribution document (Betzler et al. 2018b) was developed to communicate and socialize these preliminary high-level functional needs with relevant stakeholders (i.e., the industry, regulators, laboratories, and subject matter experts), to solicit feedback, identify any missing functional needs, and refine existing ones. A functionality datasheet template was distributed along with the document (Appendix A). This document was distributed with a request to provide feedback within a few weeks. 
Feedback was fielded from the distribution of the functional needs document, and each comment was explicitly addressed. Responses were written (Appendix B), and functional need inputs and outputs were updated to reflect comments. No additional functionalities were identified and added in this process.

\subsection{Findings}

The functional needs assessment yielded two key observations:

1. Many of the functional needs in fuel, nuclear, and thermal hydraulic design (ch. 4) and accident analyses (ch. 15) are required for several other licensing components; and

2. Fluoride salt-cooled systems have several unique functionalities due to their solid fuel forms.

Because the functionalities that apply to several licensing components are considered the most critical, the functional needs in this report are focused on safety analysis report chapters 4 and 15 (Table 1). For brevity, the complete list of modeling and simulation functionalities with datasheets and visualizations is found in Appendix C.

Table 1. List of modeling and simulation functional needs.

\begin{tabular}{ll}
\hline $\begin{array}{l}\text { Licensing component (design } \\
\text { control document chapter) }\end{array}$ & Functional need \\
\hline Nuclear Design (Ch. 4) & Fuel depletion \\
& Steady-state core neutronics \\
& Reactivity coefficients \\
& Kinetics parameters \\
& Reactivity control behavior \\
& Dose rate estimation \\
& Demonstration of reactor startup procedure \\
& In-core material performance \\
& Liquid fuel properties \\
& TRISO fuel performance \\
& Salt thermochemistry \\
& Salt thermophysical properties \\
& Component corrosion \\
& Salt reaction kinetics \\
& Mass transport \\
& Salt freezing \\
& Multiphase flow (bubbling) \\
& Source term accountability \\
& Heat conduction, heat transfer, and fluid flow \\
& Pebble bed convection and conduction \\
& Time-dependent granular flow \\
\hline Thermal Hydraulic Design (Ch. 4) &
\end{tabular}


Table 1. List of modeling and simulation functional needs (continued).

Accident Analyses (Ch. 15)
Control and protection system

Impact of instrumentation drift and uncertainty

Active and passive safety systems and components

Source term definition

Component failure and human factors

Static and dynamic fluid flow and heat transfer

Behavior during power-cooling mismatch events

Reactor kinetics feedback and coupled response

Other possible design-dependent events

Radioactive release from subsystem of component

Atmospheric transport of radioactive plume

segments

Particularly for liquid-fueled MSRs, many of the modeling and simulation components are highly interdependent, and inputs and underlying models are shared across several functionalities. Identifying and leveraging these interdependences is critical for providing timely and relevant modeling and simulation applications and tools. These interdependencies are apparent in a progression from a simple fuel cycle analysis to a detailed material distribution. Consider a representative MSR system model with a core, pipe components, pumps, and tanks (Figure 10). The objective is to gain a full understanding of the material distribution throughout the system.

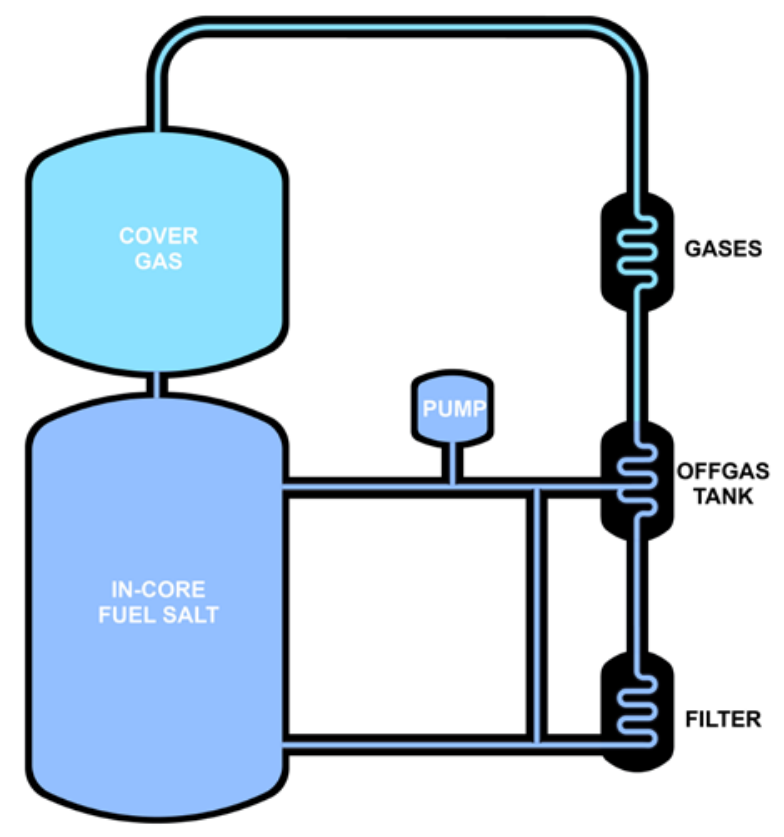

Figure 10. Diagram of a representative MSR system.

The first step in this process is to understand how the liquid fuel salt material evolves in time (Figure 11). This is largely a fuel depletion problem; inputs from steady-state reactor physics and temperatures (approximate or simulated) are required to understand the flux spectrum and distribution in the system. The fidelity of the reactor physics simulation, the neutron energy spectrum, associated cross section uncertainties, the fueling scheme, and aggregate elemental removal rates (informed from understanding of 
physical processes) all determine the accuracy of the simulation. Modeling and simulation tools that have incorporated material removal and feed capabilities are able to estimate the fuel salt material composition throughout the primary loop (Aufiero et al. 2013, Betzler et al. 2017).

The second step is to quantify the material being removed from the fuel salt material (Figure 12). Again, this is largely a fuel depletion problem with some additional inputs from steady-state reactor physics. However, the accuracy of the quantity of removed material is highly dependent on the assumed removal rates used in the depletion simulation, which are dependent on an understanding of processing methods, efficiencies, and mass flows. Quantification of these removed materials is useful for fuel cycle simulations and fission product disposition to understand the quantity of fission product wastes, their radioactivity, and their form. In addition, removal, feed, and plate-out of materials may impact the chemical and thermophysical properties of the fuel salt.

The third step is to fully quantify the salt composition throughout the primary loop (Figure 13). While the first approximation is that the in-core fuel salt and primary loop material has the same material composition, a more detailed understanding is relevant for quantifying material holdup and source terms in the system. The problem being addressed here is largely a fuel depletion problem, but additional information is required from mass transport functionality to quantify the movement and accumulation of fuel material within the primary loop.

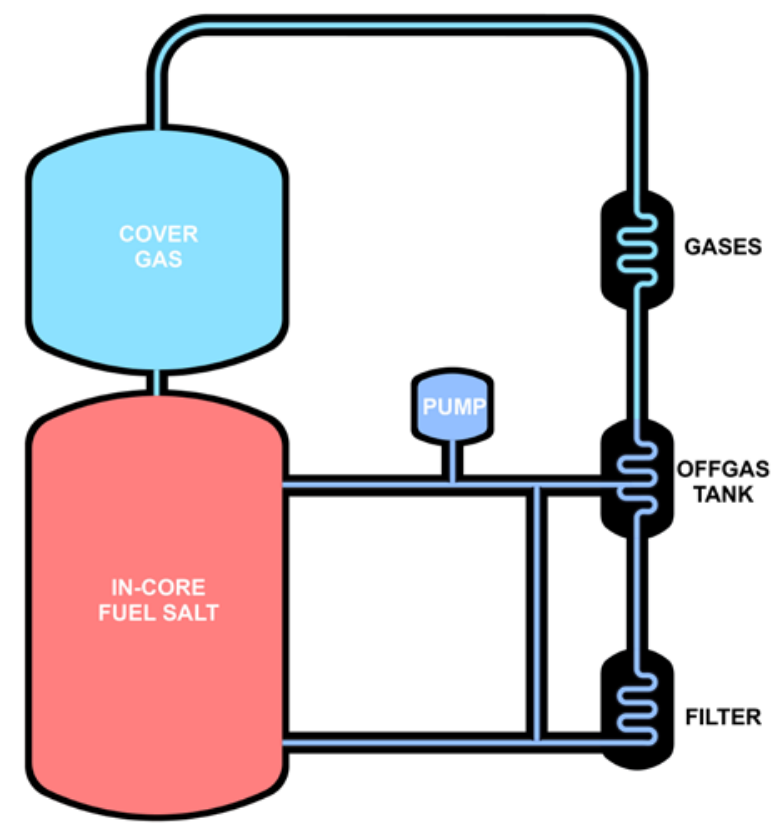

Figure 11. Diagram of a representative MSR system highlighting isotopic composition of in-core fuel salt. 


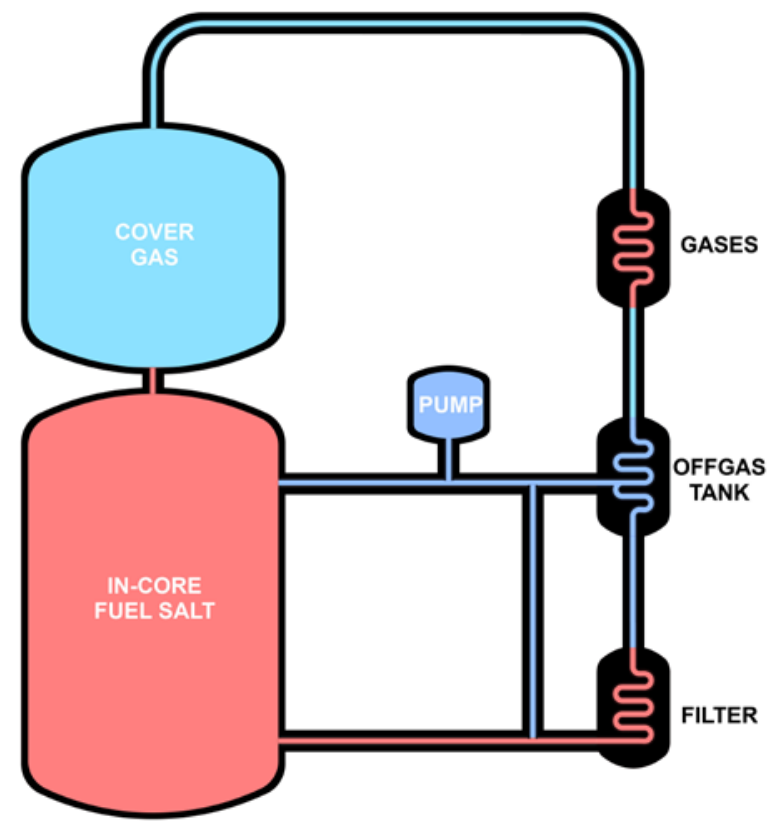

Figure 12. Diagram of a representative MSR system highlighting isotopic composition of in-core fuel salt and processing tanks.

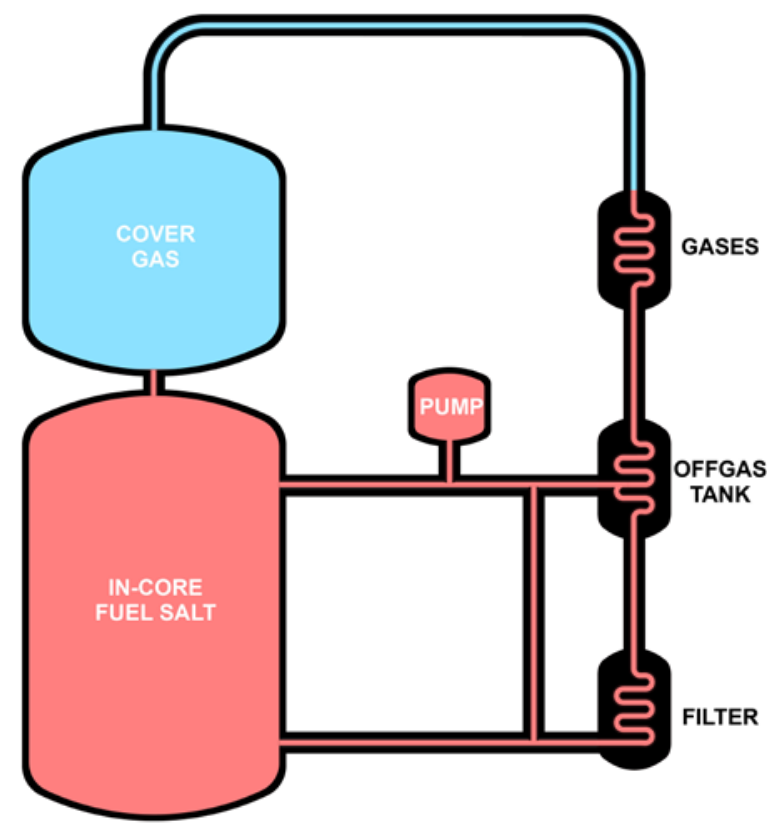

Figure 13. Diagram of a representative MSR system highlighting isotopic composition of in-core fuel salt, processing tanks, and all pipes and components within the primary system.

The fourth step is to quantify the material being fed into the cover gas and reaching the off-gas system (Figure 14). This step goes beyond the previous step, as it involves additional functional needs related to characterizing the salt-cover gas interface and determining how some constituents within the fuel salt reach this interface, release into the cover gas, and transport to processing and capture systems. Relevant fuel salt conditions (e.g., composition, temperature, thermochemical state, pressure) are required to appropriately quantify the salt constituents escaping into this volume. Characterizing these salt conditions 
require the use of several other MSR functionalities. This fidelity of mass accountancy is informative for source term quantification, safeguards analysis, and dose estimation.

The fifth step is to quantify the material that precipitates and attaches to the salt-facing surfaces within the core and primary loop, including pump surfaces, heat exchanger surfaces, core structural materials, pipes, and tanks. This step requires a detailed understanding of the fuel salt conditions within the primary loop (e.g., temperature, compositions, thermochemical state, chemical reaction rates) to characterize depositing material onto salt-facing surfaces or drawing material from surfaces of structural alloys (i.e., corrosion). Thus, many of the MSR functionalities are required to accurately characterize the material distribution to this fidelity, with salt chemistry and mass transport being the most notable. Attachment of radioactive and stable fission products directly impacts dose rates to components, dose rates outside the primary loop, and material lifetimes. Understanding the material balance in the system to this level and with sufficient fidelity is important for prediction of material flows during operation and after shutdown.

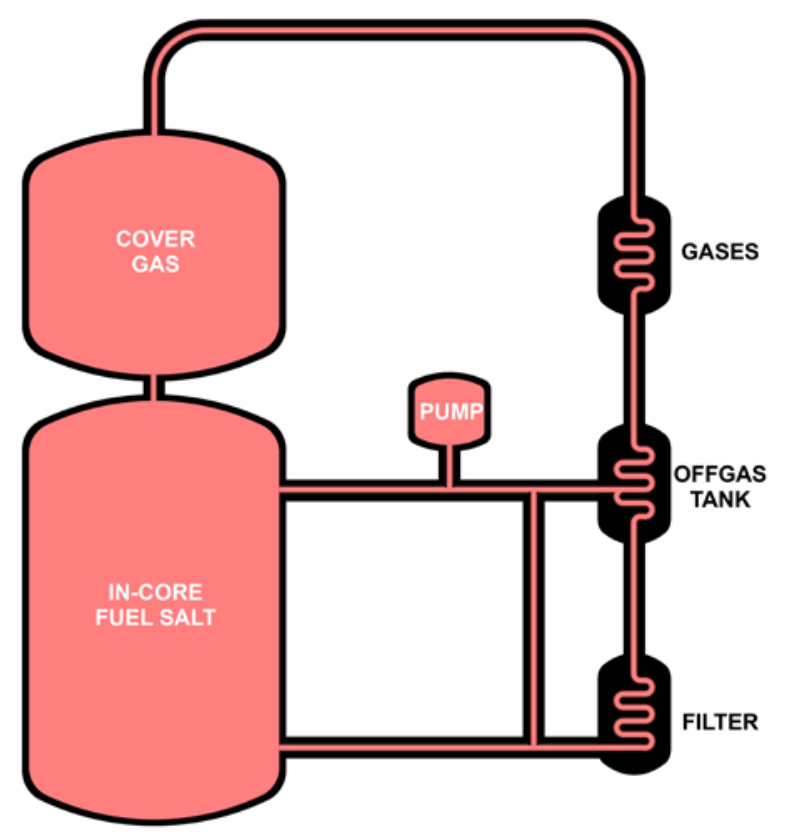

Figure 14. Diagram of a representative MSR system highlighting isotopic composition of in-core fuel salt, processing tanks, all pipes and components within the primary system and cover gas system.

This progression of detail regarding material balance in an MSR shows the level of fidelity necessary to fully understand the behavior of materials within the reactor system in a way that is most informative for licensing, safety analysis, and operations. It is necessary to understand the material balance in the system as a function of time for operation and maintenance and for accident conditions and transients when salt and material conditions (e.g., temperature) may fluctuate. With temperature fluctuations, material that may be previously attached to surfaces may change phase and be released into the fuel salt. The application of this material distribution across multiple functional needs is an example of the inherently coupled nature of MSR modeling and simulation. 


\section{FUNCTIONAL NEEDS PRIORITIZATION}

Following the functional needs assessment, a systematic approach to prioritization was defined, implemented, and deployed to generate a list of the most important functionalities and inputs to these functionalities. These prioritized lists were used to develop high-level program focus areas and goals for MSR campaign modeling and simulation activities.

\subsection{Approach}

The functional needs assessment was leveraged to quantitatively weight the value of the functional needs relative to two key priority outcomes (Figure 6):

1. mechanistic source term estimation, prediction of radioactive release, and atmospheric transport of the radioactive release (highest priority), and

2. analysis of design basis accidents, including power-cooling mismatches, reactivity accidents, and other events such as potential disruption of the primary coolant boundary (high priority).

All functionalities were iteratively weighted according to the number of times they were used to obtain these outcomes. This quantitative weighting was not intended to produce an absolute prioritization, but rather to be combined with expert elicitation to yield a final list of priorities. It is also possible to tailor this quantitative approach to specific licensing approaches. For example, separate weightings can be used for test, demonstration, and commercial prototype reactors. Another approach that provides additional granularity is to use separate weightings for each reactor system to highlight the functionalities that apply only to those reactors and those that are cross-cutting. But, using this approach requires that functionalities be defined more narrowly for each reactor type.

\subsection{Method and Implementation}

The assessment activity provided a list of functional needs with their associated inputs and outputs, along with a method to visualize linkages between different functionalities. An example is shown in Figure 15. Generating these visualizations relied on the connections specified between the inputs and outputs of each functionality. These existing connections were leveraged to build a scoring method to be used for evaluating the relationships between different functionalities via their shared inputs and outputs.

For this scoring method, the critical outputs that feed a licensing case are given initial weights $\left(w_{\mathrm{o}, n}^{\prime}\right)$ which are used to calculate weights of functionalities $\left(w_{\mathrm{f}, n}\right)$ and inputs $\left(w_{\mathrm{i}, n}\right)$ (Figure 15). This scoring method is based on the equations for calculating weights of functionalities, inputs, and outputs for a given functionality,

$$
\begin{gathered}
w_{\mathrm{f}, n}=\sum_{j}^{N_{\mathrm{f}, n \rightarrow \mathrm{o}}} w_{\mathrm{o}, j}+w_{\mathrm{o}, j}^{\prime} \\
w_{\mathrm{i}, n}=\frac{w_{\mathrm{f}, j}}{N_{\mathrm{i} \rightarrow \mathrm{f}, n}} \\
w_{\mathrm{o}, n}=\sum_{j}^{N_{\mathrm{i} \rightarrow \mathrm{o}, n}} w_{\mathrm{i}, j},
\end{gathered}
$$

where $N_{\mathrm{f}, n \rightarrow \mathrm{o}}$ is the number of outputs that functionality $n$ generates, $N_{\mathrm{i} \rightarrow \mathrm{f}, n}$ is the number of inputs that feed functionality $n$, and $N_{\mathrm{i} \rightarrow \mathrm{o}, n}$ is the number of inputs generated from output $n$. As common inputs and outputs are distributed across functionalities, a global sum of these weights is taken after performing the scoring for all functionalities. Due to the interdependence of the weights of outputs, inputs, and functionalities, an iterative process is required to satisfy the governing weight equations. This iterative process starts with the initial weighting and ends when the relative weights of the inputs, outputs, and functionalities in the system are converged (Figure 16). Functionalities that generate several outputs that are used in several other functionalities amass the most weight. 


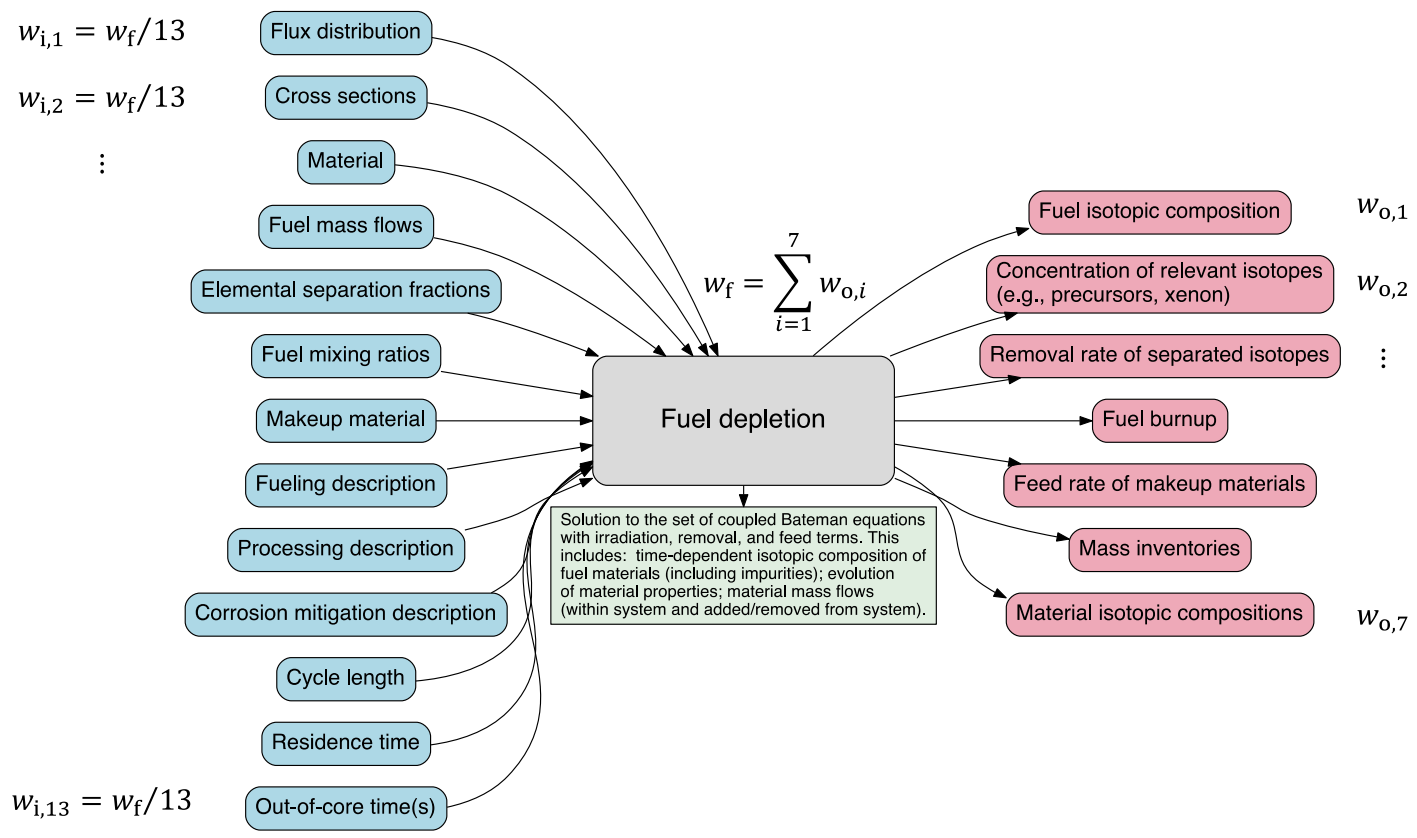

Figure 15. Fuel depletion functionality diagram showing input, output, and function weights.

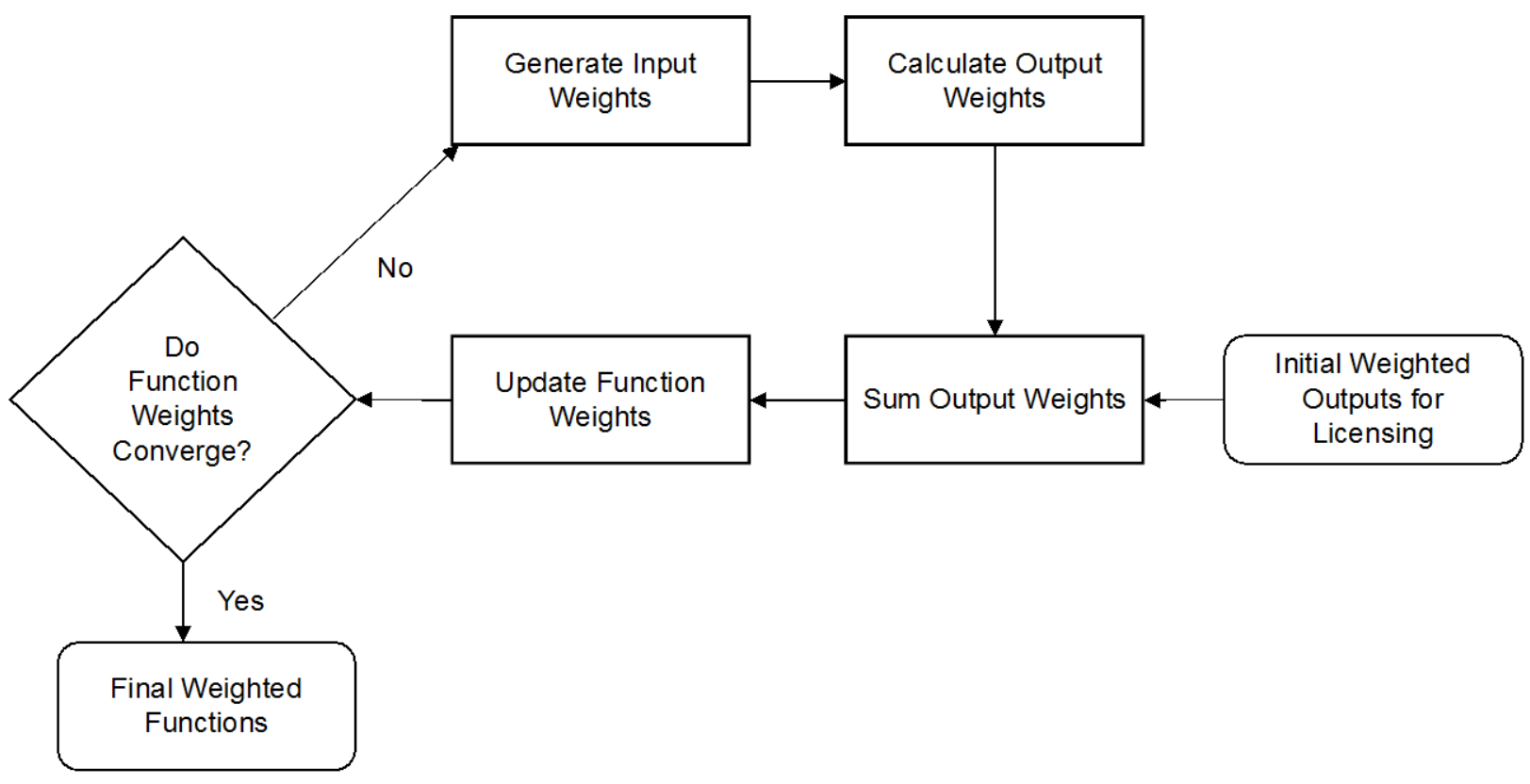

Figure 166. Iterative scoring method to generating and converge weights of inputs, outputs, and functionalities.

The final scoring method was designed to have minimal outside inputs to allow the interdependencies between functionalities to govern the scoring results. The final scoring method was a combination of 
several approaches, using initial weights of two Chapter 15 outputs and for source term estimation for each iteration:

1. $w_{\mathrm{o}}=0.5$ for performance relative to safety limits for power-cooling mismatch and designdependent events,

2. $w_{\mathrm{o}}=0.5$ for conservative predictions of consequences analysis for Chapter 15, and

3. $w_{\mathrm{f}}=0.5$ for the source term estimation functionality.

These weights were selected specifically, as these Chapter 15 outputs and functionalities directly feed a safety basis for a given MSR system. The final scoring method also uses weight multipliers, in part to reflect a given functionality's applicability to the three different concepts that serve as the main focus for the MSR campaign: FHRs and fluoride- and chloride-based liquid-fueled MSRs. This method uses a combined weighting with multipliers to weight for applicability to systems (e.g., $1 / 3$ or $2 / 3$ for one or two of the reactor concepts addressed). This approach is chosen for its simplicity and for generating a single set of scores that considers all factors. Multipliers are applied to several functionalities:

1. $1 / 3$ for pebble bed seismic response,

2. $2 / 3$ for liquid fuel performance,

3. $1 / 3$ for TRISO fuel performance,

4. $5 / 6$ for salt thermochemistry,

5. $5 / 6$ for component corrosion,

6. $5 / 6$ for salt reaction kinetics,

7. $5 / 6$ for mass transport,

8. $2 / 3$ for multiphase flow,

9. $5 / 6$ for heat conduction, convection, and radiation in core structure/moderator, heat transfer, and fluid flow,

10. $1 / 3$ for pebble bed conduction, convection, and radiation, and

11. $1 / 3$ for pebble bed granular flow.

The $1 / 3$ multipliers are applied to specific pebble-bed or solid-fueled FHR functionalities, the $2 / 3$ multipliers are applied to liquid-fueled-specific functionalities, and the $5 / 6$ multipliers are applied to functionalities that have a lower importance for FHRs. As input and output weights are also generated using this scoring method, these are also prioritized to identify the inputs most commonly used across multiple functionalities.

\subsection{Results}

The initial weights of outputs and functionalities force higher weights for the following specific functionalities:

- $\quad$ source term estimation,

- prediction of atmospheric transport of radioactive plume segments,

- prediction of radioactive release from a subsystem or component,

- prediction of other possible design-dependent events,

- simulation of reactivity accidents and coupled response, and

- prediction of behavior during power-cooling mismatch events. 
These functionalities are already seen as critical for a licensing case and are not ranked as part of this scoring method. While providing the exact specific scores for each functionality is not constructive, showing the relative magnitude of each functionality's score (Figure 17) shows the relative difference between the most critical functionalities and those niche functionalities that serve a specific purpose. This does not imply that some of these functionalities are unnecessary; the fact that these functionalities were identified during the assessment shows their necessity. This ranking is dependent on the approach taken and would yield different results provided different assumptions regarding the initial weighting.

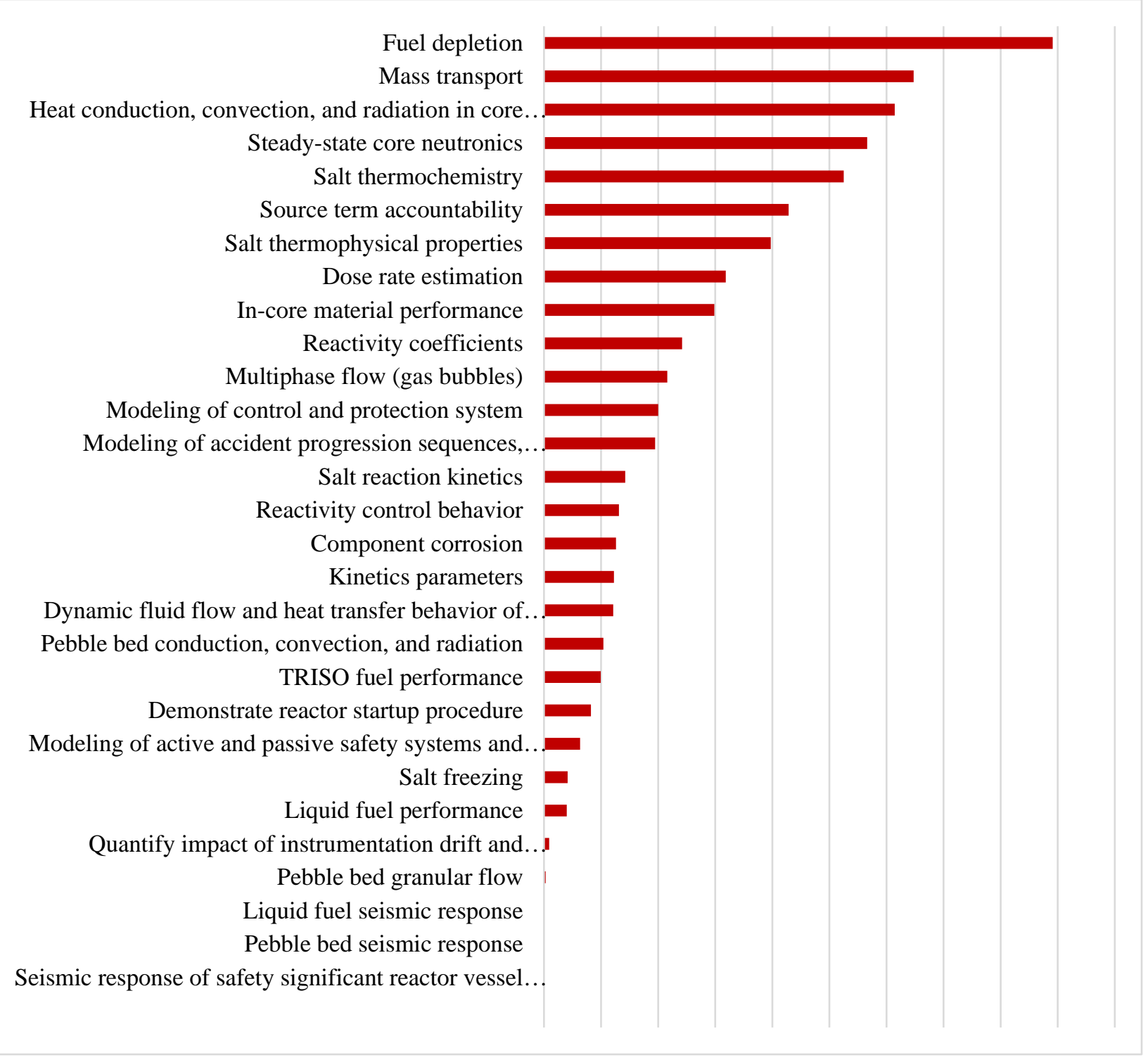

Figure 17. Prioritized functionalities with relative scores.

The prioritized functionalities are categorized into several groups of decreasing importance (Figure 17). Fuel depletion is the most critical functionality, as it produces the isotopic composition of fuel and nonfuel materials, removal rates of elements to processing systems, and general element mass inventories. This information is highly critical for many of the identified functionalities. The next group of functionalities includes mass transport; heat conduction, convection, and radiation and heat transfer; steady-state core neutronics; salt thermochemistry; source term accountability; and salt thermophysical 
properties. These functionalities generate outputs that are critical to quantify the generation, movement, and behavior of material in MSR systems. The next group of functionalities includes dose rate estimation, in-core material performance, reactivity coefficients, multiphase flow, modeling of control and protections system, and modeling of accident progression sequences. These functionalities represent functionalities that feed into only a few other functionalities. The last group of functionalities includes niche functionalities that generate specific targeted outputs that are not used in many other functionalities.

The prioritized inputs are almost as informative as the prioritized functionalities (Figure 18). The highestscoring input functionality is salt thermophysical properties. This is because it is critical to obtain, store, and accurately interpolate these data for two other high-ranking functionalities: thermal hydraulic calculations and mass transport. These two functionalities determine the temperatures and relevant salt conditions that serve as a basis for several other functionalities. The next group of functionality inputs includes volatilities and solubilities of salt constituents, mass inventory distribution, mass inventories, and chemical interactions. These are all important inputs for understanding the behavior of fuel material and fuel constituents, which are imperative for understanding and quantifying the location of fuel and fission product material within the system. The remaining inputs include outputs from high-priority functionalities (e.g., temperatures and compositions) and input data (e.g., thermodynamic data, cross sections). With this scoring method, design-dependent information (e.g., geometry, material, system description) has higher priority. 


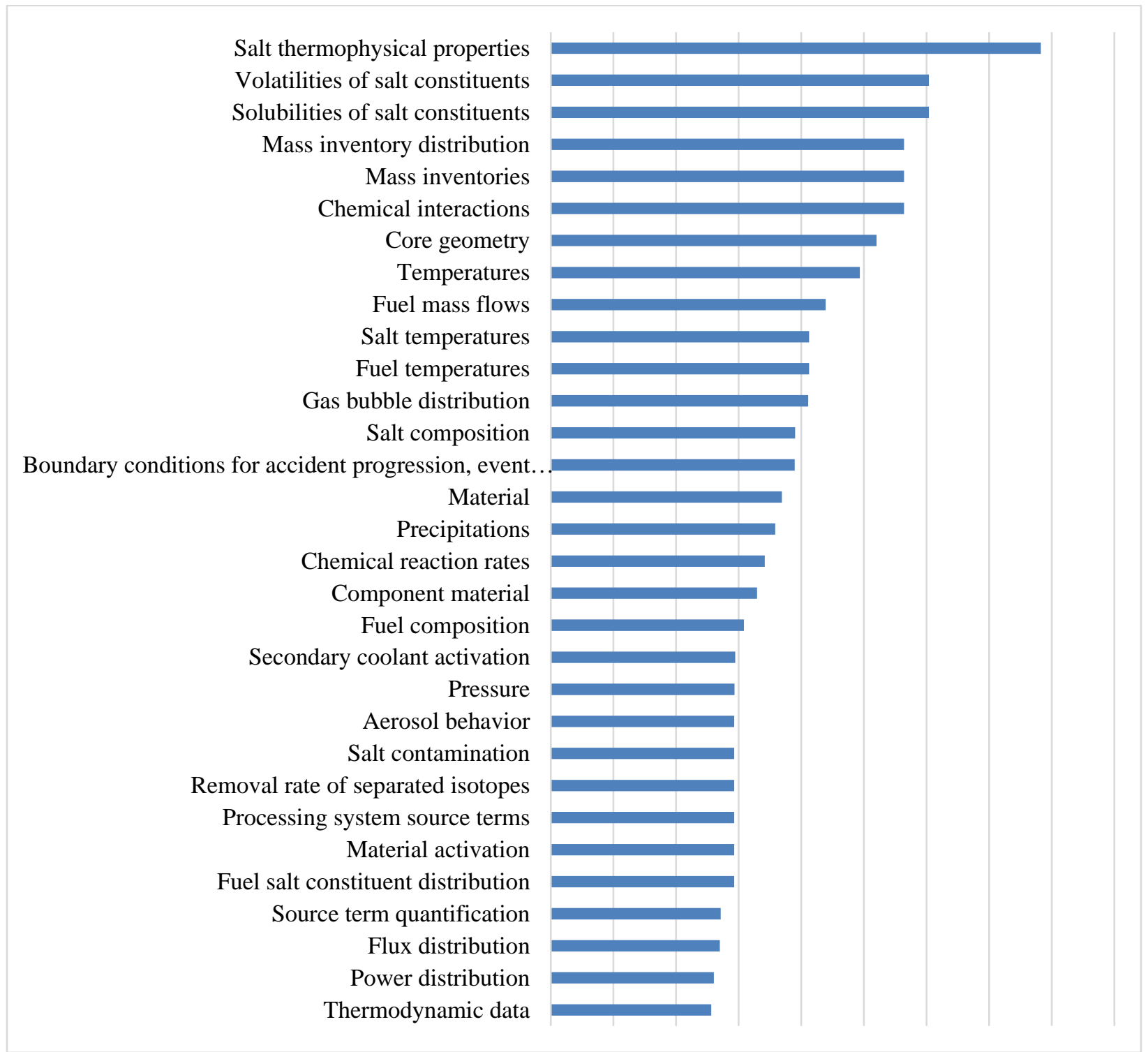

Figure 18. Highest priority inputs ordered by relative scores. 


\section{ACTIVITIES AND IMPLEMENTATION}

Modeling and simulation focus areas and goals are identified using the prioritized functionalities and inputs as a guide. From this, specific activities have been identified to meet these objectives. These activities do not include all potential MSR modeling and simulation activities, but they do include critical activities that are on the path to licensing. Critical chemistry-related components such as salt thermochemistry and salt thermophysical properties are not included in these activities as these functionalities are more closely tied to the chemistry efforts within the campaign (McMurray et al. 2018). Additional activities have been identified to interface with other DOE-NE programs that have an objective to leverage the MSR campaign modeling and simulation capabilities and results. Some of these additional activities do not feed directly into a licensing case.

\subsection{Timeliness and Non-Licensing Functional Needs}

The time and effort needed to employ or improve a given functionality is a highly relevant factor due to the rapidly evolving advanced reactor technology landscape. Quantifying time to deployment for these functionalities requires an assessment of the current modeling and simulation tool capabilities and decisions on deployment strategies. Another way to address timeliness is to consider whether a functionality will be needed for a test, demonstration, or commercial prototype reactor. However, this requires breaking down functionalities to consider the deployment application, requiring additional efforts in the functional needs assessment. For these reasons, timeliness was not considered in the prioritization effort, but it is incorporated into activity planning using expert judgement and the general knowledge of the state of the art.

All proposed activities have a specific application in mind; these are not solely tool development activities. However, there are fewer tools capable of liquid-fueled reactor physics and systems analysis that do not require additional development. Thus, development activities funded under this campaign are all focused on gaining a better understanding and predicting the complex behavior of these systems.

Some additional activities supported under the campaign do not directly feed a licensing case: safeguards and sensitivity and uncertainty analyses. Safeguards activities under MPACT have interest in MSR systems and require expertise to provide relevant and accurate inputs for safeguards models. This collaboration only benefits the MSR campaign, as safeguards modeling and simulation needs have a large overlap with needs identified for licensing: source term estimation, dose estimation, and mass transport. Understanding uncertainties and quantifying their effects on reactor physics, thermal hydraulics, and systems simulations provides bounds and requirements for input data: thermophysical properties, cross sections, thermochemical properties.

\subsection{Program Focus Areas and Objectives}

Results from the prioritization of functional needs have led to the identification of several specific activities to address these needs. The identified needs generally fall into three focus areas, listed below in no particular order:

- Source term definition, material accountancy, and radiological consequences: functional needs that directly feed the source term accountability, which relate to composition and behavior of fuel salt in the primary system, including transmutation and material processing. These functionalities are necessary for definition of the source term, analysis of the reactor operation at fuel cycle equilibrium, as well as safeguards and nonproliferation. These functionalities are essential for licensing and the ability to export such designs from the United States. For radiological consequences, this includes salt thermochemistry, including volatilities and phase behavior, mass transport of salt constituents throughout the primary/secondary/tertiary systems, radioactive release from a subsystem or component, and atmospheric transport of radioactive plume segments. This includes deposition and plate-out as a function of local conditions. These 
functionalities are essential for consequence analysis of design basis accidents and beyond design basis accidents. These functionalities also include probabilistic risk assessment (PRA) and the relevant interfaces with both Level 2 PRA and Level 3 PRA models.

- Safety analysis: includes the capability to provide best-estimate or conservative predictions of anticipated operational occurrences and design basis accident scenarios. This includes powercooling mismatches (e.g., loss-of-flow), reactivity accidents (control rod withdrawal), and many other design basis events. Capabilities are needed for scoping analysis and design, licensing, and confirmatory analysis. No licensing tools or confirmatory analysis grade tools exist for MSRs. These tools must also dynamically include some targeted mass transport capabilities to feed consequences analysis. These functionalities interface with Level 1 PRA models.

- Analysis and design of steady-state neutronics and thermal hydraulics: includes bestestimate design and analysis tools to describe reactor operation, including neutronics, thermal hydraulics, and chemistry.

To address these areas, five high-level modeling and simulation goals have been developed which are on the critical path for MSR deployment. These goals are to be accomplished over the next four fiscal years. These goals are all high priority; the ordering below does not imply any prioritization or ranking.

- Systems and safeguards analysis computational tool. This tool will focus on development of a tool for systems and safety analysis which includes transport of fission and transmutation products throughout the primary and secondary loops. The material tracking capabilities of this tool should also have cross-cutting applications for safeguards. This tool interfaces with all three focus areas, but the core capability addresses focus area 1 and 2 . This goal should be completed by the end of FY21.

- Source term analysis and interface with the NRC on accident progression analysis. The key aspects of the focus on source term quantification are fuel depletion/transmutation, salt processing, mass transport, and chemistry models. This goal would include source terms for consequences analysis of design basis accidents and for severe accident analysis. This will provide key information for, and leverage the results of, development of accident progression and analysis tools being funded by the NRC. This goal should be completed by the end of FY22.

- Point designs for liquid-fueled thermal-spectrum and fast-spectrum MSRs. One serious limitation for evaluation of modeling and simulation tools is the lack of a modern liquid-fueled designs that share characteristics with the concepts being developed by industry proponents. These point designs would be the equivalent to the mHTGR-350 (MHTGR 1986) for mHTGRs, S-PRISM (PRISM 1987) for SFRs, or the AHTR for FHRs. This goal should be completed by the middle of FY21.

- Safety analysis specifications and reference solutions for Molten Salt Reactor Experiment (MSRE) transients. Several open safety analysis cases exist for both SFR and mHTGR systems, such as the EBR-II shutdown heat removal tests (IAEA 2017) and the HTR-10 (Wu et al. 2002) loss-of-flow tests. The objective of this focus area is to use data from MSRE (Haubenreich and Engel 1970) to develop an open specification for system code analysis for steady state and transients with and without neutronic feedback. The cases with feedback will include the MSRE zero power physics tests, the fuel pump start-up and coast down tests, and the natural circulation transient. These will be code-to-code verification exercises as well as comparisons with available experimental data, and will be useful to test safety analysis codes developed by DOE-NE, confirmatory analysis tools developed by NRC, and tools to be used or developed by industry. These specifications will be useful for testing a variety of system and safety analysis tools. This goal should be completed by the middle of FY20. 
- Interface with the chemistry database for fuel salt thermochemistry information. A centralized database will be generated that distills the information developed within the chemistry modeling into useful information for reactor design, operations, safety, source term, and safeguards analysis. This database and the associated application program interfaces is necessary for several of the other focus areas. This goal should be completed by the middle of FY21.

\subsection{Tasks}

Source term definition, material accountancy, and radiological consequences immediate term priorities:

- The MSR systems analysis tool must perform the functions of a tool designed for traditional solid-fueled reactor systems, but characterize additional physical phenomena unique to fluidfueled MSRs. This includes identifying and grouping appropriate fission products, transmutation products, and other chemical species for scenarios of interest to feed consequences analysis and PRA. This may include the ability to couple with a Bateman equation solver and to capture transient fissile material behavior (e.g., transmutation), as well as fuel processing or other component-dependent thermo-physical or thermo-chemical properties and constitutive relationships. In addition to fuel processing, example processes include tritium capture and chemistry control.

- The tool must also be capable of integration and demonstration of noble metal deposition models into high-fidelity core and analysis tools. This includes enhancement of noble metal plating models with more mechanistic models, as well as implementation of improved models developed by the MSR campaign chemistry modeling team. This includes understanding the behavior of salt constituents at steady-state and during transients.

- The tool must be capable of coupling the thermophysical and thermochemistry database with core and system analysis tools, including adapting the thermophysical database as alternate fluid property source for existing scoping MSR tools.

System and safety analysis immediate-term priorities (FY19):

- A systems analysis tool is needed to perform scoping sensitivity and uncertainty analysis of important physical parameters to understand and prioritize their significance. This is important for defining future work and can be both design- and scenario-dependent. The systems analysis tool must include MSR components, including molten fuel processing systems.

- Development of a software quality assurance plan for an MSR systems and safety analysis tool is a vital, immediate-term activity. There is a need to roadmap development or adaptation of a system analysis tool that meets quality assurance requirements to enable eventual commercial dedication and licensing analysis of MSRs. Although these tools exist for light water reactors, sodium fast reactors, and modular high temperature gas reactors, no such tools exist for MSRs. Presently, only scoping capability exists for MSRs.

- Another high priority capability is the demonstration of high-fidelity core analysis tools for a range of design basis accidents for liquid-fueled MSRs. This includes improvements to transient capabilities to ensure fast, robust solutions, selection of example design basis accidents based on open information for historical reactors or designs, and demonstration of a high-fidelity analysis tool for those example design basis accident events.

Analysis of steady-state neutronics and thermal hydraulics immediate-term priorities (FY19):

- An activity should be implemented that is focused on coupling high-fidelity and low-fidelity physics models and code-to-code verification of these models at various fidelity. This provides confidence in these developed models in the absence of validation data. 
- It is essential to develop methods for MSR fine-group cross section generation and validation for fast and thermal liquid-fueled MSRs. This would initially be focused on group structure for historical thermal and fast MSR designs, but it could be extended to concepts from industry components.

System and safety analysis intermediate-term priorities (FY20 and FY21):

- Introduce level tracking pipe models (i.e., the ability to calculate the level of molten salt in components) to investigate fill and drain scenarios in anticipated operational occurrences and accidents. This includes the modeling the operation of a passive freeze value in an accident scenario.

- Implement the previously developed plan for a licensing fidelity system analysis tool, and continue to improve and implement quality assurance procedures and documentation. This could be adapted from an existing tool or an entirely new tool.

- Couple system analysis tools to high fidelity core models to capture the dynamic behavior in accident and transient scenarios.

- Add chemistry models to capture processes such as corrosion, tritium chemistry, and redox potential.

Analysis of steady-state neutronics and thermal hydraulics intermediate-term priorities (FY20 and FY21):

- Development of reference point designs for thermal and fast-spectrum liquid-fueled MSRs. One serious limitation is the lack of a modern design that shares characteristics with the concepts being developed by industry proponents. 


\section{CONCLUSIONS}

Modeling and simulation play a key role in accelerating the design, licensing, and deployment of advanced reactor technology. The intent of the MSR campaign is to facilitate the development and application of analysis tools to achieve these ends. Thus, it is important to address the needs of the domestic MSR community on a relevant timeline. The functional needs assessment and prioritization activities identified those modeling and simulation components important to a licensing case, identified interdependencies between these needs, and provided a prioritization identifying the most critical components. These interdependencies show the level of complexity and interdependency in MSRs and the shared underlying physical models that contribute to several functional needs (e.g., fuel salt chemistry, fuel depletion).

Program modeling and simulation focus areas, goals, and activities were identified using the functional needs prioritization and subsequent expert knowledge on current state-of-the-art MSR modeling and simulation. The identified focus areas centered around system-level material accounting, safety and systems analysis, and steady-state reactor core analysis. Activities that fall within these focus areas leverage existing capabilities and data existing within the DOE complex and interface with existing DOE programs that have interests in MSR technology. 


\section{REFERENCES}

(Andreades et al. 2016) Andreades, G. et al., 2016. "Design Summary of the Mark-I Pebble-Bed, Fluoride Salt-Cooled, High-Temperature Reactor Commercial Power Plant,” Nuclear Technology 195, 223-238.

(Aufiero et al. 2013) Aufiero, M., Cammi, A., Fiorina, C., and Ricotti, M. E., 2013. “An extended version of the SERPENT-2 code to investigate fuel burn-up and core material evolution of the Molten Salt Fast Reactor.” J. Nucl. Mater. 441 (1), 473-486.

(Belles et al. 2017) Belles, R. et al., 2017. "Proposed Adaptation of the Standard Review Plan NUREG-0800, Chapter 4 (Reactor) for Sodium-Cooled Fast Reactors and Modular HighTemperature Gas-Cooled Reactors,” ORNL/TM-2017/151.

(Belles et al. 2018) Belles, R. et al., 2018. "Proposed Guidance for Preparing and Reviewing Molten Salt Nonpower Reactor License Applications (NUREG-1537),” ORNL/TM-2018/834.

(Bettis and Robertson 1970) Bettis, E. S. and Robertson, R. C., 1970. “The design and performance features of a single fluid molten-salt breeder reactor.” Nucl. Appl. Technol. 8, 190-207.

(Betzler et al. 2018a) Betzler, B. R., Robertson, S., Davidson (née Sunny), E. E., Powers, J. J., Worrall, A., Dewan, L., and Massie, M., 2018. "Fuel Cycle and Neutronic Performance of a Spectral Shift Molten Salt Reactor Design,” Annals of Nuclear Energy 119, 396-410.

(Betzler et al. 2018b) Betzler, B. R., Brown, N. R., Feng, B., Heidet, F., Rabiti, C., Sofu, T., and Wysocki, A. J., 2018. "Molten Salt Reactor Modeling and Simulation Functional Needs, Molten Salt Reactor Campaign Report,” NTRD-MSR-2018-000450, Nuclear Technology Research and Development, US Department of Energy (DOE).

(Betzler et al. 2017) Betzler, B. R., Powers, J. J., and Worrall, A., 2017. "Molten Salt Reactor and Fuel Cycle Modeling and Simulation with SCALE,” Annals of Nuclear Energy 101, 489-503.

(Brown et al. 2017) Brown, N. R., Betzler, B. R., Carbajo, J. J., Wysocki, A. J., Greenwood, M. S., Gentry, C., and Qualls, A. L., 2017. "Preconceptual design of a fluoride high temperature salt-cooled engineering demonstration reactor: Core design and safety analysis," Annals of Nuclear Energy 103, pp. 49-59.

(Brown et al. 2016) Brown, N. R., Pointer, W. D., Sieger, M., Flanagan, G. F., Moe, W. and Holbrook, M., 2016. "Qualification of Simulation Software for Safety Assessment of Sodium Cooled Fast Reactors. Requirements and Recommendations,” ORNL/TM-2016/80, Oak Ridge National Laboratory (ORNL).

(Brown et al. 2015) Brown, N. R., Powers, J. J., Feng, B., Heidet, F., Stauff, N. E., Zhang, G., Todosow, M., Worrall, A., Gehin, J. C., Kim, T. K., and Taiwo, T.A., 2015. "Sustainable thorium nuclear fuel cycles: A comparison of intermediate and fast neutron spectrum systems," Nuclear Engineering and Design 289, 252-265.

(Brunett et al. 2017) Brunett, A. J., Briggs, L. L. and Fanning, T. H., 2017. "Status of SFR Codes and Methods QA Implementation” (No. ANL-ART-83). Argonne National Laboratory (ANL).

(Diamond et al. 2018) Diamond, D. J., Brown, N. R., Denning, R., and Bajorek, S., 2018.

"Phenomena Important in Modeling and Simulation of Molten Salt Reactors," BNL-114869-2018-IR, Brookhaven National Laboratory (BNL).

(Elsheikh 2013) Elsheikh, B. M., 2013. "Safety assessment of molten salt reactors in comparison with light water reactors,” Journal of Radiation Research and Applied Sciences 6(2), 63-70. 
(Engel et al. 1980) Engel, J. R., Grimes, W. R., Bauman, H. F., McCoy, H. E., Dearing, J. F., and Rhoades, W. A., 1980. "Conceptual Design Characteristics of a Denatured Molten-Salt Reactor with Once-Through Fueling,” ORNL/TM-7207, Oak Ridge National Laboratory (ORNL).

(EVOL 2015) Evaluation and Viability of Liquid Fuel (EVOL) Project Final Report, 2015.

(Forsberg et al. 2003) Forsberg, C. W., Peterson, P. F., and Pickard, P. S., 2003. "Molten-Salt-Cooled Advanced High-Temperature Reactor for Production of Hydrogen and Electricity,” Nuclear Technology 144, 289-302.

(Greene et al. 2010) Greene S. R. et al., 2010. "Pre-Conceptual Design of a Fluoride- Salt-Cooled Small Modular Advanced High-Temperature Reactor (SmAHTR),” ORNL/TM-2010/199, Oak Ridge National Laboratory (ORNL).

(Haubenreich and Engel 1970) Haubenreich, P. N. and Engel, J. R., 1970. "Experience with the Molten Salt Reactor Experiment,” Nuclear Applications \& Technology 8 118-136.

(Holbrook and Kinsey 2015) Holbrook, M. and Kinsey, J., 2015. "Guidance for Developing Principal Design Criteria for Advanced (Non-Light Water) Reactors,” INL/EXT-14-31179.

(Holcomb et al. 2011) Holcomb, D. E. et al., 2011. "Fast Spectrum Molten Salt Reactor Options,” ORNL/TM-2011/105, Oak Ridge National Laboratory (ORNL).

(IAEA 2017) “Benchmark Analysis of EBR-II Shutdown Heat Removal Tests,” 2017. IAEATECDOC-1819, International Atomic Energy Agency, Vienna.

(Ignatiev et al. 2009) Ignatiev, V. and Feynberg, O., 2009, "Molten Salt Actinide Recycle and Transmuter System: Fuel cycle and Safety related Issues,” Proceedings of ICENES 2009, Ericeira, Portugal, 29 June - 02 July 2009.

(Mazza 2018) Mazza, J., 2018, “Guidance for Developing Principal Design Criteria for Non-LightWater Reactors,” US Nuclear Regulatory Commission, Regulatory Guide 1.232, Revision 0.

(McMurray et al. 2018) McMurray, J., Besmann, T., Jerden, J., Williamson, M., Ard, J., Fitzpatrick, B., Piro, M., Graham, A., Taylor, Z., Collins, B., Betzler, B., Qualls, L., Pandya, T., Greenwood, S., and Johnson, S., 2018. "Multi-physics Simulations for Molten Salt Reactor Evaluation: Chemistry Modeling and Database Development,” ORNL/SPR-2018/864, Oak Ridge National Laboratory (ORNL).

(MHTGR 1986) "Preliminary Safety Information Document for the Standard MHTGR,” 1986. Stone \& Webster Engineering Corp., HTGR-86-024.

(Mourogov and Bokov 2006) Mourogov, A. and Bokov, P. M., 2006. "Potentialities of the fast spectrum molten salt reactor concept: REBUS-3700.” Energy Convers. Manage. 47, 2761-2771.

(NRC 2017a) “NRC Non-Light Water Reactor Near-Term Implementation Action Plans,” 2017. United States Nuclear Regulatory Commission Report, United States Nuclear Regulatory Commission Report ML17165A069.

(NRC 2017b) "NRC Non-Light Water Reactor Mid-Term and Long-Term Implementation Action Plans,” United States Nuclear Regulatory Commission Report ML17164A173.

(NRC 2016) "NRC Vision and Strategy: Safely Achieving Effective and Efficient Non-Light Water Reactor Mission Readiness,” 2016. United States Nuclear Regulatory Commission Report ML16356A670.

(Petti et al. 2016) Petti, D., Hill, R., Gehin, J., Gougar, H., Strydom, G., Heidet, F., Kinsey, J., Grandy, C., Qualls, A., Brown, N., Powers, J., Hoffman, E., and Croson, D., 2016. “Advanced 
Demonstration and Test Reactor Options Study,” Idaho National Laboratory Technical Report, INL/EXT-16-37867.

(PRISM 1987) "PRISM Preliminary Safety Information Document,” 1987. General Electric Report, GEFR-00793.

(Qualls et al. 2017) Qualls, A. L., Betzler, B. R., Brown, N. R., Carbajo, J. J., Greenwood, M. S., Hale, R. E., Harrison, T. J., Powers, J. J., Robb, K. R., Terrell, J. W., Wysocki, A. J., Gehin, J. C., and Worrall, A., 2017. "Pre-Conceptual Design of a Fluoride High Temperature Salt-Cooled Engineering Demonstration Reactor: Motivation and Overview,” Annals of Nuclear Energy 107, 144-155.

(Rahnema et al. 2016) Rahnema, F., Edgar, C., Zhang, D., and Petrovic, B., 2016. "Phenomena Identification and Ranking Tables (PIRT) Report for Fluoride High-Temperature Reactor (FHR) Neutronics,” Georgia Institute of Technology Report CRMP-2016-08-001.

(Robertson et al. 1971) Robertson, R. C. et al., 1971. Conceptual Design Study of a Single-Fluid Molten Salt Breeder Reactor ORNL-4541. Union Carbide Nuclear Division, Oak Ridge National Laboratory.

(Sun et al. 2017) Sun, X., Yoder, Jr., G. L., Christensen, R. N. Shi, S., Lin, H-C., Wu, X., and Zhang, S., 2017. "Thermal Hydraulics Phenomena Identification and Ranking Table (PIRT) for Advanced High Temperature Reactor” (AHTR), Nuclear Energy University Programs, US Department of Energy.

(Smith and Simmons 1974) Smith, J., and Simmons, W. E., 1974. “An Assessment of a 2500 MWe Molten Chloride Salt Fast Reactor AEEW-R 956.” United Kingdom Atomic Energy Authority.

(Szakaly et al. 2007) Szakaly, F. J., Kim, T. K., and Taiwo, T. A., 2007. "Neutronics Assessment of Stringer Fuel Assembly Designs for the Liquid-Salt-Cooled Very High Temperature Reactor (LSVHTR)" in Proceedings of Joint International Topical Meeting on Mathematics \& Computation and Supercomputing in Nuclear Applications (M\&C + SNA 2007).

(Taube and Ligou 1974) Taube, M. and Ligou, J., 1974. "Molten plutonium chloride fast breeder reactor cooled by molten uranium chloride,” Ann. Nucl. Sci. Eng. 1, 277-281.

(Williams et al. 2006) Williams, D. F., Toth, L. M., and Clarno, K. T., 2006. “Assessment of Candidate Molten Salt Coolants for the Advanced High-Temperature Reactor (AHTR)," ORNL/TM2006/12, Oak Ridge National Laboratory (ORNL).

(Wu et al. 2002) Wu, Z., Lin, D., Zhong, D., 2002. “The design features of the HTR-10,” Nuclear Engieneering and Design 218, 25-32. 


\section{Appendix A}

\section{Modeling and Simulation Data Sheet}




\section{Template}

The following data sheet is to be populated for a given functionality, with care taken to be as complete as possible regarding inputs and outputs to each functionality.

\section{MSR Modeling and Simulation Functionality Datasheet}

Version 0.0 - Feb. 28, 2018

Version 0.1 - Mar. 15, 2018

\section{Date of Submission ( $\mathrm{mm} / \mathrm{dd} / \mathrm{yyyy})$} $04 / 15 / 2018$

\begin{tabular}{|c|c|c|}
\hline Contributor Name(s) & Organization(s) & Email(s) \\
\hline MSR Campaign Modeling \& & Oak Ridge National Laboratory & betzlerbr@ornl.gov \\
Simulation Team & Argonne National Laboratory & \\
& Idaho National Laboratory & \\
& Pennsylvania State University & \\
\hline
\end{tabular}

Modeling and Simulation Functionality

Fuel depletion

Inputs Required (as comprehensive as possible)

Flux distribution

\section{Definition and Phenomena}

Solution to the set of coupled Bateman equations with irradiation, removal, and feed terms. Includes: Time-dependent isotopic composition of fuel materials (including impurities); evolution of material properties.

\section{Outputs Obtained}

Fuel isotopic composition; concentration of relevant isotopes (e.g., precursors, xenon); removal rate of separated isotopes

\section{Additional Comments (links to other functionalities)}

Links to: steady-state core neutronics. Exists in unvalidated, limited forms; requires extension of current depletion solvers; requires appropriate mathematical characterization of processes

\section{For Internal Use Only}

F-04.05 


\section{Appendix B}

\section{Functional Needs Assessment Feedback}




\section{Comments and Responses}

The following is a list of all comments collected from the functional needs assessment socialization (Betzler et al. 2018b) and responses. Actions taken from these comments are reflected in the functional needs list (Appendix C). Comments are written in italics, with responses following in normal text. Comments have been lightly edited for publication. The order of these comments is arbitrary.

1. There is no discussion on radiative heat transfer properties (meaning IR absorption and heat transfer).

This discussion is inherent to the functionality titled "Heat conduction, convection, and radiation in core structure/moderator, heat transfer, and fluid flow." The functionality uses relevant emissivity, related to absorptivity, as input, and also includes radiation heat transfer. To address this comment, the following statement was added: "Radiative emissivity of salt not well characterized. Additional validation and/or analysis may be needed to understand the effect of radiative heat transfer."

2. Regarding salt thermophysical properties, the output should also include temperature. The properties are meant to determine those values.

We recognize that to some degree there is an inherently circular nature to this functionality. Temperature is included as an input, because it will be an independent variable for many of these constitutive relationships.

3. Regarding salt thermophysical properties, there are no standards established to measure the properties.

To address this comment, we have noted that the thermophysical properties require an experimental program and relevant measurement standards.

4. There is a need for in-pile or radioactive capable measurement techniques.

We agree that this is the case, however we do not see how this is within the scope of a modeling and simulation functional need. Modeling and simulation would provide an initial performance envelope for this instrumentation. This research and development need is important but is outside the scope of the present assessment.

5. At this point the functionality is very general. Many of these functions have been discussed in the NRC pre-PIRT report, in the reports based on the FHR IRPs, and in other documents. Perhaps reference to those parallel efforts would be useful.

This comment is noted, and we agree that these efforts were useful in the preparation of this assessment. References to these PIRT efforts have been added to the discussion in the report.

6. Regarding heat transfer and fluid flow, you have mass transport and then under heat transfer function there is fluid flow. Then to really confuse me there is "Dynamic fluid flow and heat transfer..." And you included different accidents which also require heat transfer and fluid flow.

We agree with this comment. Fluid flow is one form of mass transport, but there are other forms of transport processes which are relevant for modeling and simulation of molten salt reactors. Fluid flow is mentioned in the heat transfer functionality because it is important for convective heat transfer. To address this comment, fluid flow was added as an output of the mass transport functionality, and an input of the heat transfer functionality.

Dynamic fluid flow and heat transfer is included as a functionality because there are unique issues related to flow and heat transfer transients, such as the transition from steady state forced circulation to natural circulation in a loss of flow accident. This was clarified in the additional comments.

7. I didn't see any mention of pump characteristics as input anywhere. 
We agree that pump characteristics are very important. This is inherent in the "primary system description" input. This includes pump characteristics for steady state operation, transients, and accident events. We have added a statement regarding pump and other flow component characteristics to the additional comments of several functionalities.

8. Interesting that you put human factors with component failure. Might be better with modeling of control and protection.

Human factors were included in component failure because human error is an important aspect of accident progression, as is understanding operator intervention after a component failure (or perceived component failure). We understand the comment and have addressed it by changing the name of the functionality to "Modeling of accident progression sequences, including component failure and human factors." The level of granularity for this functionality is broad, but all Chapter 15 functionalities are at a high level, and so it is appropriate for this assessment.

9. You separate out modeling of safety systems and components, but you need to model all systems and components that are present, for example separate blanket circuits. And I didn't notice any mention of tertiary circuits.

We have addressed this by changing all instances of "Primary system description" to "System description" throughout the functional needs assessment. Active and passive safety systems are included as a distinct functionality because they are important for accident progression, and power-cooling mismatches in particular. We agree that modeling of the entire system is necessary, and that is the objective of this functional needs assessment.

10. Would be good to understand what "liquid fuel property changes" you are referring to under liquid fuel performance.

We are referring to the evolution of these properties during operation and have changed the description to reflect fuel property evolution during operation.

11. You need a totally different expertise to do the seismic/structural functionality, so I don't know why you would add it to this document.

This information was included where relevant to Chapter 4 and Chapter 15 . We recognize that the structural and seismic functionalities included are not at the same level of fidelity as the Chapter 4 and Chapter 15 functionalities. We removed these from the report.

12. Why the emphasis on supporting licensing? All of this also support operations.

The emphasis on supporting licensing comes from the overarching Campaign objective of accelerating the deployment of MSRs. We recognize that modeling and simulation needs are also present for design and operations, and that there is overlap between these missions. We have adjusted our discussion to mention operations.

13. Reactivity coefficients are needed for reactor startup.

We have added this as an input for the functionality "Demonstrate Reactor Startup Procedure."

14. For the liquid fuel properties, you need the cleanup removal rate of fission products, new material addition rates, etc. to calculate the fuel property changes over time.

Each of these is part of the fuel depletion functionality, which is used to generate the fuel and material isotopic composition during operation. Changes in this composition drive changes in the properties of a liquid fuel salt. Thus, this isotopic composition is then used as input to determine the liquid fuel properties. This linkage is noted in the document.

15. TRISO Fuel Performance: Links to TRISO fuel performance codes developed for mHTGRs 
The Advanced Reactor Technologies program has supported TRISO fuel development, qualification, and performance evaluation. We have added a statement to the additional comments noting that these functional needs are similar to the needs for mHTGRs.

16. Does the statement "Historical diffusion coefficients are too high (over-prediction of fission product release) and need to be re-measured" refer to data from recent TRISO fuel irradiations?

For more information on this statement, it is suggested that the reader refer to: Powers, J. J. and Wirth, B. D., 2010. “A review of TRISO fuel performance models.” Journal of Nuclear Materials, 405(1), 74-82.

17. For mass transport, information is needed related to the lift off of plated materials and solubility. Noble metals are particularly important.

We agree, and a statement has been added which notes that this includes plate-out and lift off of materials, e.g. noble metals, from surfaces throughout the system.

18. How is salt freezing related to bubbling? I would think bubbling would be related to reactivity feedback phenomena as far as safety issues are concerned. Also need to model collapse of bubbles and associated reactivity effects.

References to salt freezing have been removed from the multi-phase flow (gas bubbles) functionality. Salt freezing has been included as a separate functional need in the latest report. To further address this comment, the link between reactivity feedback and bubbles in the salt has been included.

19. The source term accountability and definition need to relate to behavior of fuel salt outside the core and primary system, deposition, and plate-out as a function of material temperature either as a liquid or gas. Evolution of material from filters is part of this both charcoal traps and hyper fine filter systems, heat generation rate on filters will be issues as well.

This is an insightful comment. Mass transport, including precipitation, plate-out, and gas permeation, have been added as inputs to the source term accountability and estimation.

20. The thermophysical properties used for heat transfer and fluid flow should include the evolution of these properties throughout operation.

We agree, and this is included in the inputs to those properties. In addition, we have a functionality that is related directly to the heat transfer and fluid flow.

\section{Transition from forced to natural circulation is of particular importance.}

We agree, and we included dynamic fluid flow and heat transfer is included as a functionality specifically for these and other scenarios.

22. The source term estimation should include plate-out phenomena, fallout, plugging, and aerosol, behavior if oxygen is present in containment

To address this comment, these phenomena were included as inputs, explicitly: component material, chemical interactions, chemical reaction rates, fuel isotopic composition, fuel salt constituent distribution, fuel temperatures, gas bubble distribution, mass inventories, mass inventory distribution, material activation, precipitations, processing system source terms, removal rate of separated isotopes, salt contamination, salt temperatures, salt thermophysical properties, secondary coolant activation, solubilities of salt constituents, volatilities of salt constituents. In addition, aerosol behavior was added as an explicit output of mass transport and included as an input to source term estimation.

23. Hypothetical Core disruptive events have no meaning in MSR fluid fueled systems, and we need to define these extreme events for fluid fueled systems at low pressure before we determine the phenomena that need to be modeled. I noted you did call this out in your comments. 
We agree and have replaced the terminology for hypothetical core disruption to reflect hypothetical disruptions of the core, coolant boundary, or other relevant components.

24. Note, MELCOR is being modified to account for Chapter 19 fluid fueled MSRs. Need to monitor this work sponsored by NRC at SNL.

We have added a statement to reflect this in the narrative of the report. 


\section{Appendix C}

\section{Functional Needs List}




\section{Visualizations and Datasheets}

This appendix contains the list of functionalities, described via the input and output visualization and functionality datasheet.

\section{Fuel depletion}

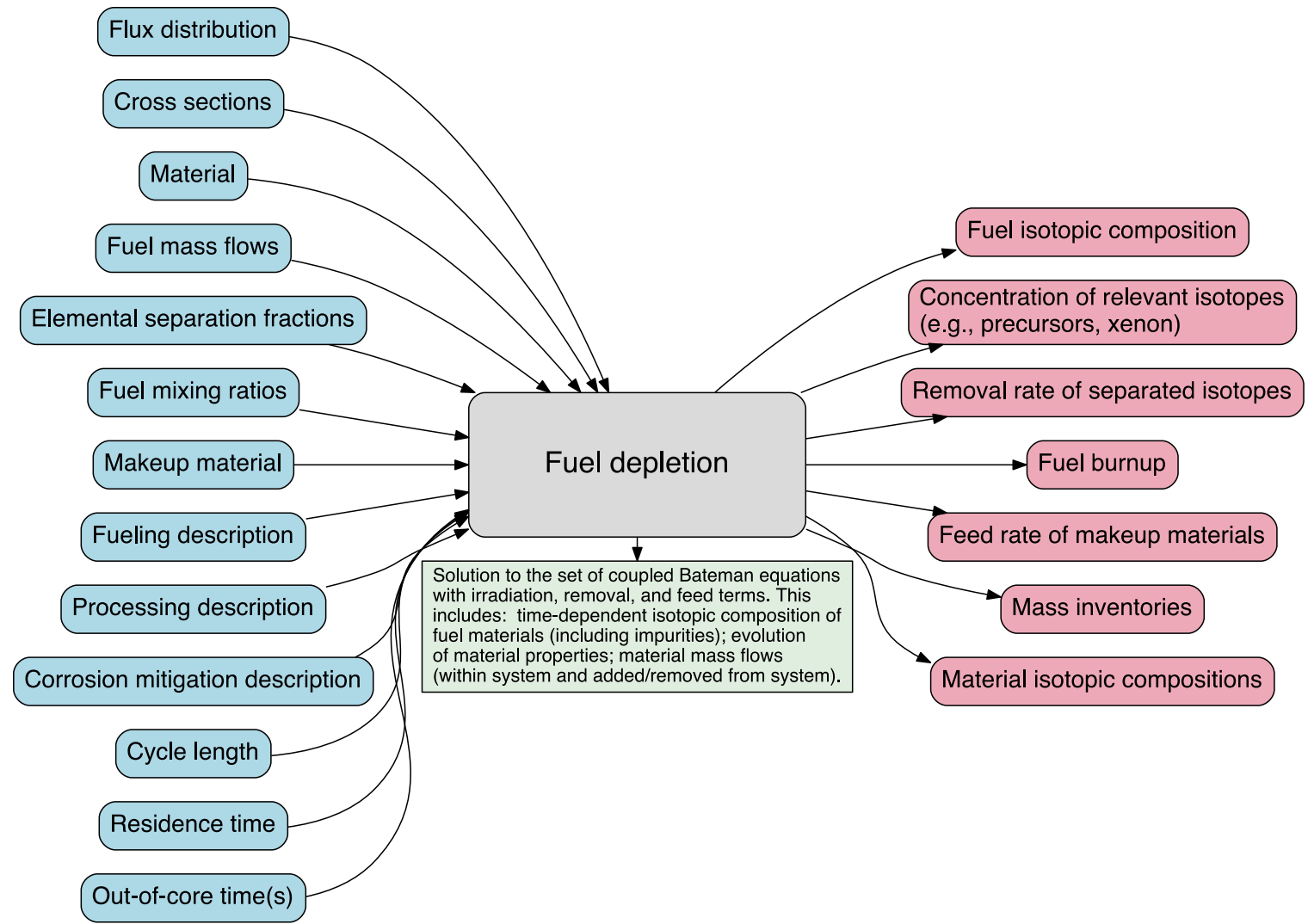

\section{MSR Modeling and Simulation Functionality Datasheet}

Version 0.0 - Feb. 28, 2018

Version 0.1 - Mar. 15, 2018

Date of Submission (mm/dd/yyyy)

$04 / 15 / 2018$

\begin{tabular}{|c|c|c|}
\hline Contributor Name(s) & Organization(s) & Email(s) \\
\hline MSR Campaign Modeling \& & Oak Ridge National Laboratory & betzlerbr@ornl.gov \\
Simulation Team & Argonne National Laboratory & \\
& Idaho National Laboratory & \\
& Pennsylvania State University & \\
\hline
\end{tabular}

Modeling and Simulation Functionality

Fuel depletion 
Inputs Required (as comprehensive as possible)

Flux distribution; Cross sections; Material; Fuel mass flows; Elemental separation fractions; Fuel mixing ratios; Makeup material; Fueling description; Processing description; Corrosion mitigation description; Cycle length; Residence time; Out-of-core time(s).

\section{Definition and Phenomena}

Solution to the set of coupled Bateman equations with irradiation, removal, and feed terms. This includes: time-dependent isotopic composition of fuel materials (including impurities); evolution of material properties; material mass flows (within system and added/removed from system).

\section{Outputs Obtained}

Fuel isotopic composition; Concentration of relevant isotopes (e.g., precursors, xenon); Removal rate of separated isotopes; Fuel burnup; Feed rate of makeup materials; Mass inventories; Material isotopic compositions.

Additional Comments (links to other functionalities)

Links to: Heat conduction, convection, and radiation in core structure/moderator, heat transfer, and fluid flow; Pebble bed conduction, convection, and radiation; Steady-state core neutronics; Liquid fuel performance; Mass transport; Salt reaction kinetics; Salt thermochemistry; Component corrosion; Salt thermophysical properties; Predict radioactive release from a subsystem or component; Predict atmospheric transport of radioactive plume segments; Source term estimation; Multiphase flow (gas bubbles); Pebble bed granular flow.

Exists in unvalidated, limited forms; Requires extension of current depletion solvers; Requires appropriate mathematical characterization of processes.

\section{For Internal Use Only}

F-04.05 


\section{Steady-state core neutronics}

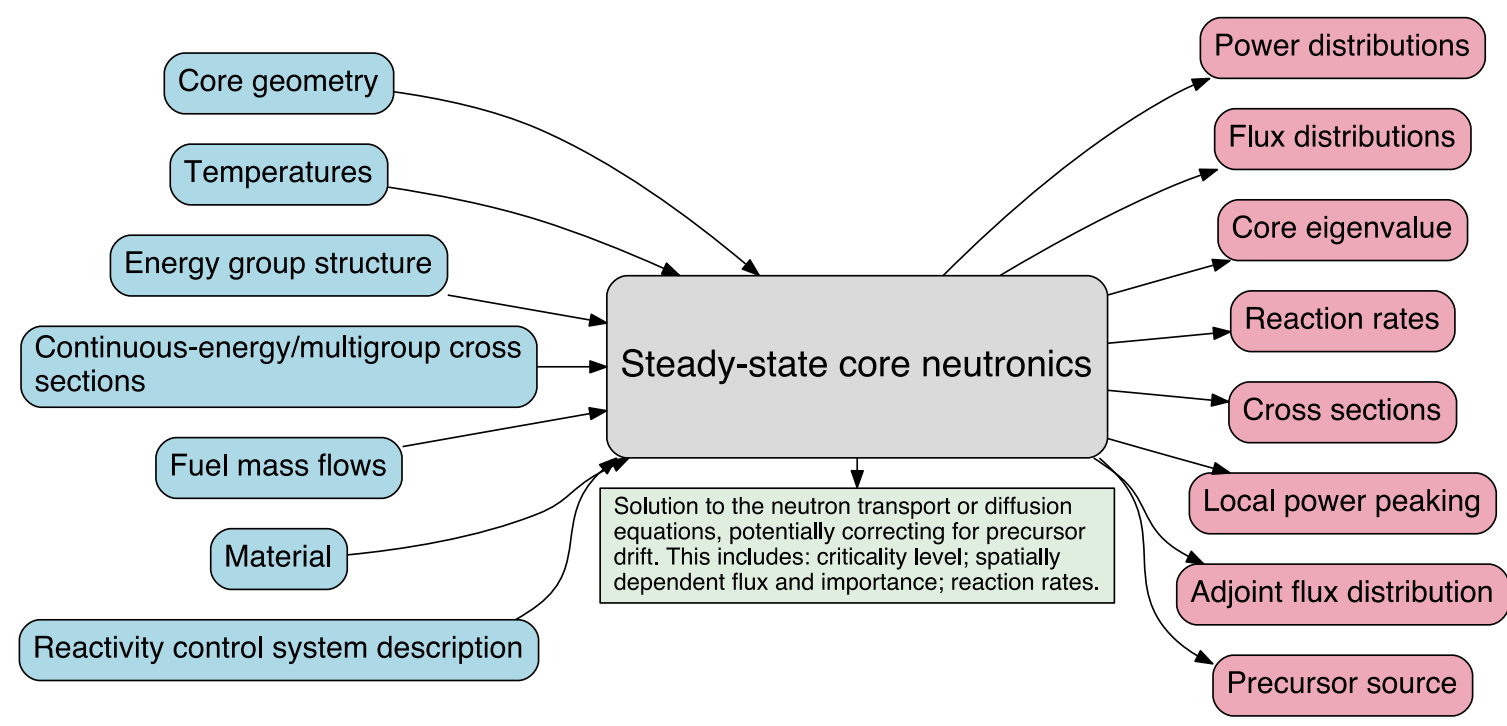

MSR Modeling and Simulation Functionality Datasheet

Version 0.0 - Feb. 28, 2018

Version 0.1 - Mar. 15, 2018

\begin{tabular}{|c|c|c|}
\hline & Date of Submission (mm/dd/yyyy) & \\
\hline & $04 / 15 / 2018$ & \\
\hline Contributor Name(s) & Organization(s) & Email(s) \\
\hline $\begin{array}{c}\text { MSR Campaign Modeling \& } \\
\text { Simulation Team }\end{array}$ & $\begin{array}{l}\text { Oak Ridge National Laboratory } \\
\text { Argonne National Laboratory } \\
\text { Idaho National Laboratory } \\
\text { Pennsylvania State University }\end{array}$ & betzlerbr@ornl.gov \\
\hline
\end{tabular}

Modeling and Simulation Functionality

Steady-state core neutronics

Inputs Required (as comprehensive as possible)

Core geometry; Temperatures; Energy group structure; Continuous-energy/multigroup cross sections; Fuel mass flows; Material; Reactivity control system description.

\section{Definition and Phenomena}

Solution to the neutron transport or diffusion equations, potentially correcting for precursor drift. This includes: criticality level; spatially dependent flux and importance; reaction rates. 


\section{Outputs Obtained}

Power distributions; Flux distributions; Core eigenvalue; Reaction rates; Cross sections; Local power peaking; Adjoint flux distribution; Precursor source.

Additional Comments (links to other functionalities)

Links to: In-core material performance; Heat conduction, convection, and radiation in core structure/moderator, heat transfer, and fluid flow; Pebble bed conduction, convection, and radiation; Demonstrate reactor startup procedure; Mass transport; Predict other possible design dependent events; Simulation of reactor kinetics feedback and coupled response; Predict behavior during powercooling mismatch events; Modeling of active and passive safety systems and components; Dynamic fluid flow and heat transfer behavior of primary and secondary side components; Fuel depletion; Dose rate estimation; Reactivity control behavior; Reactivity coefficients; Kinetics parameters.

Exists in unvalidated, limited forms; Requires extension of current neutronics methods and tools. 


\section{Reactivity coefficients}

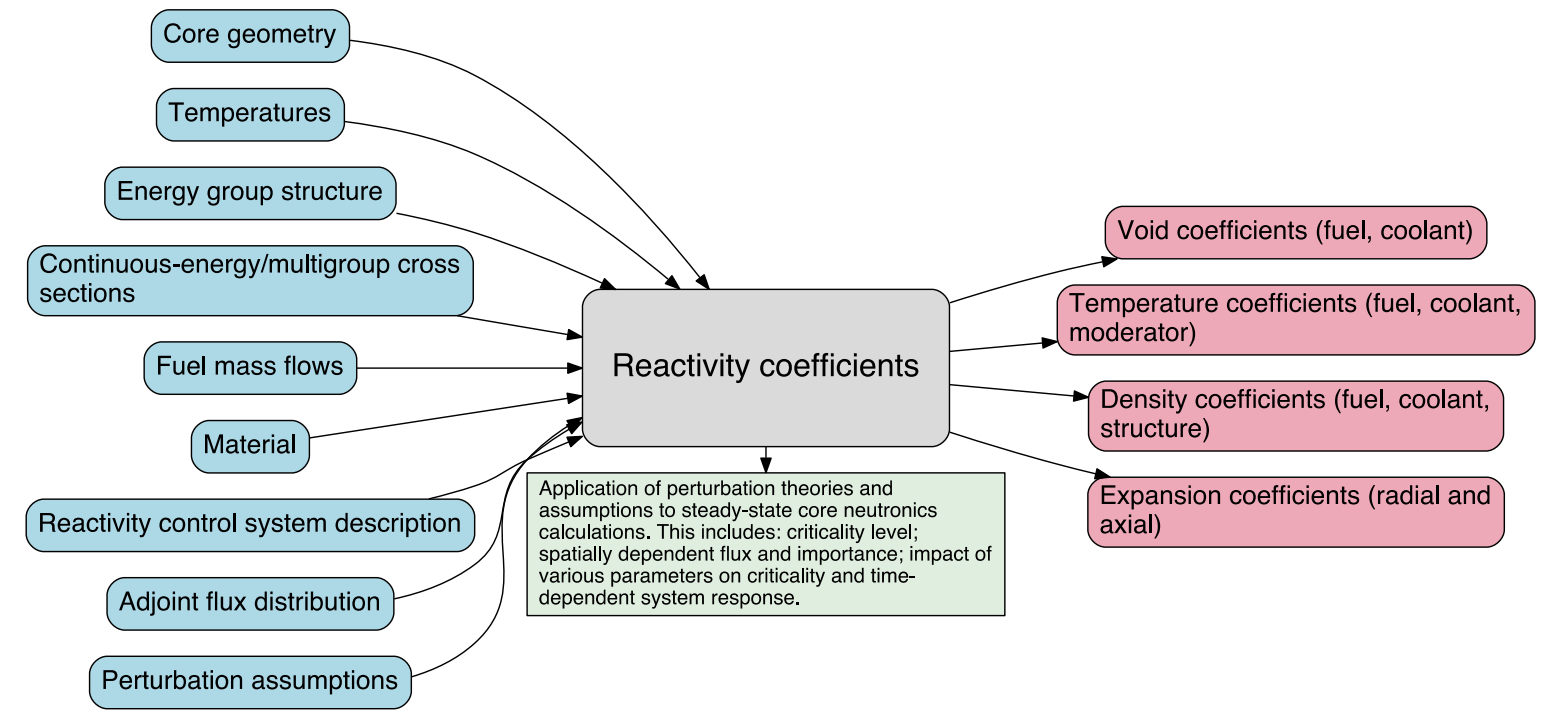

\section{MSR Modeling and Simulation Functionality Datasheet}

Version 0.0 - Feb. 28, 2018

Version 0.1 - Mar. 15, 2018

Date of Submission ( $\mathrm{mm} / \mathrm{dd} / \mathrm{yyyy})$ $04 / 15 / 2018$

\begin{tabular}{|c|c|c|}
\hline Contributor Name(s) & Organization(s) & Email(s) \\
\hline MSR Campaign Modeling \& & Oak Ridge National Laboratory & betzlerbr@ornl.gov \\
Simulation Team & Argonne National Laboratory & \\
& Idaho National Laboratory & \\
& Pennsylvania State University & \\
\hline
\end{tabular}

Modeling and Simulation Functionality

Reactivity coefficients

Inputs Required (as comprehensive as possible)

Core geometry; Temperatures; Energy group structure; Continuous-energy/multigroup cross sections; Fuel mass flows; Material; Reactivity control system description; Adjoint flux distribution; Perturbation assumptions. 


\section{Definition and Phenomena}

Application of perturbation theories and assumptions to steady-state core neutronics calculations. This includes: criticality level; spatially dependent flux and importance; impact of various parameters on criticality and time-dependent system response.

\section{Outputs Obtained}

Void coefficients (fuel, coolant); Temperature coefficients (fuel, coolant, moderator); Density coefficients (fuel, coolant, structure); Expansion coefficients (radial and axial).

\section{Additional Comments (links to other functionalities)}

Links to: Steady-state core neutronics; Heat conduction, convection, and radiation in core structure/moderator, heat transfer, and fluid flow; Pebble bed conduction, convection, and radiation; Predict other possible design dependent events; Simulation of reactor kinetics feedback and coupled response; Predict behavior during power-cooling mismatch events; Modeling of control and protection system.

Exists without consideration for precursor drift effect.

\section{For Internal Use Only}

F-04.05 


\section{Kinetics parameters}

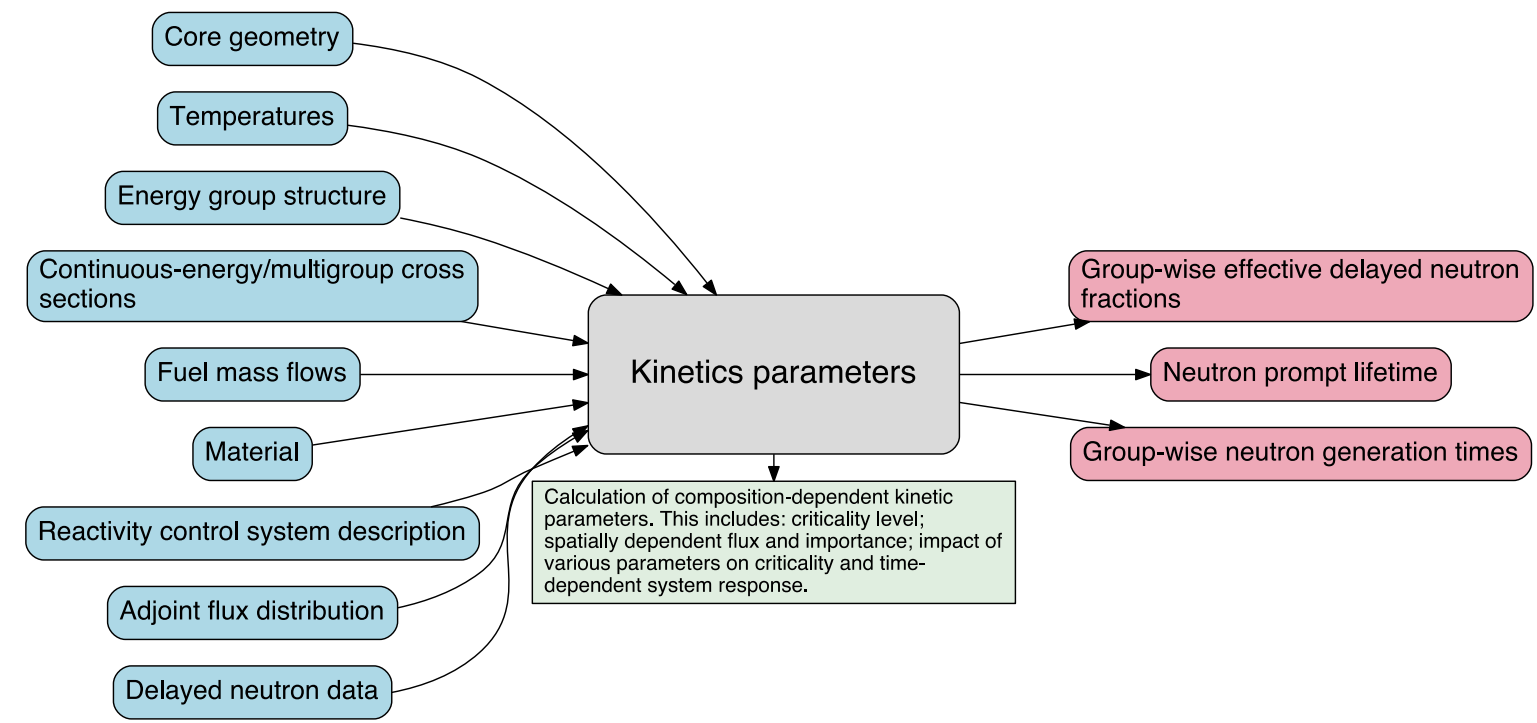

\section{MSR Modeling and Simulation Functionality Datasheet}

Version 0.0 - Feb. 28, 2018

Version 0.1 - Mar. 15, 2018

Date of Submission (mm/dd/yyyy)

$04 / 15 / 2018$

\begin{tabular}{|c|c|c|}
\hline Contributor Name(s) & Organization(s) & Email(s) \\
\hline MSR Campaign Modeling \& & Oak Ridge National Laboratory & betzlerbr@ornl.gov \\
Simulation Team & Argonne National Laboratory & \\
& Idaho National Laboratory & \\
& Pennsylvania State University & \\
\hline
\end{tabular}

Modeling and Simulation Functionality

Kinetics parameters

Inputs Required (as comprehensive as possible)

Core geometry; Temperatures; Energy group structure; Continuous-energy/multigroup cross sections; Fuel mass flows; Material; Reactivity control system description; Adjoint flux distribution; Delayed neutron data. 


\section{Definition and Phenomena}

Calculation of composition-dependent kinetic parameters. This includes: criticality level; spatially dependent flux and importance; impact of various parameters on criticality and time-dependent system response.

\section{Outputs Obtained}

Group-wise effective delayed neutron fractions; Neutron prompt lifetime; Group-wise neutron generation times.

Additional Comments (links to other functionalities)

Links to: Steady-state core neutronics; Heat conduction, convection, and radiation in core structure/moderator, heat transfer, and fluid flow; Pebble bed conduction, convection, and radiation; Predict other possible design dependent events; Simulation of reactor kinetics feedback and coupled response; Predict behavior during power-cooling mismatch events; Modeling of control and protection system.

Exists without consideration for precursor drift effect.

For Internal Use Only

F-04.05 


\section{Reactivity control behavior}

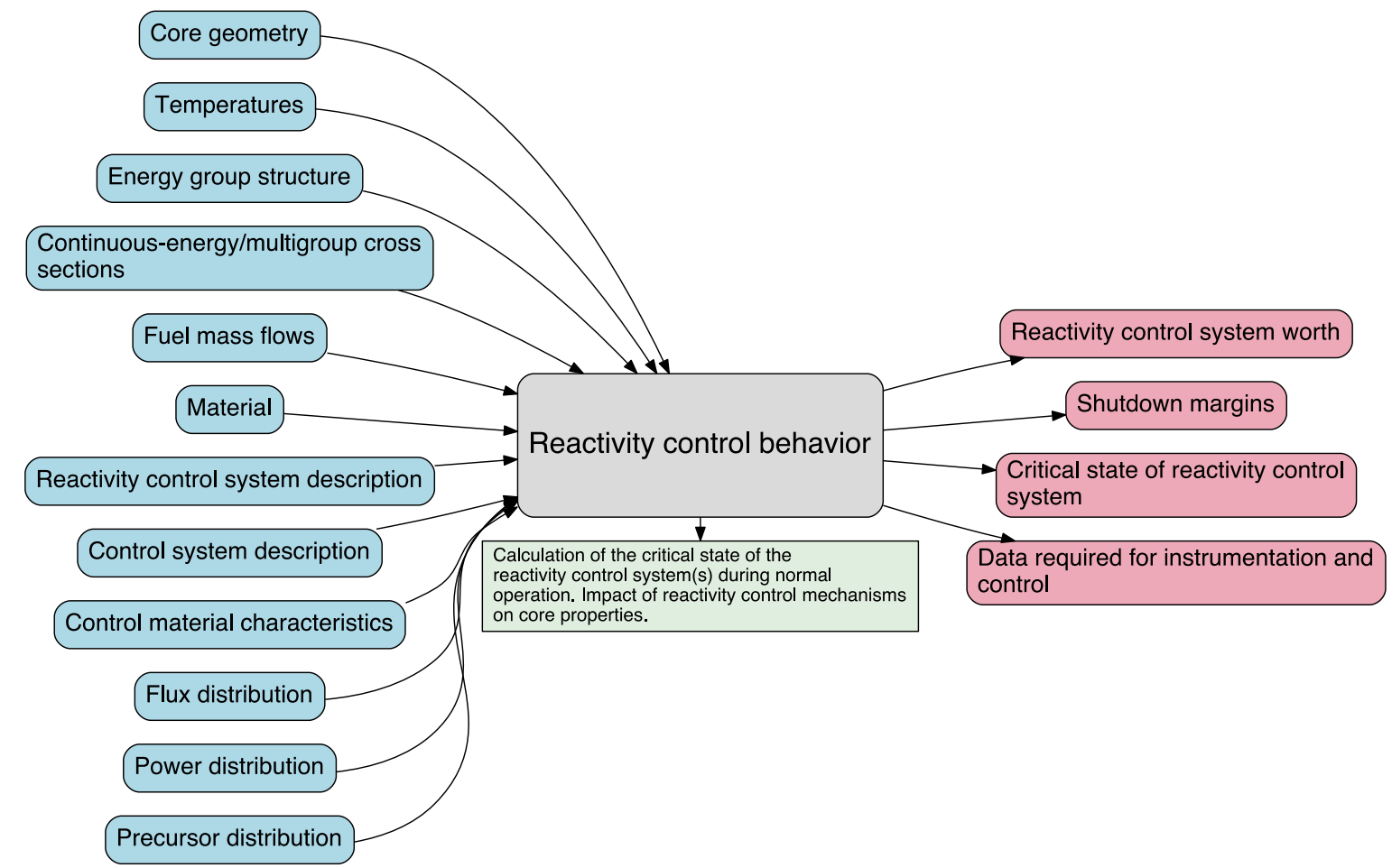

MSR Modeling and Simulation Functionality Datasheet

Version 0.0 - Feb. 28, 2018

Version 0.1 - Mar. 15, 2018

Date of Submission (mm/dd/yyyy)

$04 / 15 / 2018$

\begin{tabular}{|c|c|c|}
\hline Contributor Name(s) & Organization(s) & Email(s) \\
\hline MSR Campaign Modeling \& & Oak Ridge National Laboratory & betzlerbr@ornl.gov \\
Simulation Team & Argonne National Laboratory & \\
& Idaho National Laboratory & \\
& Pennsylvania State University & \\
\hline
\end{tabular}

Modeling and Simulation Functionality

Reactivity control behavior

Inputs Required (as comprehensive as possible)

Core geometry; Temperatures; Energy group structure; Continuous-energy/multigroup cross sections; Fuel mass flows; Material; Reactivity control system description; Control system description; Control material characteristics; Flux distribution; Power distribution; Precursor distribution. 


\section{Definition and Phenomena}

Calculation of the critical state of the reactivity control system(s) during normal operation. Impact of reactivity control mechanisms on core properties.

\section{Outputs Obtained}

Reactivity control system worth; Shutdown margins; Critical state of reactivity control system; Data required for instrumentation and control.

Additional Comments (links to other functionalities)

Links to: Reactor kinetics behavior, Demonstrate reactor startup procedure; Fuel depletion; Heat conduction, convection, and radiation in core structure/moderator, heat transfer, and fluid flow; Pebble bed conduction, convection, and radiation; Mass transport; Steady-state core neutronics; Predict other possible design dependent events; Simulation of reactor kinetics feedback and coupled response; Predict behavior during power-cooling mismatch events; Modeling of control and protection system; Quantify impact of instrumentation drift and uncertainty on predictions; Modeling of component failure and human factors.

Exists without consideration for precursor drift effect.

For Internal Use Only

F-04.05 


\section{Dose rate estimation}

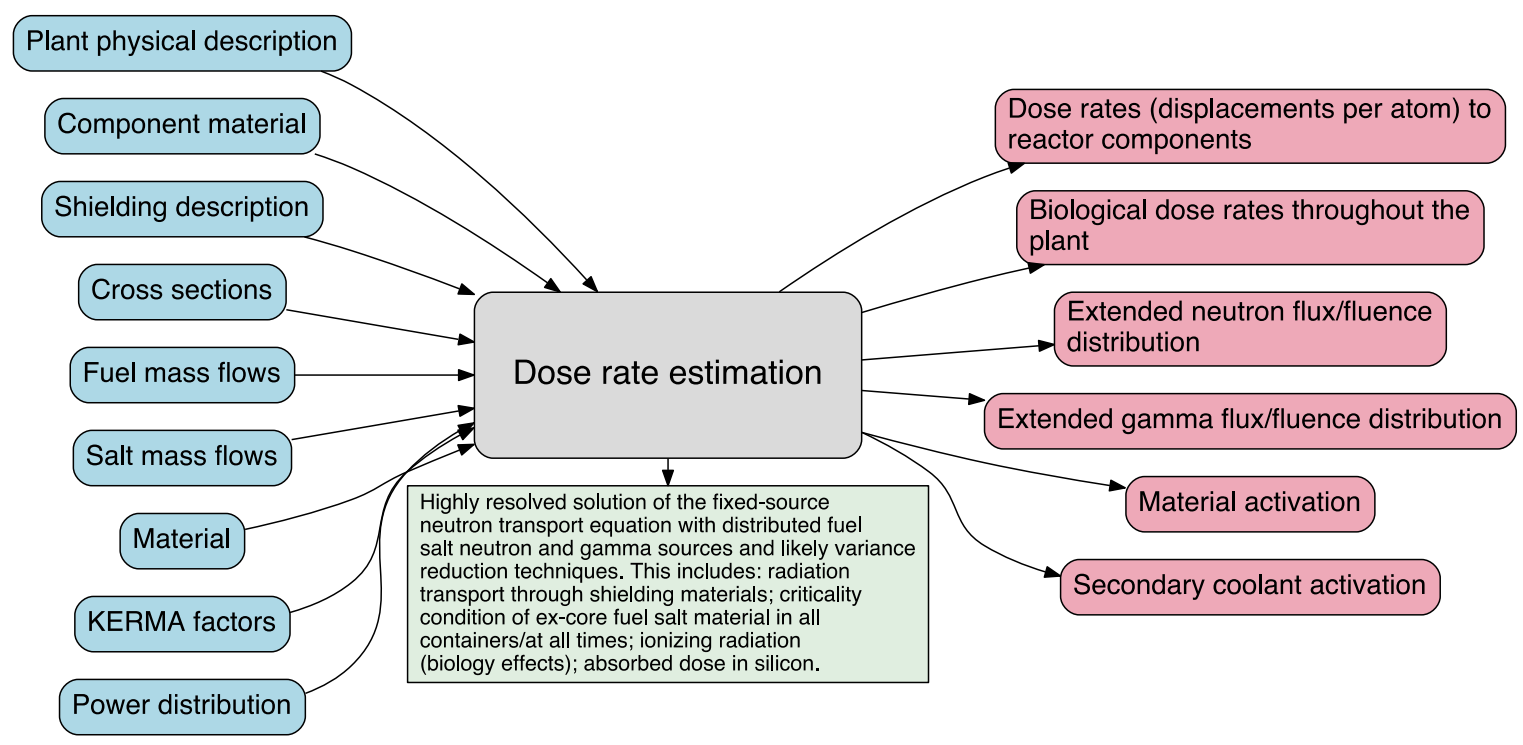

MSR Modeling and Simulation Functionality Datasheet

Version 0.0 - Feb. 28, 2018

Version 0.1 - Mar. 15, 2018

Date of Submission ( $\mathrm{mm} / \mathrm{dd} / \mathrm{yyyy})$ $04 / 15 / 2018$

\begin{tabular}{|c|c|c|}
\hline Contributor Name(s) & Organization(s) & Email(s) \\
\hline MSR Campaign Modeling \& & Oak Ridge National Laboratory & betzlerbr@ornl.gov \\
Simulation Team & Argonne National Laboratory & \\
& Idaho National Laboratory & \\
& Pennsylvania State University & \\
\hline
\end{tabular}

Modeling and Simulation Functionality

Dose rate estimation

Inputs Required (as comprehensive as possible)

Plant physical description; Component material; Shielding description; Cross sections; Fuel mass flows; Salt mass flows; Material; KERMA factors; Power distribution. 


\section{Definition and Phenomena}

Highly resolved solution of the fixed-source neutron transport equation with distributed fuel salt neutron and gamma sources and likely variance reduction techniques. This includes: radiation transport through shielding materials; criticality condition of ex-core fuel salt material in all containers/at all times; ionizing radiation (biology effects); absorbed dose in silicon.

\section{Outputs Obtained}

Dose rates (displacements per atom) to reactor components; Biological dose rates throughout the plant; Extended neutron flux/fluence distribution; Extended gamma flux/fluence distribution; Material activation; Secondary coolant activation.

\section{Additional Comments (links to other functionalities)}

Links to: Modeling of control and protection system, In-core material performance; Heat conduction, convection, and radiation in core structure/moderator, heat transfer, and fluid flow; Pebble bed conduction, convection, and radiation; Steady-state core neutronics; Modeling of component failure and human factors; Modeling of active and passive safety systems and components; Source term estimation; In-core material performance; Liquid fuel performance; TRISO fuel performance.

Exists in unvalidated, limited forms; Shielding calculations require the use of multiple tools (many considerations go into shielding). 


\section{Demonstrate reactor startup procedure}

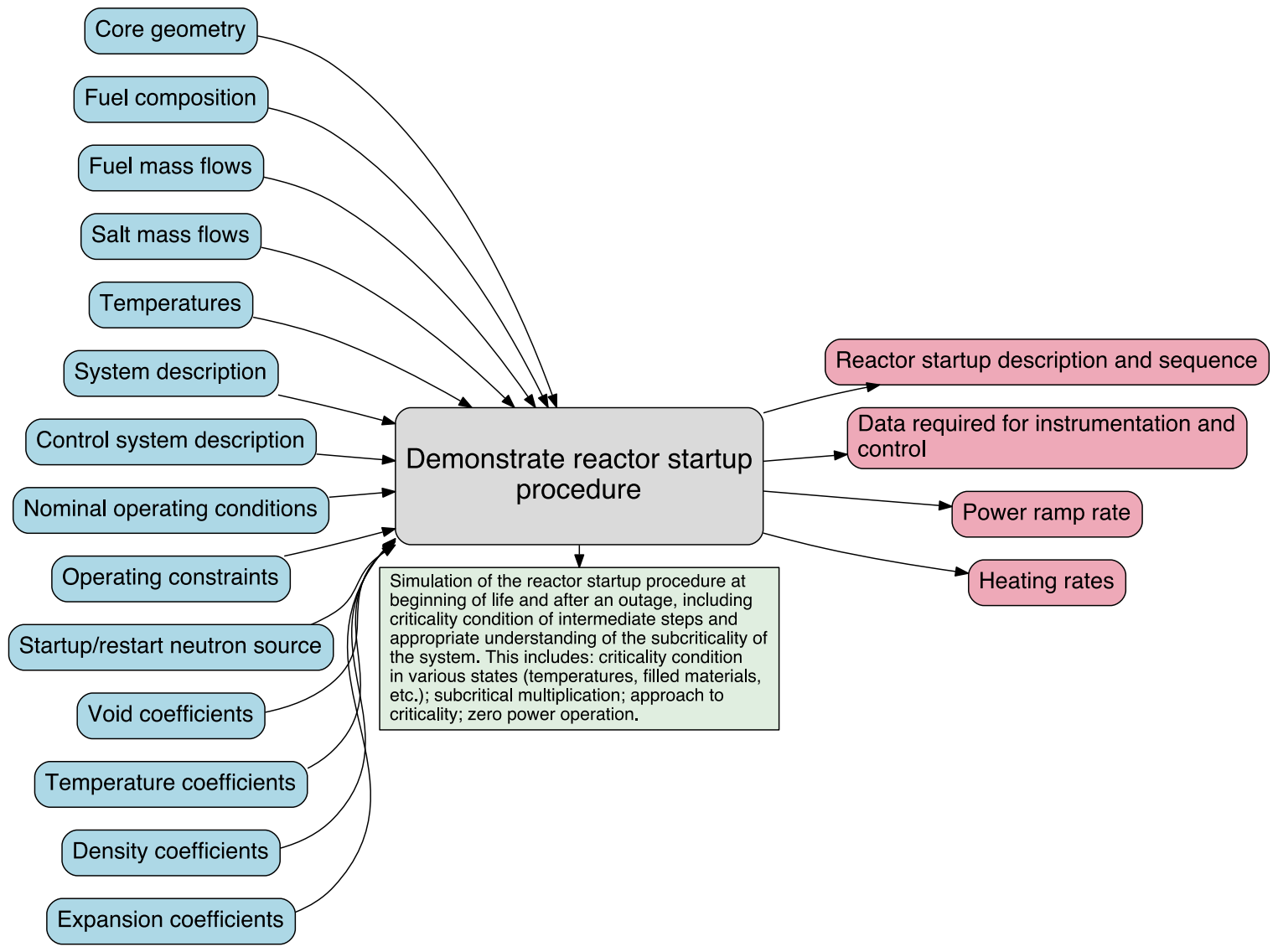

\section{MSR Modeling and Simulation Functionality Datasheet}

Version 0.0 - Feb. 28, 2018

Version 0.1 - Mar. 15, 2018

\section{Date of Submission ( $\mathrm{mm} / \mathrm{dd} / \mathrm{yyyy})$}

$04 / 15 / 2018$

\begin{tabular}{|c|c|c|}
\hline Contributor Name(s) & Organization(s) & Email(s) \\
\hline MSR Campaign Modeling \& & Oak Ridge National Laboratory & betzlerbr@ornl.gov \\
Simulation Team & Argonne National Laboratory & \\
& Idaho National Laboratory & \\
& Pennsylvania State University & \\
\hline
\end{tabular}

Modeling and Simulation Functionality

Demonstrate reactor startup procedure 
Inputs Required (as comprehensive as possible)

Core geometry; Fuel composition; Fuel mass flows; Salt mass flows; Temperatures; System description; Control system description; Nominal operating conditions; Operating constraints; Startup/restart neutron source; Void coefficients; Temperature coefficients; Density coefficients; Expansion coefficients.

\section{Definition and Phenomena}

Simulation of the reactor startup procedure at beginning of life and after an outage, including criticality condition of intermediate steps and appropriate understanding of the subcriticality of the system. This includes: criticality condition in various states (temperatures, filled materials, etc.); subcritical multiplication; approach to criticality; zero power operation.

\section{Outputs Obtained}

Reactor startup description and sequence; Data required for instrumentation and control; Power ramp rate; Heating rates.

\section{Additional Comments (links to other functionalities)}

Links to: Heat conduction, convection, and radiation in core structure/moderator, heat transfer, and fluid flow; Pebble bed conduction, convection, and radiation; Reactivity control behavior; Pebble bed granular flow; Fuel depletion; Multiphase flow (gas bubbles); Steady-state core neutronics; Mass transport; Salt thermochemistry; Modeling of control and protection system; Salt freezing; Quantify impact of instrumentation drift and uncertainty on predictions; Modeling of component failure and human factors.

Methods are undefined.

\section{For Internal Use Only}




\section{In-core material performance}

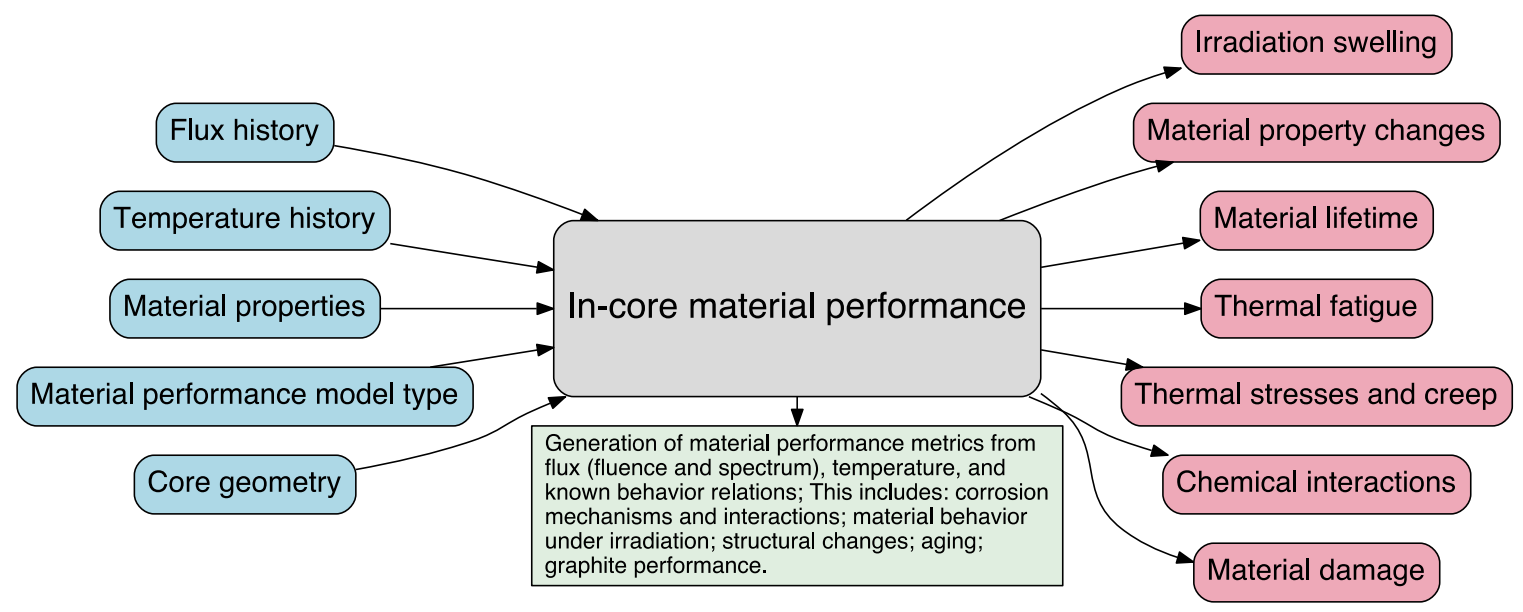

MSR Modeling and Simulation Functionality Datasheet

Version 0.0 - Feb. 28, 2018

Version 0.1 - Mar. 15, 2018

Date of Submission ( $\mathrm{mm} / \mathrm{dd} / \mathrm{yyyy})$

$04 / 15 / 2018$

\begin{tabular}{|c|c|c|}
\hline Contributor Name(s) & Organization(s) & Email(s) \\
\hline MSR Campaign Modeling \& & Oak Ridge National Laboratory & betzlerbr@ornl.gov \\
Simulation Team & Argonne National Laboratory & \\
& Idaho National Laboratory & \\
& Pennsylvania State University & \\
\hline
\end{tabular}

Modeling and Simulation Functionality

In-core material performance

Inputs Required (as comprehensive as possible)

Flux history; Temperature history; Material properties; Material performance model type; Core geometry.

Definition and Phenomena

Generation of material performance metrics from flux (fluence and spectrum), temperature, and known behavior relations; This includes: corrosion mechanisms and interactions; material behavior under irradiation; structural changes; aging; graphite performance. 


\section{Outputs Obtained}

Irradiation swelling; Material property changes; Material lifetime; Thermal fatigue; Thermal stresses and creep; Chemical interactions; Material damage.

Additional Comments (links to other functionalities)

Links to: Dose rate estimation; Steady-state core neutronics; Heat conduction, convection, and radiation in core structure/moderator, heat transfer, and fluid flow; Pebble bed conduction, convection, and radiation; Modeling of component failure and human factors; Predict radioactive release from a subsystem or component; Predict atmospheric transport of radioactive plume segments; Source term estimation.

Underlying functionality exists, but coupled modeling of time-dependent deformations and behavior may need validation.

\section{For Internal Use Only}

F-04.05 


\section{Liquid fuel properties}

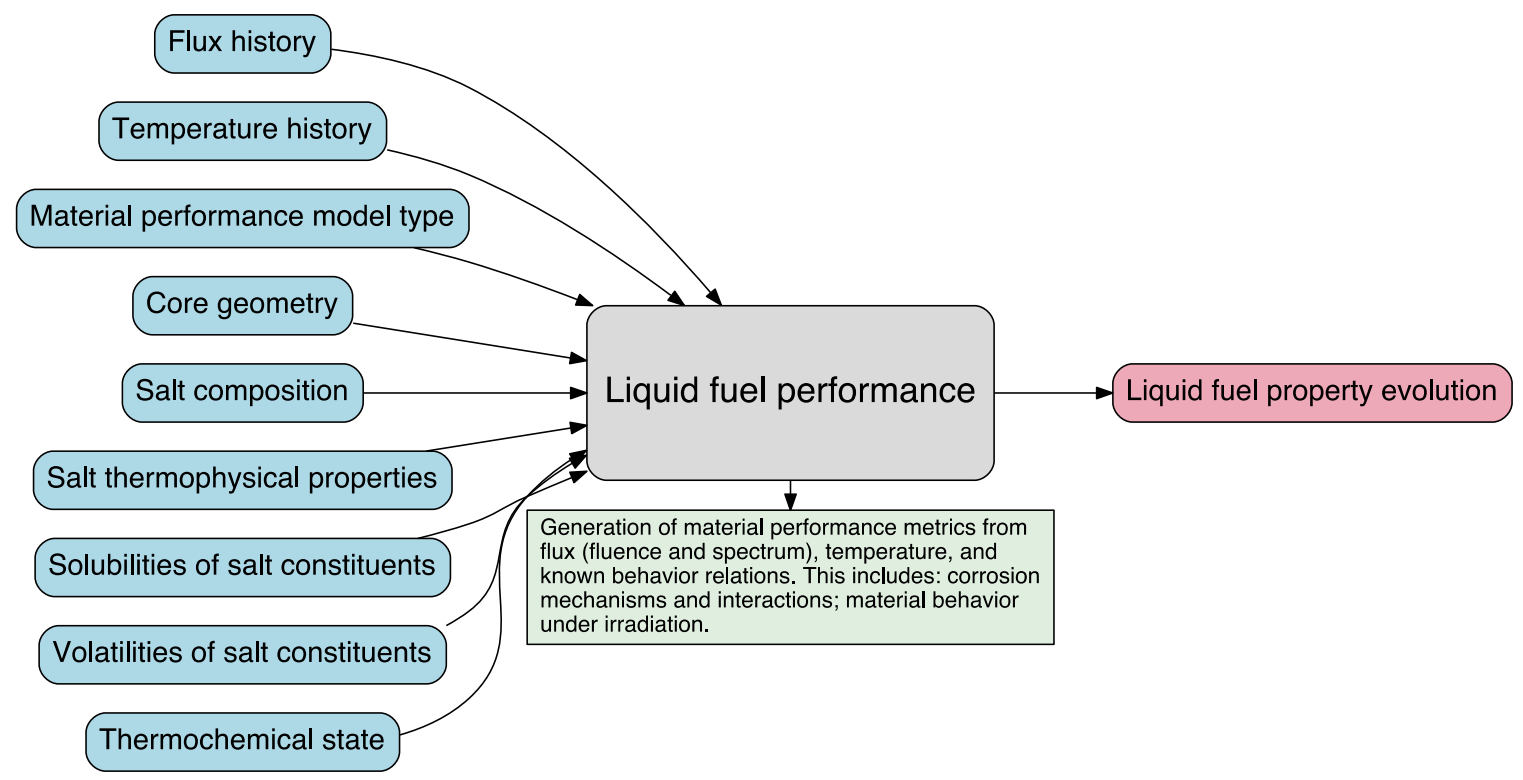

MSR Modeling and Simulation Functionality Datasheet

Version 0.0 - Feb. 28, 2018

Version 0.1 - Mar. 15, 2018

Date of Submission (mm/dd/yyyy) $04 / 15 / 2018$

\begin{tabular}{|c|c|c|}
\hline Contributor Name(s) & Organization(s) & Email(s) \\
\hline MSR Campaign Modeling \& & Oak Ridge National Laboratory & betzlerbr@ornl.gov \\
Simulation Team & Argonne National Laboratory & \\
& Idaho National Laboratory & \\
& Pennsylvania State University & \\
\hline
\end{tabular}

Modeling and Simulation Functionality

Liquid fuel performance

Inputs Required (as comprehensive as possible)

Flux history; Temperature history; Material performance model type; Core geometry; Salt composition; Salt thermophysical properties; Solubilities of salt constituents; Volatilities of salt constituents; Thermochemical state. 


\section{Definition and Phenomena}

Generation of material performance metrics from flux (fluence and spectrum), temperature, and known behavior relations. This includes: corrosion mechanisms and interactions; material behavior under irradiation.

\section{Outputs Obtained}

Liquid fuel property evolution.

Additional Comments (links to other functionalities)

Links to: Dose rate estimation; Steady-state core neutronics; Salt thermophysical properties; Fuel depletion; Heat conduction, convection, and radiation in core structure/moderator, heat transfer, and fluid flow; Pebble bed conduction, convection, and radiation; Predict other possible design dependent events; Simulation of reactor kinetics feedback and coupled response; Predict behavior during powercooling mismatch events; Modeling of active and passive safety systems and components; Dynamic fluid flow and heat transfer behavior of primary and secondary side components.

For Internal Use Only

F-04.05 


\section{TRISO fuel performance}

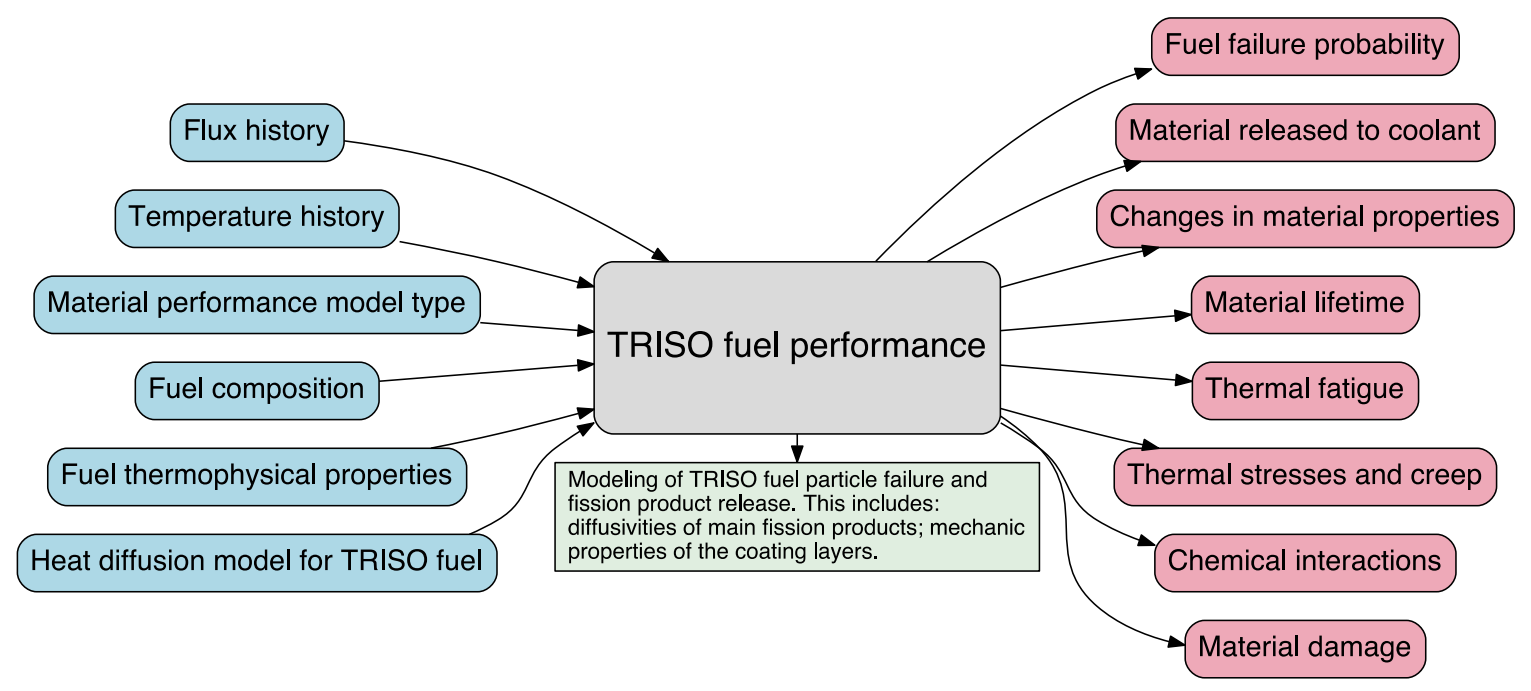

MSR Modeling and Simulation Functionality Datasheet

Version 0.0 - Feb. 28, 2018

Version 0.1 - Mar. 15, 2018

\begin{tabular}{|c|c|c|}
\cline { 2 - 3 } \multicolumn{1}{c|}{} & \multicolumn{2}{c|}{ Date of Submission (mm/dd/yyyy) } \\
\cline { 2 - 3 } \multicolumn{2}{c|}{$04 / 15 / 2018$} \\
\hline Contributor Name(s) & Organization(s) & Email(s) \\
\hline $\begin{array}{c}\text { MSR Campaign Modeling \& } \\
\text { Simulation Team }\end{array}$ & $\begin{array}{c}\text { Oak Ridge National Laboratory } \\
\text { Argonne National Laboratory } \\
\text { Idaho National Laboratory } \\
\text { Pennsylvania State University }\end{array}$ \\
\hline
\end{tabular}

Modeling and Simulation Functionality

TRISO fuel performance

Inputs Required (as comprehensive as possible)

Flux history; Temperature history; Material performance model type; Fuel composition; Fuel thermophysical properties; Heat diffusion model for TRISO fuel.

Definition and Phenomena

Modeling of TRISO fuel particle failure and fission product release. This includes: diffusivities of main fission products; mechanic properties of the coating layers. 


\section{Outputs Obtained}

Fuel failure probability; Material released to coolant; Changes in material properties; Material lifetime; Thermal fatigue; Thermal stresses and creep; Chemical interactions; Material damage.

Additional Comments (links to other functionalities)

Links to: Fuel depletion; Dose rate estimation; Steady-state core neutronics; Salt thermophysical properties; Heat conduction, convection, and radiation in core structure/moderator, heat transfer, and fluid flow; Pebble bed conduction, convection, and radiation; Modeling of component failure and human factors; Predict radioactive release from a subsystem or component; Predict atmospheric transport of radioactive plume segments; Source term estimation.

Functional needs are similar to those for mHTGRs. Observed failure mechanisms do not match historical ones; Material properties missing to model observed failure mechanisms; Historical diffusion coefficients are too high (over-prediction of fission product release) and need to be remeasured.

For Internal Use Only

F-04.05 


\section{Salt thermochemistry}

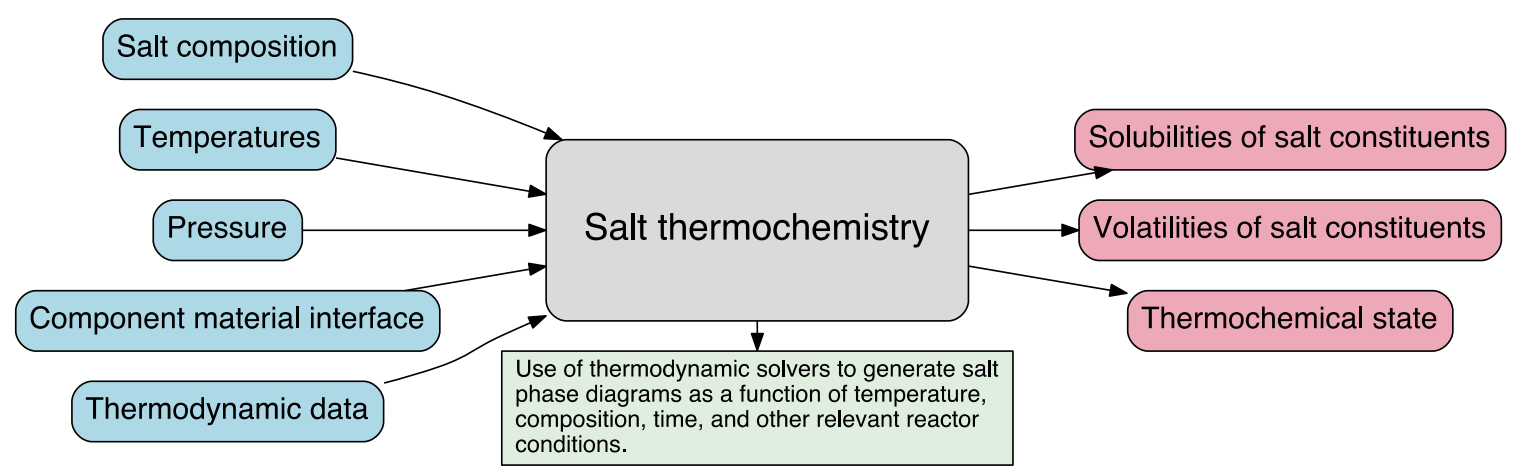

\section{MSR Modeling and Simulation Functionality Datasheet}

Version 0.0 - Feb. 28, 2018

Version 0.1 - Mar. 15, 2018

Date of Submission ( $\mathrm{mm} / \mathrm{dd} / \mathrm{yyyy})$ $04 / 15 / 2018$

\begin{tabular}{|c|c|c|}
\hline Contributor Name(s) & Organization(s) & Email(s) \\
\hline MSR Campaign Modeling \& & Oak Ridge National Laboratory & betzlerbr@ornl.gov \\
Simulation Team & Argonne National Laboratory & \\
& Idaho National Laboratory & \\
& Pennsylvania State University & \\
\hline
\end{tabular}

Modeling and Simulation Functionality

Salt thermochemistry

Inputs Required (as comprehensive as possible)

Salt composition; Temperatures; Pressure; Component material interface; Thermodynamic data.

\section{Definition and Phenomena}

Use of thermodynamic solvers to generate salt phase diagrams as a function of temperature, composition, time, and other relevant reactor conditions.

\section{Outputs Obtained}

Solubilities of salt constituents; Volatilities of salt constituents; Thermochemical state. 
Additional Comments (links to other functionalities)

Links to: Fuel depletion; Heat conduction, convection, and radiation in core structure/moderator, heat transfer, and fluid flow; Pebble bed conduction, convection, and radiation; Mass transport; Component corrosion.

Exists in unvalidated, limited forms; Requires extension of current neutronics methods and tools.

For Internal Use Only

F-04.05 


\section{Salt thermophysical properties}

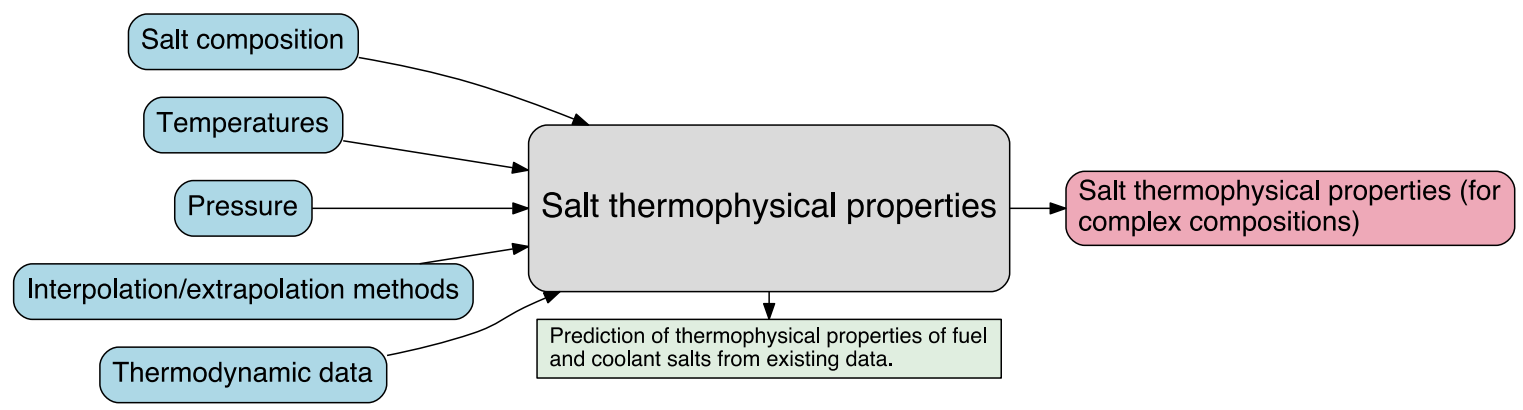

\section{MSR Modeling and Simulation Functionality Datasheet}

Version 0.0 - Feb. 28, 2018

Version 0.1 - Mar. 15, 2018

Date of Submission ( $\mathrm{mm} / \mathrm{dd} / \mathrm{yyyy})$ $04 / 15 / 2018$

\begin{tabular}{|c|c|c|}
\hline Contributor Name(s) & Organization(s) & Email(s) \\
\hline MSR Campaign Modeling \& & Oak Ridge National Laboratory & betzlerbr@ornl.gov \\
Simulation Team & Argonne National Laboratory & \\
& Idaho National Laboratory & \\
& Pennsylvania State University & \\
\hline
\end{tabular}

Modeling and Simulation Functionality

Salt thermophysical properties

Inputs Required (as comprehensive as possible)

Salt composition; Temperatures; Pressure; Interpolation/extrapolation methods; Thermodynamic data.

Definition and Phenomena

Prediction of thermophysical properties of fuel and coolant salts from existing data.

Outputs Obtained

Salt thermophysical properties (for complex compositions). 
Additional Comments (links to other functionalities)

Links to: Chapter 4 thermal hydraulics components; Mass transport; Fuel depletion; Heat conduction, convection, and radiation in core structure/moderator, heat transfer, and fluid flow; Pebble bed conduction, convection, and radiation; Predict radioactive release from a subsystem or component; Predict atmospheric transport of radioactive plume segments; Predict other possible design dependent events; Simulation of reactor kinetics feedback and coupled response; Predict behavior during power-cooling mismatch events; Modeling of active and passive safety systems and components; Source term estimation; Dynamic fluid flow and heat transfer behavior of primary and secondary side components;

Requires experimental program and relevant measurement standards; May require significant development (depending on uncertainties in methods); Limited set of fuel salt thermophysical properties is available (derived from Molten Salt Reactor Experiment data and other sources); Large uncertainties exist for the thermophysical properties as a function of eutectic composition and presence of impurities/fission products.

For Internal Use Only

F-04.05 


\section{Component corrosion}

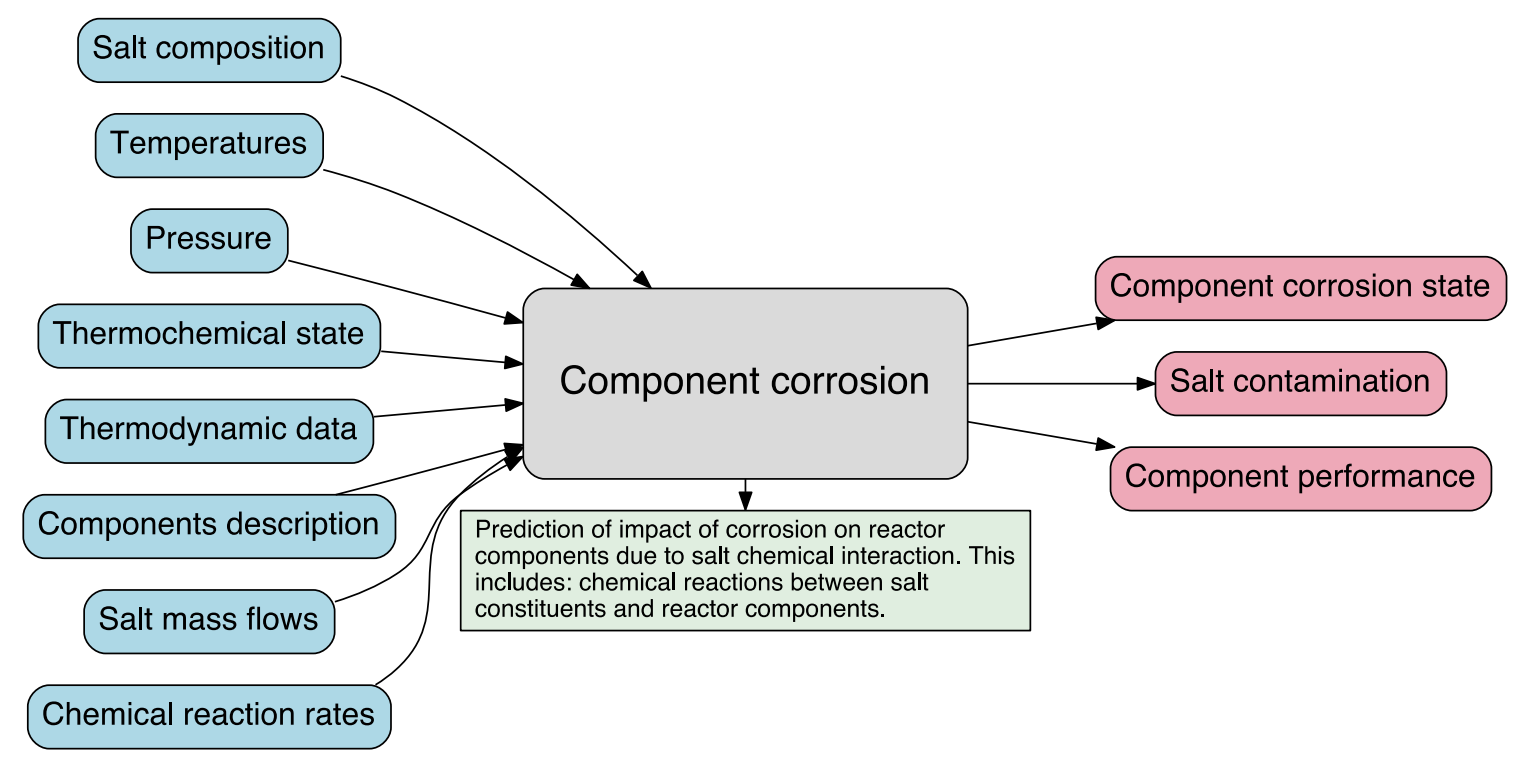

MSR Modeling and Simulation Functionality Datasheet

Version 0.0 - Feb. 28, 2018

Version 0.1 - Mar. 15, 2018

\section{Date of Submission ( $\mathrm{mm} / \mathrm{dd} / \mathrm{yyyy})$}

$04 / 15 / 2018$

\begin{tabular}{|c|c|c|}
\hline Contributor Name(s) & Organization(s) & Email(s) \\
\hline MSR Campaign Modeling \& & Oak Ridge National Laboratory & betzlerbr@ornl.gov \\
Simulation Team & Argonne National Laboratory & \\
& Idaho National Laboratory & \\
& Pennsylvania State University & \\
\hline
\end{tabular}

Modeling and Simulation Functionality

Component corrosion

Inputs Required (as comprehensive as possible)

Salt composition; Temperatures; Pressure; Thermochemical state; Thermodynamic data; Component description; Salt mass flows; Chemical reaction rates.

\section{Definition and Phenomena}

Prediction of impact of corrosion on reactor components due to salt chemical interaction. This includes: chemical reactions between salt constituents and reactor components. 


\section{Outputs Obtained}

Component corrosion state; Salt contamination; Component performance.

Additional Comments (links to other functionalities)

Links to: Chapter 4 thermal hydraulics components; Heat conduction, convection, and radiation in core structure/moderator, heat transfer, and fluid flow; Pebble bed conduction, convection, and radiation; Fuel depletion; Salt thermochemistry; Source term estimation; Modeling of active and passive safety systems and components; Modeling of component failure and human factors.

For Internal Use Only

F-04.05 


\section{Salt reaction kinetics}

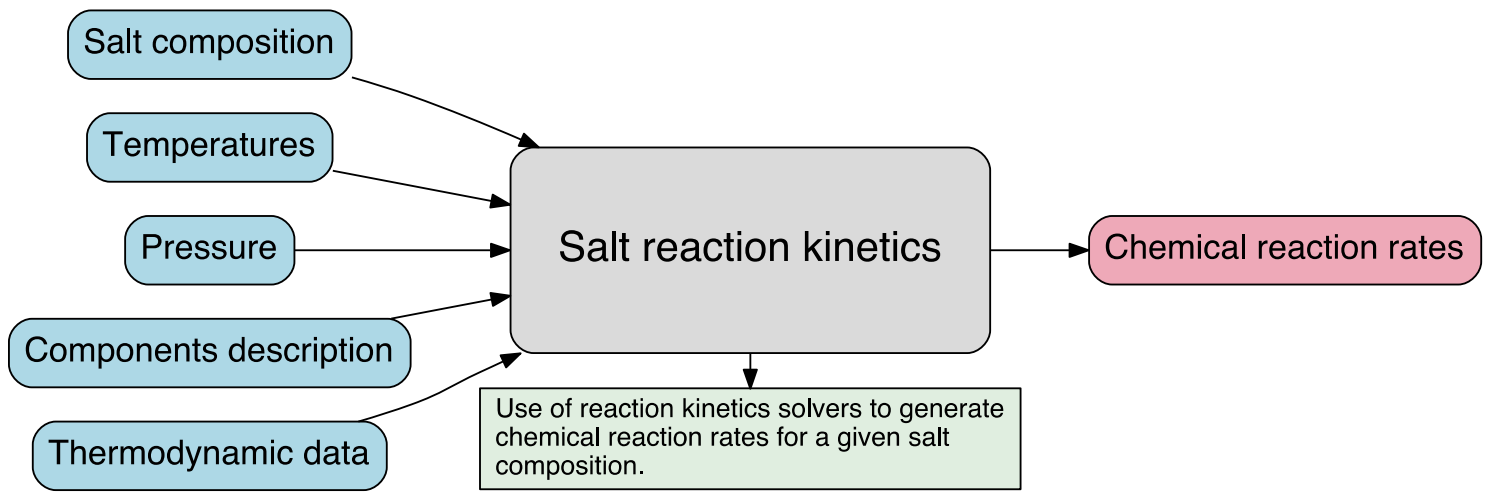

\section{MSR Modeling and Simulation Functionality Datasheet}

Version 0.0 - Feb. 28, 2018

Version 0.1 - Mar. 15, 2018

\section{Date of Submission (mm/dd/yyyy) \\ $04 / 15 / 2018$}

\begin{tabular}{|c|c|c|}
\hline Contributor Name(s) & Organization(s) & Email(s) \\
\hline MSR Campaign Modeling \& & Oak Ridge National Laboratory & betzlerbr@ornl.gov \\
Simulation Team & Argonne National Laboratory & \\
& Idaho National Laboratory & \\
& Pennsylvania State University & \\
\hline
\end{tabular}

Modeling and Simulation Functionality

Salt reaction kinetics

Inputs Required (as comprehensive as possible)

Salt composition; Temperatures; Pressure; Components description; Thermodynamic data.

Definition and Phenomena

Use of reaction kinetics solvers to generate chemical reaction rates for a given salt composition.

Outputs Obtained

Chemical reaction rates. 
Additional Comments (links to other functionalities)

Links to: Component corrosion; Fuel depletion; Heat conduction, convection, and radiation in core structure/moderator, heat transfer, and fluid flow; Pebble bed conduction, convection, and radiation; Source term estimation.

May not be necessary to resolve chemistry effects on such a short a time scale; may not have a larger effect on reactor performance or fission product behavior.

For Internal Use Only

F-04.05 


\section{Mass transport}

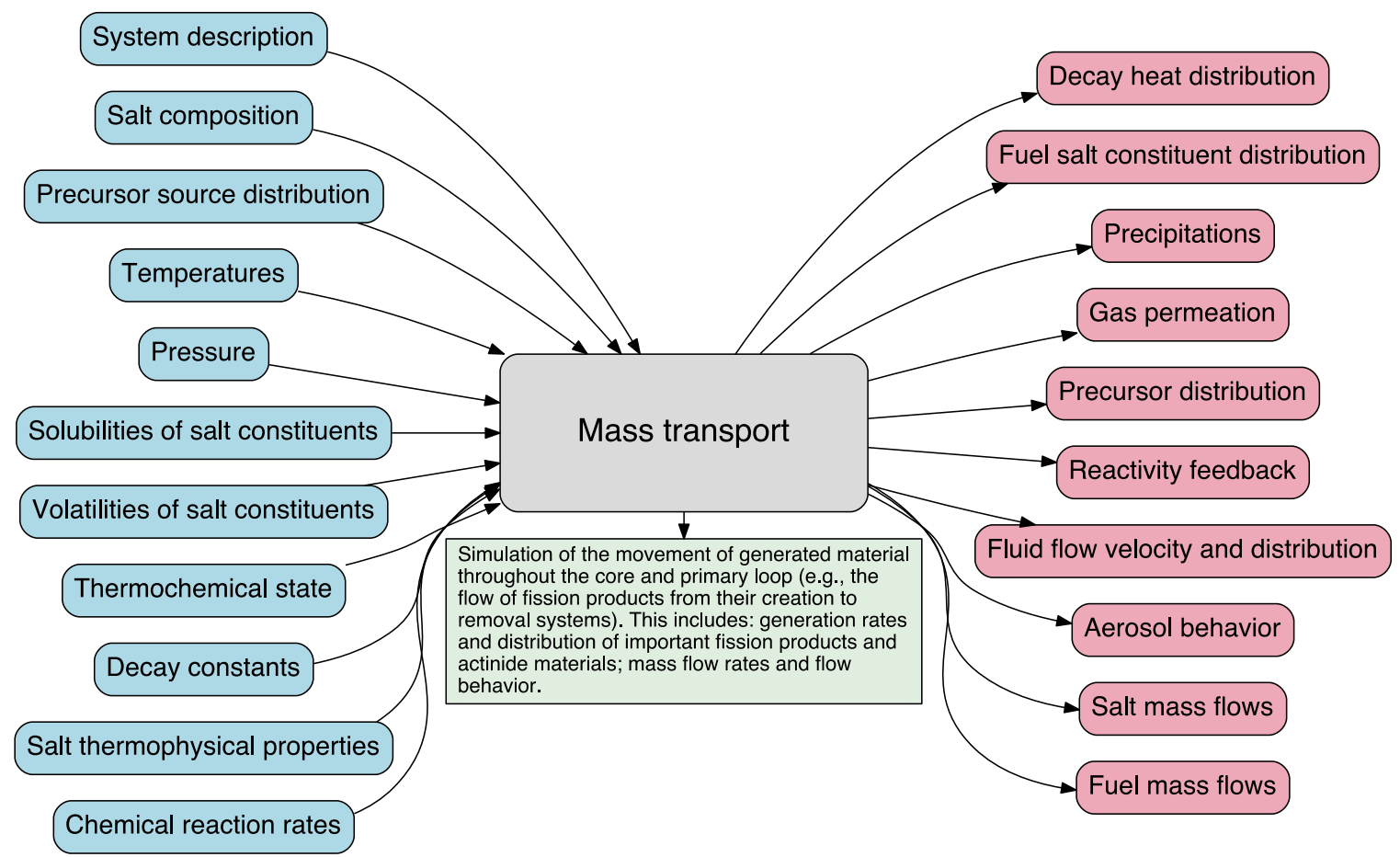

\section{MSR Modeling and Simulation Functionality Datasheet}

Version 0.0 - Feb. 28, 2018

Version 0.1 - Mar. 15, 2018

Date of Submission (mm/dd/yyyy)

\begin{tabular}{|c|c|c|}
\hline Contributor Name(s) & Organization(s) & Email(s) \\
\hline MSR Campaign Modeling \& & Oak Ridge National Laboratory & betzlerbr@ornl.gov \\
Simulation Team & Argonne National Laboratory & \\
& Idaho National Laboratory & \\
& Pennsylvania State University & \\
\hline
\end{tabular}

Modeling and Simulation Functionality

Mass transport

Inputs Required (as comprehensive as possible)

System description; Salt composition; Precursor source distribution; Temperatures; Pressure; Solubilities of salt constituents; Volatilities of salt constituents; Thermochemical state; Decay constants; Salt thermophysical properties; Chemical reaction rates. 


\section{Definition and Phenomena}

Simulation of the movement of generated material throughout the core and primary loop (e.g., the flow of fission products from their creation to removal systems). This includes: generation rates and distribution of important fission products and actinide materials; mass flow rates and flow behavior.

\section{Outputs Obtained}

Decay heat distribution; Fuel salt constituent distribution; Precipitations; Gas permeation; Precursor distribution; Reactivity feedback; Fluid flow velocity and distribution; Aerosol behavior; Salt mass flows; Fuel mass flows.

\section{Additional Comments (links to other functionalities)}

Links to: Modeling of active and passive safety systems and components; Heat conduction, convection, and radiation in core structure/moderator, heat transfer, and fluid flow; Pebble bed conduction, convection, and radiation; Fuel depletion; Steady-state core neutronics; Salt thermochemistry; Source term estimation; Reactivity control behavior; Predict other possible design dependent events; Simulation of reactor kinetics feedback and coupled response; Predict behavior during power-cooling mismatch events; Modeling of control and protection system.

Capabilities exist partially. Verification and validation are required. Some legacy codes have been extended to include the required precursor transport capability. Other codes may be extended as well, with a moderate development effort. Characteristics of pumps and other crucial flow components are necessary as part of the system description. This includes plate-out and lift off of materials, e.g. noble metals, from surfaces throughout the system. 


\section{Salt freezing}

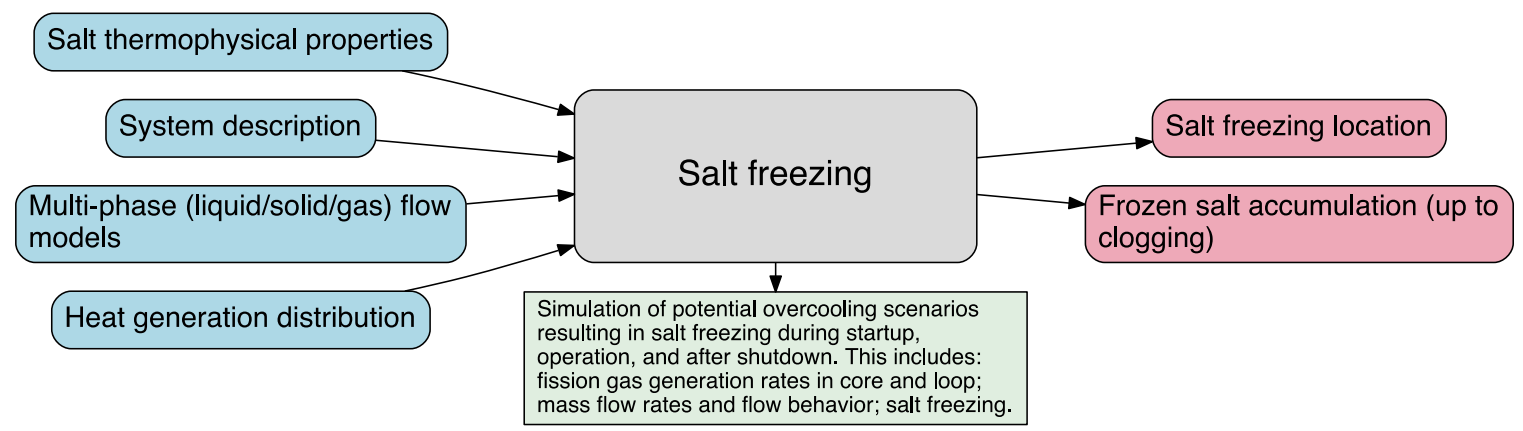

MSR Modeling and Simulation Functionality Datasheet

Version 0.0 - Feb. 28, 2018

Version 0.1 - Mar. 15, 2018

Date of Submission ( $\mathrm{mm} / \mathrm{dd} / \mathrm{yyyy})$

$04 / 15 / 2018$

\begin{tabular}{|c|c|c|}
\hline Contributor Name(s) & Organization(s) & Email(s) \\
\hline MSR Campaign Modeling \& & Oak Ridge National Laboratory & betzlerbr@ornl.gov \\
Simulation Team & Argonne National Laboratory & \\
& Idaho National Laboratory & \\
& Pennsylvania State University & \\
\hline
\end{tabular}

Modeling and Simulation Functionality

Salt freezing

Inputs Required (as comprehensive as possible)

Salt thermophysical properties; System description; Multi-phase (liquid/solid/gas) flow models; Heat generation distribution.

Definition and Phenomena

Simulation of potential overcooling scenarios resulting in salt freezing during startup, operation, and after shutdown. This includes: fission gas generation rates in core and loop; mass flow rates and flow behavior; salt freezing.

\section{Outputs Obtained}

Salt freezing location; Frozen salt accumulation (up to clogging). 
Additional Comments (links to other functionalities)

Links to: Chapter 15 functionalities for transient and accident analysis; Mass transport; Demonstrate reactor startup procedure; Salt thermophysical properties; Predict other possible design dependent events; Predict behavior during power-cooling mismatch events; Modeling of active and passive safety systems and components; Dynamic fluid flow and heat transfer behavior of primary and secondary side components.

Data are available for melting point of particular salt compositions, but melting point may be sensitive to changes in salt composition and/or addition of impurities. Code development may be needed to sufficiently resolve flow and thermal behavior in vessel and auxiliary/secondary loops during accident scenarios to predict occurrence of freezing and possibly model the behavior of two-phase liquid/solid mixture.

For Internal Use Only

F-04.05 


\section{Multiphase flow (bubbling)}

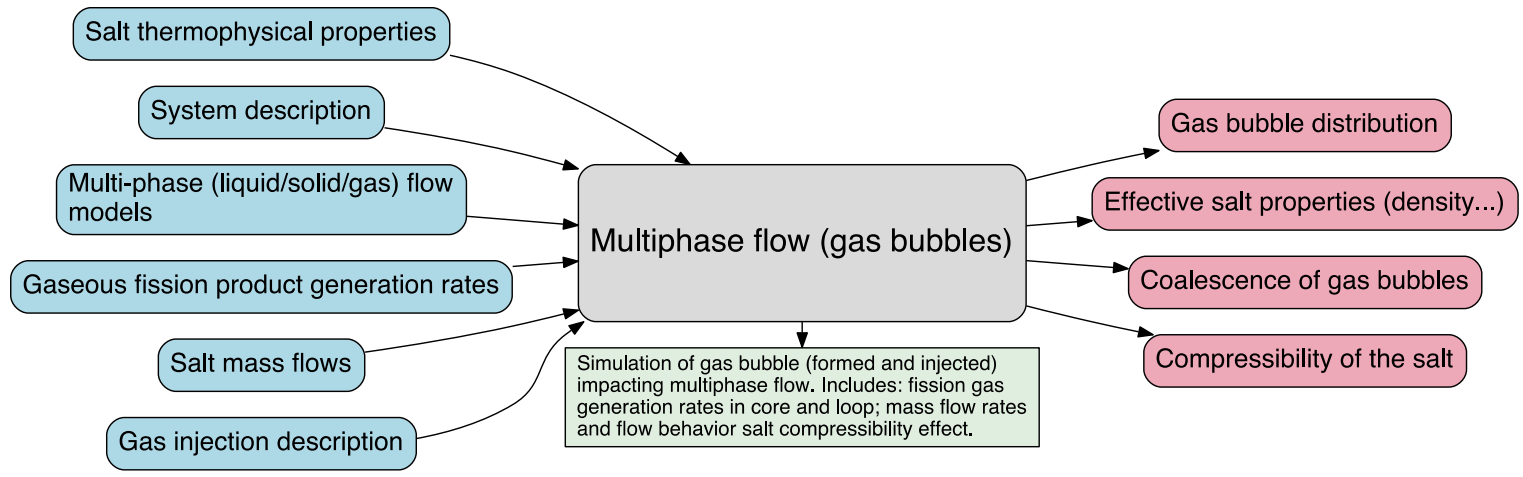

MSR Modeling and Simulation Functionality Datasheet

Version 0.0 - Feb. 28, 2018

Version 0.1 - Mar. 15, 2018

Date of Submission ( $\mathrm{mm} / \mathrm{dd} / \mathrm{yyyy})$ $04 / 15 / 2018$

\begin{tabular}{|c|c|c|}
\hline Contributor Name(s) & Organization(s) & Email(s) \\
\hline MSR Campaign Modeling \& & Oak Ridge National Laboratory & betzlerbr@ornl.gov \\
Simulation Team & Argonne National Laboratory & \\
& Idaho National Laboratory & \\
& Pennsylvania State University & \\
\hline
\end{tabular}

Modeling and Simulation Functionality

Multiphase flow (gas bubbles)

Inputs Required (as comprehensive as possible)

Salt thermophysical properties; System description; Multi-phase (liquid/solid/gas) flow models; Gaseous fission product generation rates; Salt mass flows; Gas injection description.

\section{Definition and Phenomena}

Simulation of gas bubble (formed and injected) impacting multiphase flow. Includes: fission gas generation rates in core and loop; mass flow rates and flow behavior salt compressibility effect.

\section{Outputs Obtained}

Gas bubble distribution; Effective salt properties (density...); Coalescence of gas bubbles; Compressibility of the salt. 
Additional Comments (links to other functionalities)

Links to: Mass transport; Heat conduction, convection, and radiation in core structure/moderator, heat transfer, and fluid flow; Pebble bed conduction, convection, and radiation; Fuel depletion; Salt thermophysical properties; Demonstrate reactor startup procedure; Predict other possible design dependent events; Simulation of reactor kinetics feedback and coupled response; Predict behavior during power-cooling mismatch events; Dynamic fluid flow and heat transfer behavior of primary and secondary side components.

Code development may be needed to sufficiently resolve flow and thermal behavior in vessel and auxiliary/secondary loops during accident scenarios.

For Internal Use Only

F-04.05 


\section{Source term accountability}

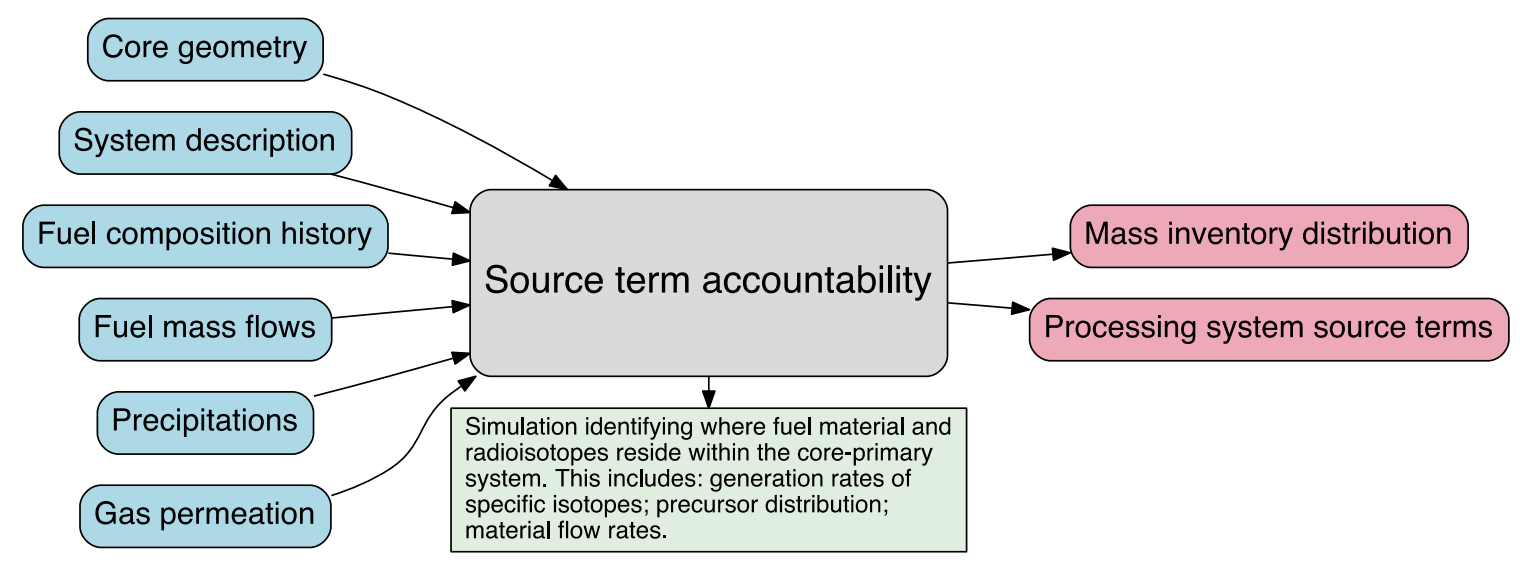

\section{MSR Modeling and Simulation Functionality Datasheet}

Version 0.0 - Feb. 28, 2018

Version 0.1 - Mar. 15, 2018

Date of Submission ( $\mathrm{mm} / \mathrm{dd} / \mathrm{yyyy})$

$04 / 15 / 2018$

\begin{tabular}{|c|c|c|}
\hline Contributor Name(s) & Organization(s) & Email(s) \\
\hline MSR Campaign Modeling \& & Oak Ridge National Laboratory & betzlerbr@ornl.gov \\
Simulation Team & Argonne National Laboratory & \\
& Idaho National Laboratory & \\
& Pennsylvania State University & \\
\hline
\end{tabular}

Modeling and Simulation Functionality

Source term accountability

Inputs Required (as comprehensive as possible)

Core geometry; System description; Fuel composition history; Fuel mass flows; Precipitations; Gas permeation.

Definition and Phenomena

Simulation identifying where fuel material and radioisotopes reside within the core-primary system.

This includes: generation rates of specific isotopes; precursor distribution; material flow rates.

\section{Outputs Obtained}

Mass inventory distribution; Processing system source terms. 
Additional Comments (links to other functionalities)

Links to: Heat conduction, convection, and radiation in core structure/moderator, heat transfer, and fluid flow; Pebble bed conduction, convection, and radiation; Fuel depletion; Source term estimation; Predict radioactive release from a subsystem or component; Predict atmospheric transport of radioactive plume segments.

Functionalities exists in partial forms; No application to molten salt reactors.

For Internal Use Only

F-04.05 


\section{Heat conduction, heat transfer, and fluid flow}

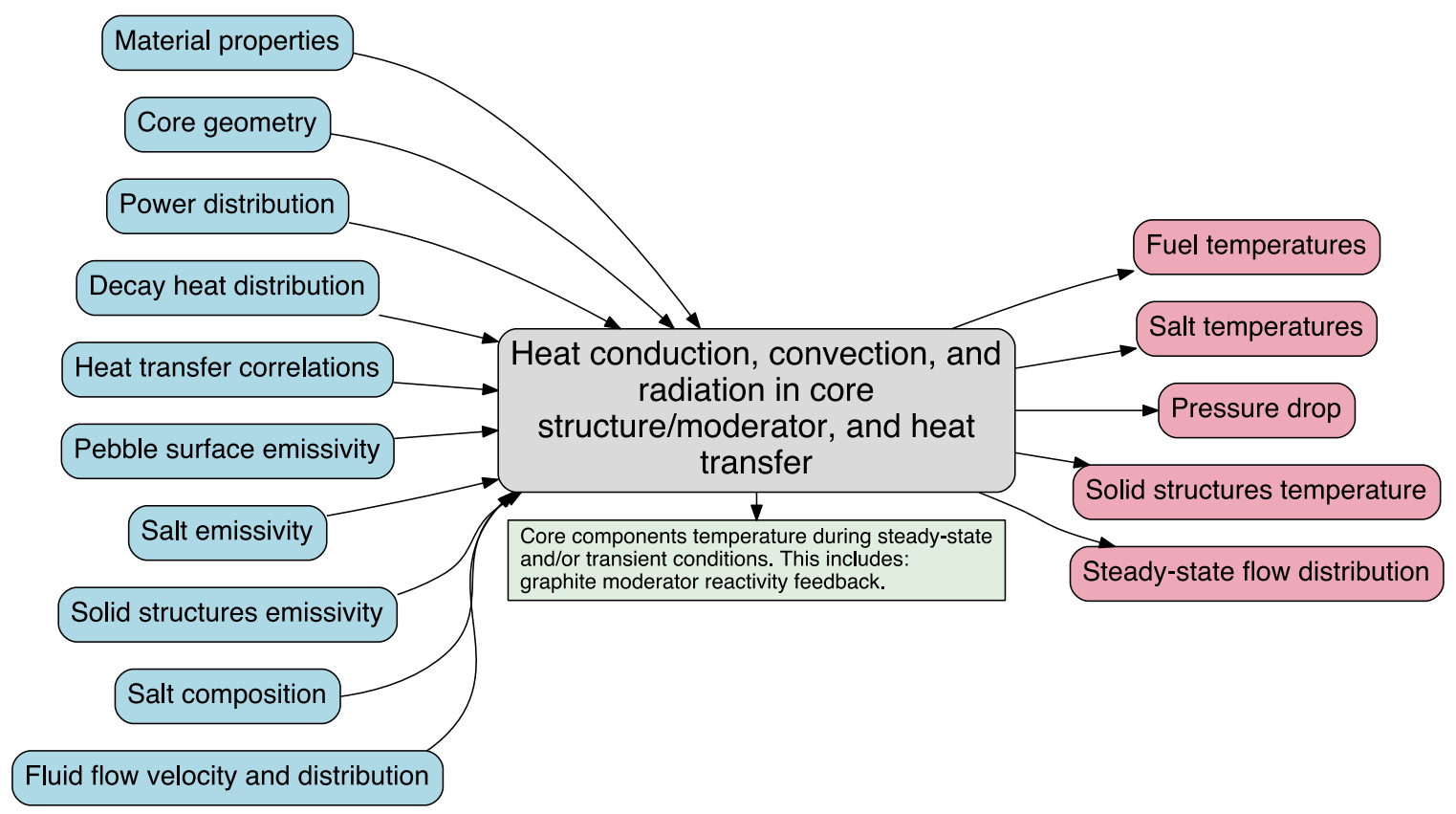

\section{MSR Modeling and Simulation Functionality Datasheet}

Version 0.0 - Feb. 28, 2018

Version 0.1 - Mar. 15, 2018

Date of Submission (mm/dd/yyyy)

$04 / 15 / 2018$

\begin{tabular}{|c|c|c|}
\hline Contributor Name(s) & Organization(s) & Email(s) \\
\hline MSR Campaign Modeling \& & Oak Ridge National Laboratory & betzlerbr@ornl.gov \\
Simulation Team & Argonne National Laboratory & \\
& Idaho National Laboratory & \\
& Pennsylvania State University & \\
\hline
\end{tabular}

Modeling and Simulation Functionality

Heat conduction, convection, and radiation in core structure/moderator, and heat transfer

Inputs Required (as comprehensive as possible)

Material properties; Core geometry; Power distribution; Decay heat distribution; Heat transfer correlations; Pebble surface emissivity; Salt emissivity; Solid structures emissivity; Salt composition; Fluid flow velocity and distribution. 


\section{Definition and Phenomena}

Core components temperature during steady-state and/or transient conditions. This includes: graphite moderator reactivity feedback.

\section{Outputs Obtained}

Fuel temperatures; Salt temperatures; Pressure drop; Solid structures temperatures; Steady-state flow distribution.

Additional Comments (links to other functionalities)

Links to: Chapter 4 functionalities for nuclear and fuel system design; Chapter 15 functionalities for transient and accident analysis; Fuel depletion; Steady-state core neutronics; Mass transport; In-core material performance; Liquid fuel performance; TRISO fuel performance; Modeling of active and passive safety systems and components; Quantify impact of instrumentation drift and uncertainty on predictions; Predict other possible design dependent events; Predict behavior during power-cooling mismatch events; Dynamic fluid flow and heat transfer behavior of primary and secondary side components.

Most existing computational tools are based on LWR (cylindrical pin) geometry. Code development may be needed on a reactor design-specific basis to accurately calculate average graphite temperatures suitable for square and/or hexagonal graphite configurations. Radiative emissivity of salt not well characterized. Additional validation and/or analysis may be needed to understand the effect of radiative heat transfer.

For Internal Use Only

F-04.05 


\section{Pebble bed convection and conduction}

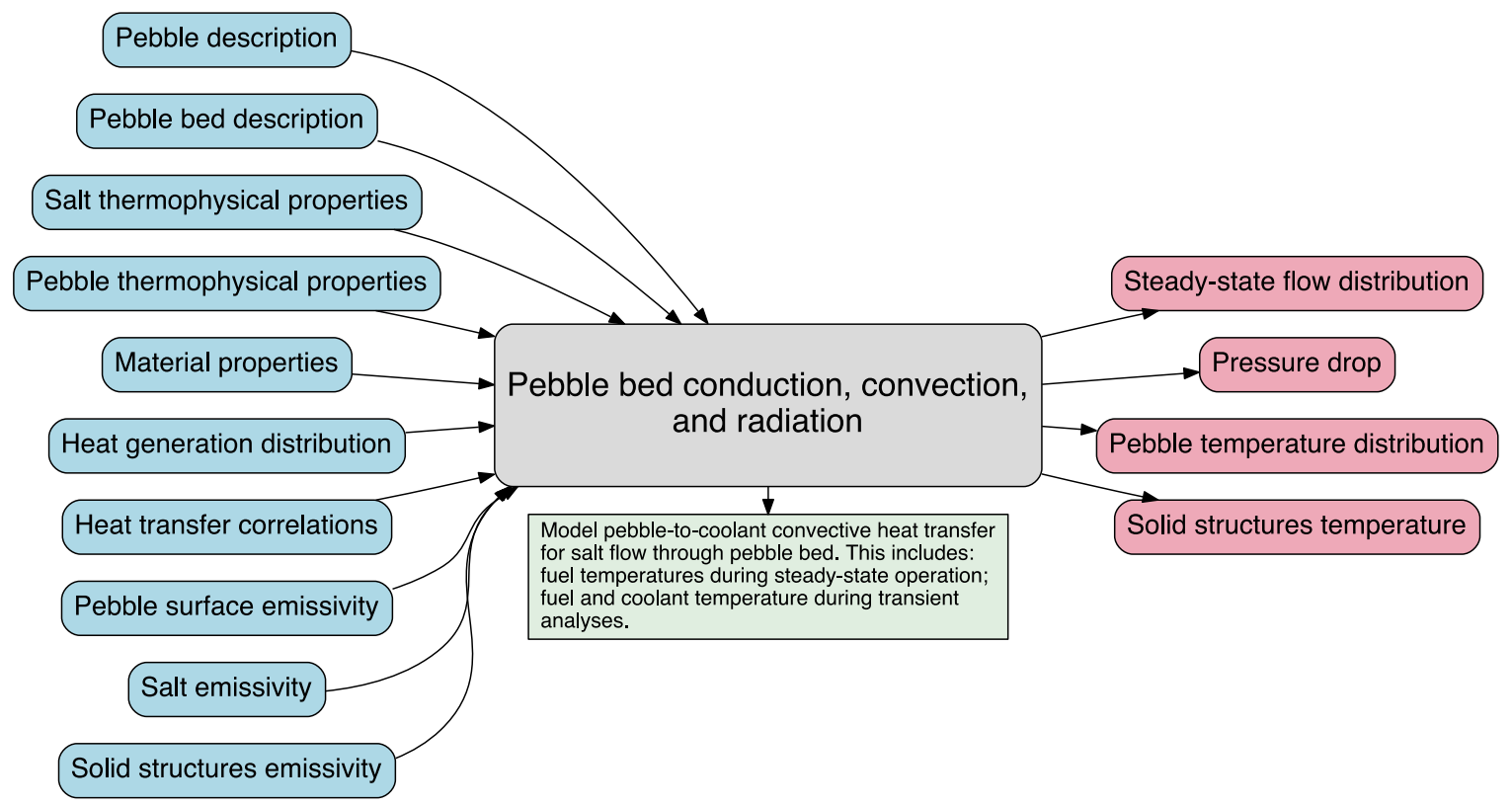

MSR Modeling and Simulation Functionality Datasheet

Version 0.0 - Feb. 28, 2018

Version 0.1 - Mar. 15, 2018

Date of Submission (mm/dd/yyyy)

$04 / 15 / 2018$

\begin{tabular}{|c|c|c|}
\hline Contributor Name(s) & Organization(s) & Email(s) \\
\hline MSR Campaign Modeling \& & Oak Ridge National Laboratory & betzlerbr@ornl.gov \\
Simulation Team & Argonne National Laboratory & \\
& Idaho National Laboratory & \\
& Pennsylvania State University & \\
\hline
\end{tabular}

Modeling and Simulation Functionality

Pebble bed conduction, convection, and radiation

Inputs Required (as comprehensive as possible)

Pebble description; Pebble bed description; Salt thermophysical properties; Pebble thermophysical properties; Material properties; Heat generation distribution; Heat transfer correlations; Pebble surface emissivity; Salt emissivity; Solid structures emissivity. 


\section{Definition and Phenomena}

Model pebble-to-coolant convective heat transfer for salt flow through pebble bed. This includes: fuel temperatures during steady-state operation; fuel and coolant temperature during transient analyses.

\section{Outputs Obtained}

Steady-state flow distribution; Pressure drop; Pebble temperature distribution; Solid structures temperature.

Additional Comments (links to other functionalities)

Links to: Chapter 4 functionalities for nuclear and fuel system design; Chapter 15 functionalities for transient and accident analysis; Mass transport; Demonstrate reactor startup procedure; Salt thermophysical properties; Pebble bed granular flow; Modeling of active and passive safety systems and components; Quantify impact of instrumentation drift and uncertainty on predictions; In-core material performance; Liquid fuel performance; TRISO fuel performance; Predict other possible design dependent events; Predict behavior during power-cooling mismatch events; Dynamic fluid flow and heat transfer behavior of primary and secondary side components.

Experimental database for pebble bed frictional and flow behavior and heat transfer behavior exists but does not include salt as working fluid. New experimental data are needed. High-fidelity computational fluid dynamics simulations may help bridge the gap and/or inform future experimental investigation. Heat conduction functionality exists in some tools designed for pebble bed reactor analysis. Generic thermal hydraulic tools typically may need to be extended to explicitly model fuel pebble and kernel heat up during fast transients. 


\section{Time-dependent granular flow}

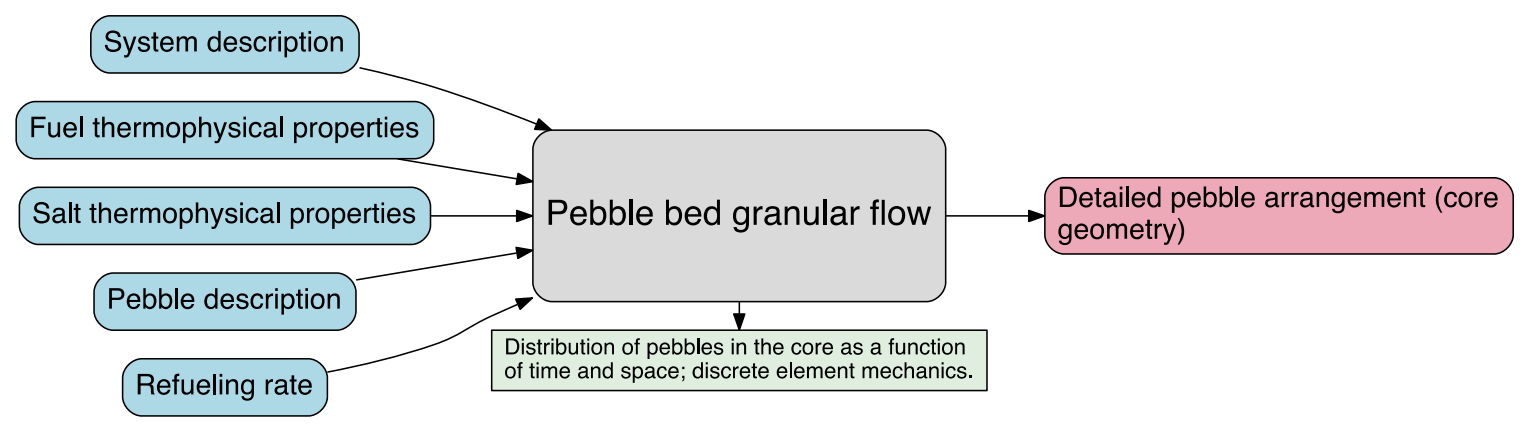

MSR Modeling and Simulation Functionality Datasheet

Version 0.0 - Feb. 28, 2018

Version 0.1 - Mar. 15, 2018

\begin{tabular}{|c|c|c|}
\hline & Date of Submission (mm/dd/yyyy) & \\
\hline & $04 / 15 / 2018$ & \\
\hline Contributor Name(s) & Organization(s) & Email(s) \\
\hline $\begin{array}{l}\text { MSR Campaign Modeling \& } \\
\text { Simulation Team }\end{array}$ & $\begin{array}{l}\text { Oak Ridge National Laboratory } \\
\text { Argonne National Laboratory } \\
\text { Idaho National Laboratory } \\
\text { Pennsylvania State University }\end{array}$ & betzlerbr@ornl.gov \\
\hline
\end{tabular}

Modeling and Simulation Functionality

Pebble bed granular flow

Inputs Required (as comprehensive as possible)

System description; Fuel thermophysical properties; Salt thermophysical properties; Pebble description; Refueling rate.

Definition and Phenomena

Distribution of pebbles in the core as a function of time and space; discrete element mechanics.

Outputs Obtained

Detailed pebble arrangement (core geometry). 
Additional Comments (links to other functionalities)

Links to: Salt thermophysical properties; Fuel depletion; Pebble bed conduction, convection, and radiation.

Functionality exists; Further validation and minor development might be needed.

For Internal Use Only

F-04.05 


\section{Control and protection system}

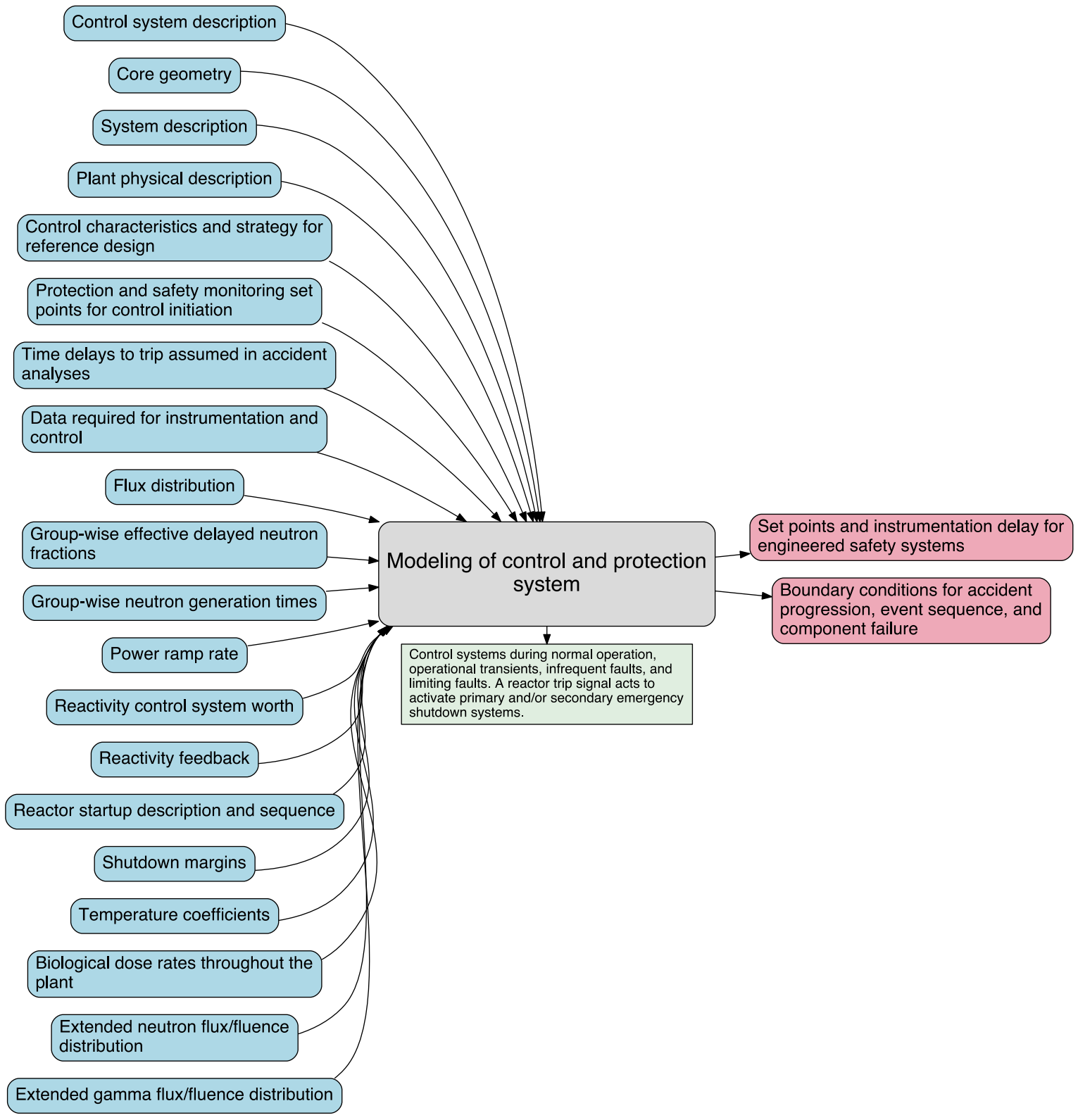

MSR Modeling and Simulation Functionality Datasheet

Version 0.0 - Feb. 28, 2018

Version 0.1 - Mar. 15, 2018

Date of Submission ( $\mathrm{mm} / \mathrm{dd} / \mathrm{yyyy})$

$04 / 15 / 2018$ 


\begin{tabular}{|c|c|c|}
\hline Contributor Name(s) & Organization(s) & Email(s) \\
\hline MSR Campaign Modeling \& & Oak Ridge National Laboratory & betzlerbr@ornl.gov \\
Simulation Team & Argonne National Laboratory & \\
& Idaho National Laboratory & \\
& Pennsylvania State University & \\
\hline
\end{tabular}

Modeling and Simulation Functionality

Modeling of control and protection system

Inputs Required (as comprehensive as possible)

Control system description; Core geometry; System description; Plant physical description; Control characteristics and strategy for reference design; Protection and safety monitoring set points for control initiation; Time delays to trip assumed in accident analyses; Data required for instrumentation and control; Flux distribution; Group-wise effective delayed neutron fractions; Group-wise neutron generation times; Power ramp rate; Reactivity control system worth; Reactivity feedback; Reactor startup description and sequence; Shutdown margins; Temperature coefficients; Biological dose rates throughout the plant; Extended neutron flux/fluence distribution; Extended gamma flux/fluence distribution.

Definition and Phenomena

Control systems during normal operation, operational transients, infrequent faults, and limiting faults. A reactor trip signal acts to activate primary and/or secondary emergency shutdown systems.

\section{Outputs Obtained}

Set points and instrumentation delay for engineered safety systems; Boundary conditions for accident progression and component failure.

\section{Additional Comments (links to other functionalities)}

Links to: Chapter 4 functionalities for reactor; Kinetics parameters; Steady-state core neutronics; Demonstrate reactor startup procedure; Mass transport; Reactivity control behavior; Reactivity coefficients; Quantify impact of instrumentation drift and uncertainty on predictions; Modeling of active and passive safety systems and components; Modeling of component failure and human factors; Predict radioactive release from a subsystem or component; Predict atmospheric transport of radioactive plume segments; Predict other possible design dependent events; Simulation of reactor kinetics feedback and coupled response; Predict behavior during power-cooling mismatch events; Dynamic fluid flow and heat transfer behavior of primary and secondary side components.

This functionality exists, and the specific systems and set points are highly design dependent. Characteristics of pumps and other crucial flow components are necessary as part of the system description. 
For Internal Use Only

F-04.05 


\section{Impact of instrumentation drift and uncertainty}

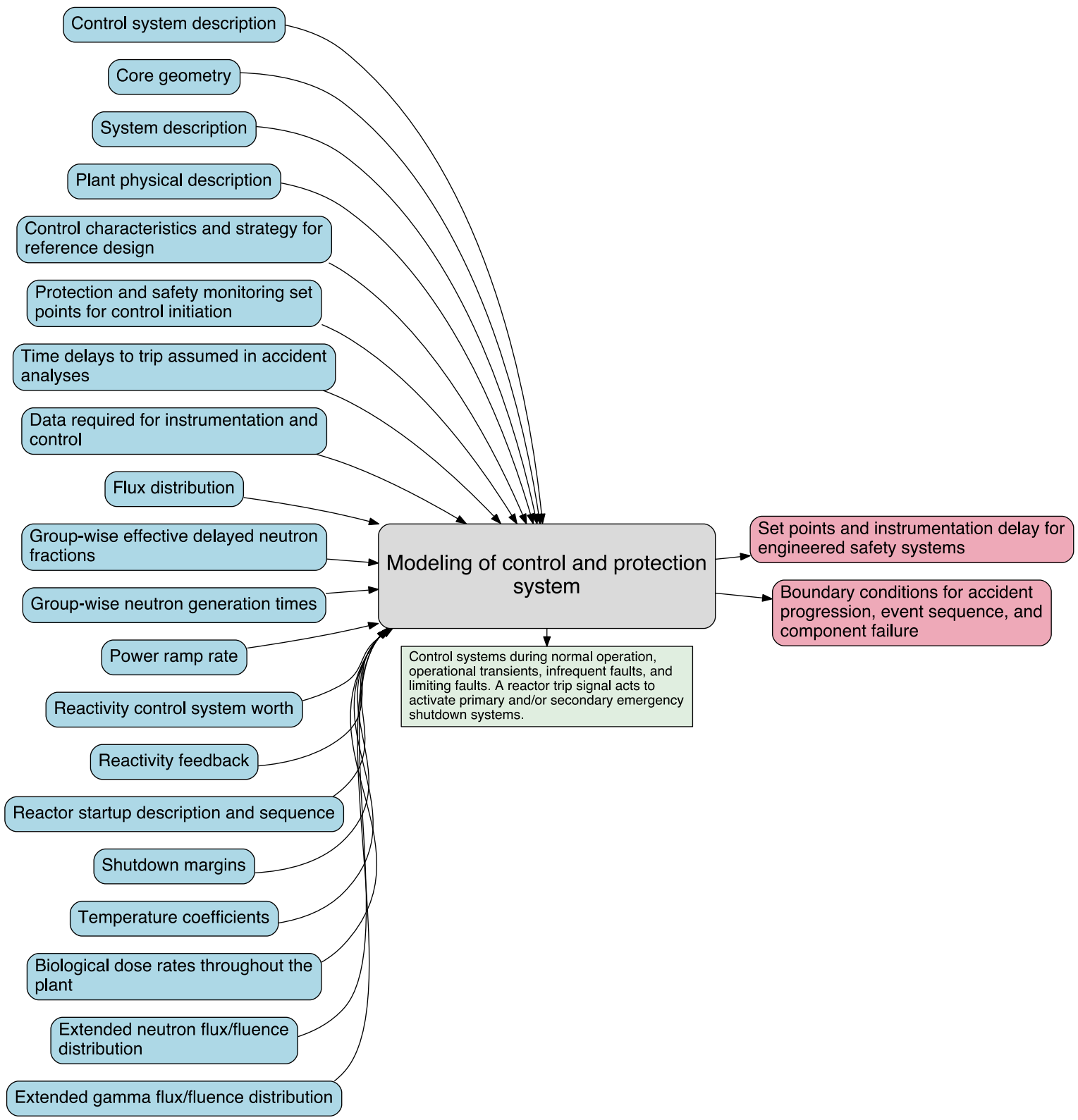

\section{MSR Modeling and Simulation Functionality Datasheet}

Version 0.0 - Feb. 28, 2018

Version 0.1 - Mar. 15, 2018

Date of Submission ( $\mathrm{mm} / \mathrm{dd} / \mathrm{yyyy})$ $04 / 15 / 2018$ 


\begin{tabular}{|c|c|c|}
\hline Contributor Name(s) & Organization(s) & Email(s) \\
\hline MSR Campaign Modeling \& & Oak Ridge National Laboratory & betzlerbr@ornl.gov \\
Simulation Team & Argonne National Laboratory & \\
& Idaho National Laboratory & \\
& Pennsylvania State University & \\
\hline
\end{tabular}

\section{Modeling and Simulation Functionality}

Quantify impact of instrumentation drift and uncertainty on predictions

\section{Inputs Required (as comprehensive as possible)}

Control system description; Definition of in-core and ex-core instrumentation and monitoring systems; Range of applicability and operating envelope for individual instrumentation; Calorimetric uncertainty of determining reactor power based on secondary systems; Definition of safety systems and components available for mitigation of accident events; Data required for instrumentation and control; Flux distribution; Pressure drop; Steady-state flow distribution; Set points and instrumentation delay for engineered safety systems.

\section{Definition and Phenomena}

Probabilistic or conservative evaluation of the impact of sensor drift, uncertainty, and errors on control system and operator response for normal operation, operational transients, and progression of fault events.

\section{Outputs Obtained}

Set points and instrumentation delay for engineered safety systems; Time delays to trip assumed in accident analyses.

\section{Additional Comments (links to other functionalities)}

Links to: Chapter 4 functionalities for reactor; Modeling of control and protection system; Steadystate core neutronics; Heat conduction, convection, and radiation in core structure/moderator, heat transfer, and fluid flow; Pebble bed conduction, convection, and radiation; Demonstrate reactor startup procedure; Reactivity control behavior; Modeling of active and passive safety systems and components; Modeling of component failure and human factors.

Main issue is characterization of instrumentation drift, associated uncertainties, and impact on reactor control.

\section{For Internal Use Only}

F-04.05 


\section{Active and passive safety systems and components}

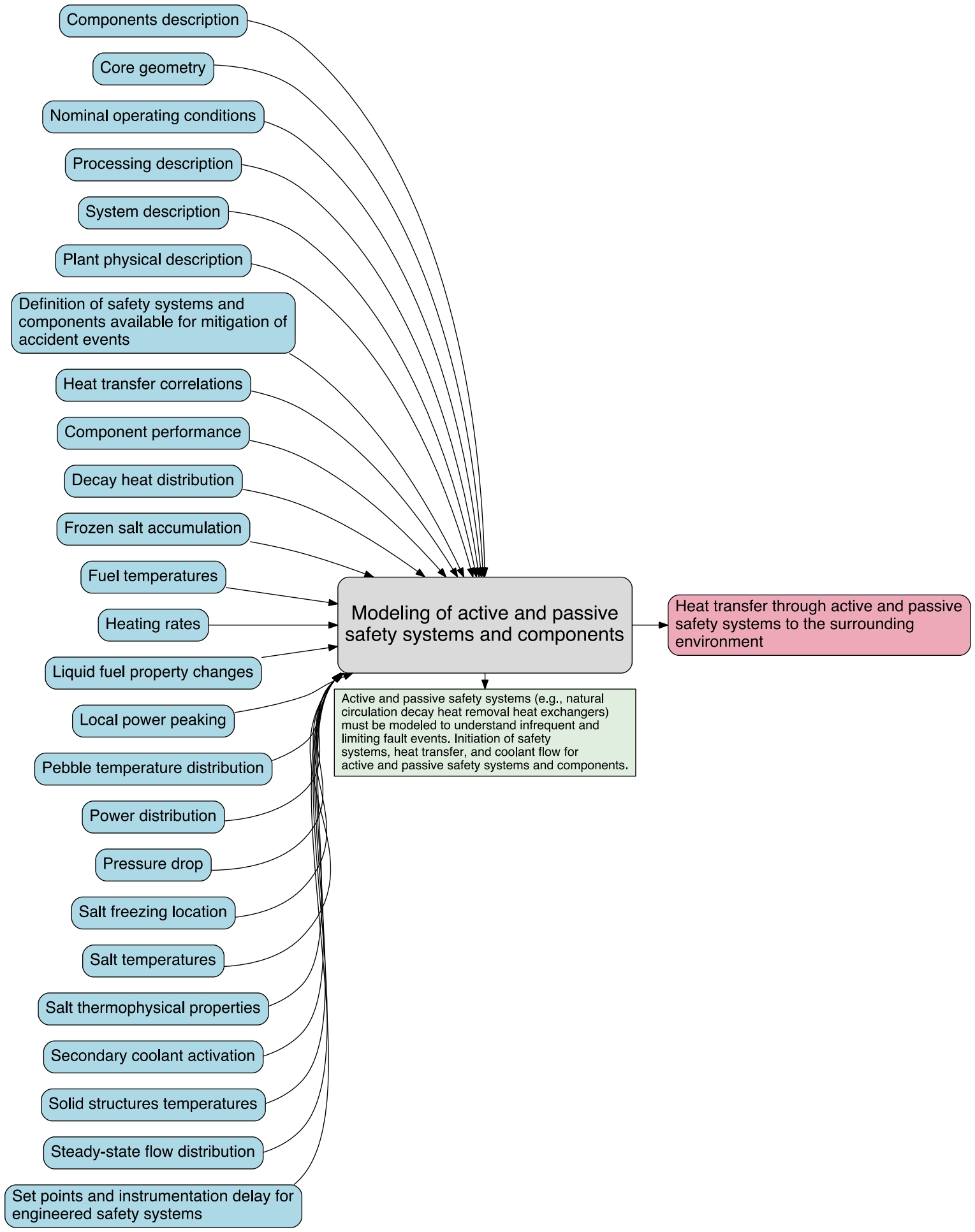




\section{MSR Modeling and Simulation Functionality Datasheet}

Version 0.0 - Feb. 28, 2018

Version 0.1 - Mar. 15, 2018

Date of Submission (mm/dd/yyyy)

$04 / 15 / 2018$

\begin{tabular}{|c|c|c|}
\hline Contributor Name(s) & Organization(s) & Email(s) \\
\hline MSR Campaign Modeling \& & Oak Ridge National Laboratory & betzlerbr@ornl.gov \\
Simulation Team & Argonne National Laboratory & \\
& Idaho National Laboratory & \\
& Pennsylvania State University & \\
\hline
\end{tabular}

Modeling and Simulation Functionality

Modeling of active and passive safety systems and components

Inputs Required (as comprehensive as possible)

Components description; Core geometry; Nominal operating conditions; Processing description; System description; Plant physical description; Definition of safety systems and components available for mitigation of accident events; Heat transfer correlations; Component performance; Decay heat distribution; Frozen salt accumulation; Fuel temperatures; Heating rates; Liquid fuel property changes; Local power peaking; Pebble temperature distribution; Power distribution; Pressure drop; Salt freezing location; Salt temperatures; Salt thermophysical properties; Secondary coolant activation; Solid structures temperatures; Steady-state flow distribution; Set points and instrumentation delay for engineered safety systems.

\section{Definition and Phenomena}

Active and passive safety systems (e.g., natural circulation decay heat removal heat exchangers) must be modeled to understand infrequent and limiting fault events. Initiation of safety systems, heat transfer, and coolant flow for active and passive safety systems and components.

\section{Outputs Obtained}

Heat transfer through active and passive safety systems to the surrounding environment. 


\section{Additional Comments (links to other functionalities)}

Links to: Chapter 4 functionalities for reactor; Modeling of control and protection system; Quantify impact of instrumentation drift and uncertainty on predictions; Steady-state core neutronics; Liquid fuel performance; Demonstrate reactor startup procedure; Heat conduction, convection, and radiation in core structure/moderator, heat transfer, and fluid flow; Salt freezing; Pebble bed conduction, convection, and radiation; Dose rate estimation; Salt thermophysical properties; Mass transport; Component corrosion; Predict other possible design dependent events; Simulation of reactor kinetics feedback and coupled response; Predict behavior during power-cooling mismatch events; Dynamic fluid flow and heat transfer behavior of primary and secondary side components; Modeling of component failure and human factors.

This functionality exists. Validation data are generally lacking. Constitutive relationships for thermophysical properties may have high uncertainties. The plant will be designed to protect against natural phenomena, postulated environmental conditions, and dynamic effects of the postulated accidents. Modeling and validation of passive and/or inherent safety systems is important for many molten salt reactor and fluoride salt-cooled high-temperature reactor designs. Active safety systems may also be used, especially for licensing of early engineering demonstration plants. Characteristics of pumps and other crucial flow components are necessary as part of the system description.

For Internal Use Only

F-04.05 


\section{Source term definition}

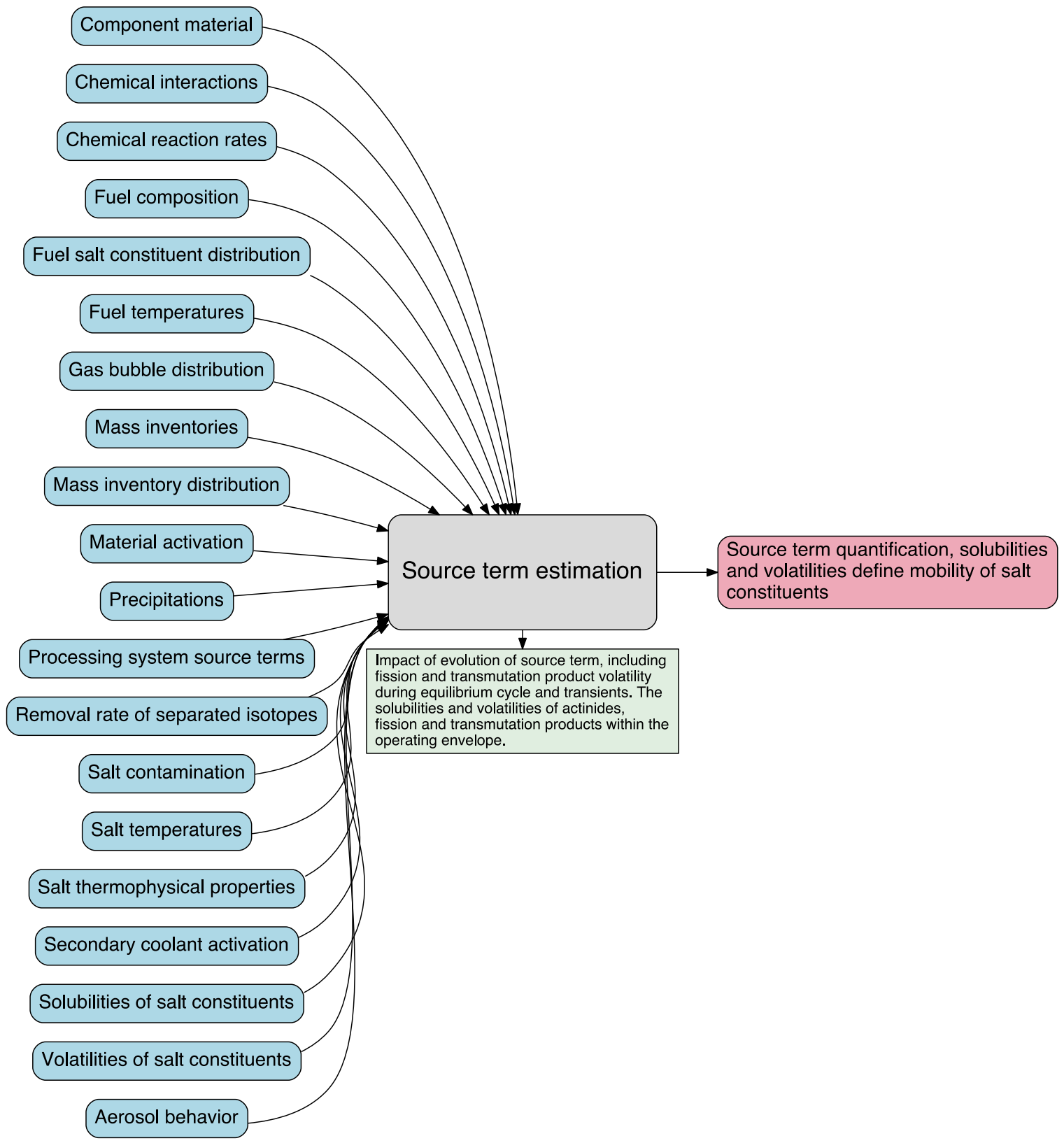

MSR Modeling and Simulation Functionality Datasheet

Version 0.0 - Feb. 28, 2018

Version 0.1 - Mar. 15, 2018

Date of Submission ( $\mathrm{mm} / \mathrm{dd} / \mathrm{yyyy})$

$04 / 15 / 2018$ 


\begin{tabular}{|c|c|c|}
\hline Contributor Name(s) & Organization(s) & Email(s) \\
\hline MSR Campaign Modeling \& & Oak Ridge National Laboratory & betzlerbr@ornl.gov \\
Simulation Team & Argonne National Laboratory & \\
& Idaho National Laboratory & \\
& Pennsylvania State University & \\
\hline
\end{tabular}

Modeling and Simulation Functionality

Source term estimation

Inputs Required (as comprehensive as possible)

Component material; Chemical interactions; Chemical reaction rates; Fuel composition; Fuel salt constituent distribution; Fuel temperatures; Gas bubble distribution; Mass inventories; Mass inventory distribution; Material activation; Precipitations; Processing system source terms; Removal rate of separated isotopes; Salt contamination; Salt temperatures; Salt thermophysical properties; Secondary coolant activation; Solubilities of salt constituents; Volatilities of salt constituents; Aerosol behavior.

\section{Definition and Phenomena}

Impact of evolution of source term, including fission and transmutation product volatility during equilibrium cycle and transients. The solubilities and volatilities of actinides, fission and transmutation products within the operating envelope.

\section{Outputs Obtained}

Source term quantification, solubilities and volatilities define mobility of salt constituents.

\section{Additional Comments (links to other functionalities)}

Links to: Chapter 4 functionalities for reactor; Fuel depletion; Multiphase flow (gas bubbles); Heat conduction, convection, and radiation in core structure/moderator, heat transfer, and fluid flow; Mass transport; Source term accountability; Dose rate estimation; Salt thermochemistry; Component corrosion; Salt thermophysical properties; In-core material performance; TRISO fuel performance; Salt reaction kinetics; Predict radioactive release from a subsystem or component; Predict atmospheric transport of radioactive plume segments.

Current understanding and validation are lacking. Behavior of pertinent chemical constituents in the salt must be understood. The sources of radioactivity for release are dependent on the specific accident. Radioactivity may be released from the primary coolant, from the secondary coolant, from structural materials (e.g., tritium from graphite), and from the reactor core.

\begin{tabular}{|l|}
\hline For Internal Use Only \\
\hline F-04.05 \\
\hline
\end{tabular}




\section{Component failure and human factors}

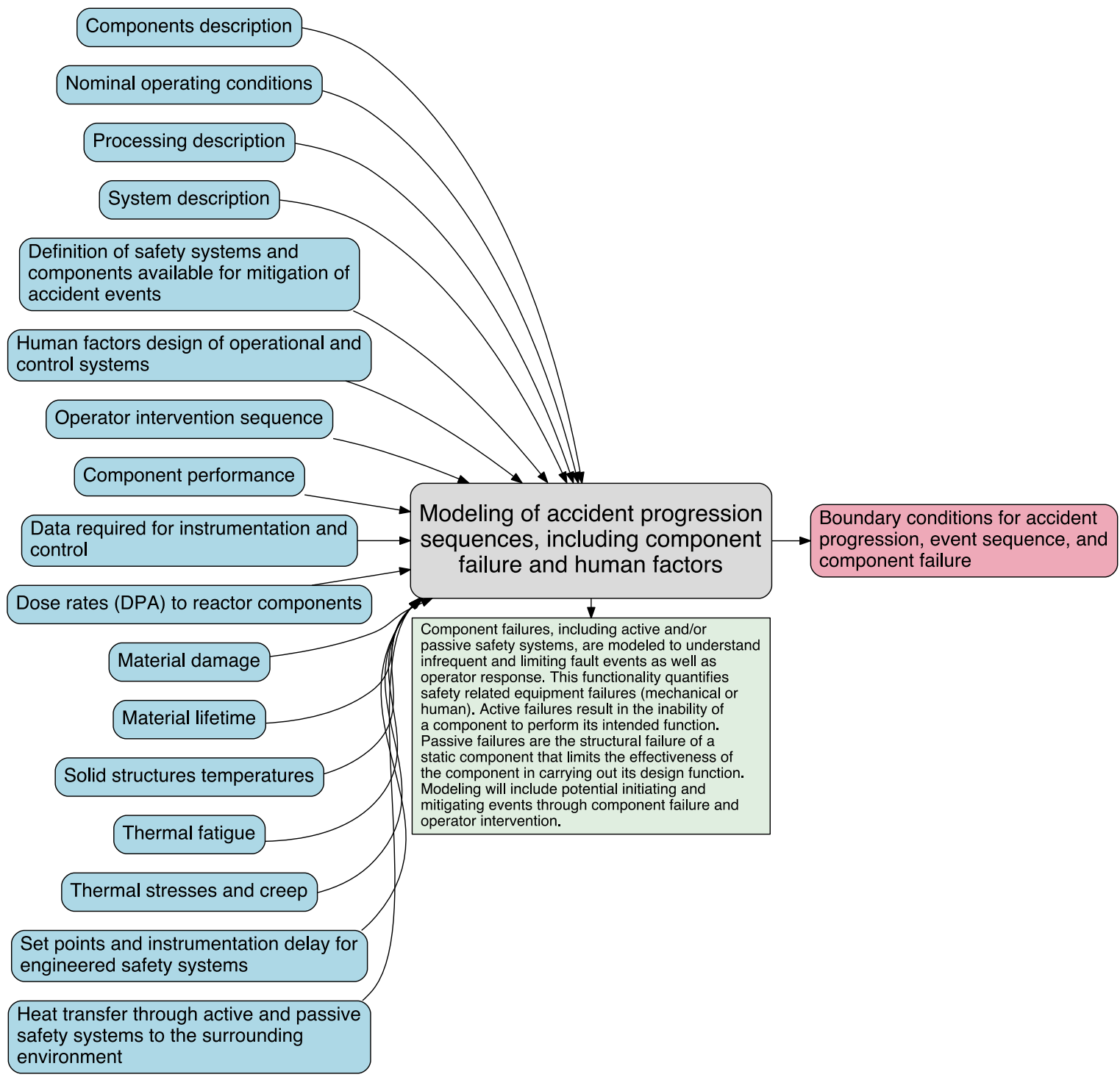

MSR Modeling and Simulation Functionality Datasheet

Version 0.0 - Feb. 28, 2018

Version 0.1 - Mar. 15, 2018

Date of Submission (mm/dd/yyyy)

04/15/2018

\begin{tabular}{|c|c|c|}
\hline Contributor Name(s) & Organization(s) & Email(s) \\
\hline MSR Campaign Modeling \& & Oak Ridge National Laboratory & betzlerbr@ornl.gov \\
Simulation Team & Argonne National Laboratory & \\
& Idaho National Laboratory & \\
& Pennsylvania State University & \\
\hline
\end{tabular}


Modeling and Simulation Functionality

Modeling of accident progression sequences, including component failure and human factors

Inputs Required (as comprehensive as possible)

Components description; Nominal operating conditions; Processing description; System description;

Definition of safety systems and components available for mitigation of accident events; Human factors design of operational and control systems; Operator intervention sequence; Component performance; Data required for instrumentation and control; Dose rates (DPA) to reactor components; Material damage; Material lifetime; Solid structures temperatures; Thermal fatigue; Thermal stresses and creep; Set points and instrumentation delay for engineered safety systems; Heat transfer through active and passive safety systems to the surrounding environment.

Definition and Phenomena

Component failures, including active and/or passive safety systems, are modeled to understand infrequent and limiting fault events as well as operator response. This functionality quantifies safety related equipment failures (mechanical or human). Active failures result in the inability of a component to perform its intended function. Passive failures are the structural failure of a static component that limits the effectiveness of the component in carrying out its design function. Modeling will include potential initiating and mitigating events through component failure and operator intervention.

\section{Outputs Obtained}

Boundary conditions for accident progression, event sequence, and component failure.

\section{Additional Comments (links to other functionalities)}

Links to: Predict behavior during power-cooling mismatch events; Modeling of control and protection system; Quantify impact of instrumentation drift and uncertainty on predictions; Modeling of active and passive safety systems and components; In-core material performance; TRISO fuel performance; Heat conduction, convection, and radiation in core structure/moderator, heat transfer, and fluid flow; Pebble bed conduction, convection, and radiation; Demonstrate reactor startup procedure; Reactivity control behavior; Dose rate estimation; Component corrosion; Predict radioactive release from a subsystem or component; Predict atmospheric transport of radioactive plume segments; Predict other possible design dependent events; Simulation of reactor kinetics feedback and coupled response; Predict behavior during power-cooling mismatch events; Dynamic fluid flow and heat transfer behavior of primary and secondary side components.

This functionality exists, but design specifics relevant to molten salt reactor plants are not yet known. Most important for limiting single failures of safety related equipment. Following event recognition, operators may take manual control and proceed with orderly shutdown of the reactor in accordance with the normal, abnormal, or emergency operating procedures. The exact actions and sequence of these actions depends on what systems are available and the plans for further plant operation. 
For Internal Use Only

F-04.05 


\section{Static and dynamic fluid flow and heat transfer}

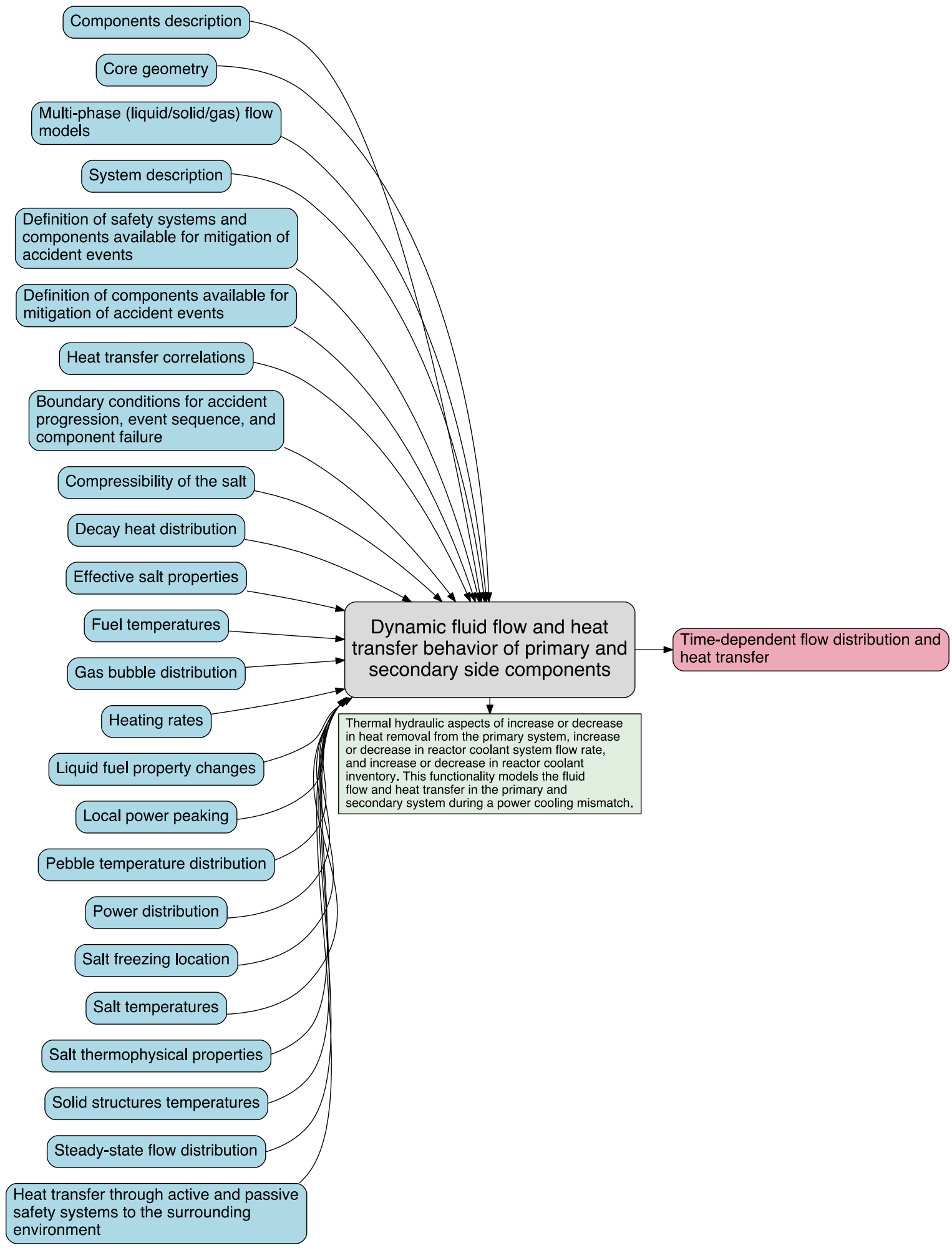




\section{MSR Modeling and Simulation Functionality Datasheet}

Version 0.0 - Feb. 28, 2018

Version 0.1 - Mar. 15, 2018

Date of Submission (mm/dd/yyyy)

$04 / 15 / 2018$

\begin{tabular}{|c|c|c|}
\hline Contributor Name(s) & Organization(s) & Email(s) \\
\hline MSR Campaign Modeling \& & Oak Ridge National Laboratory & betzlerbr@ornl.gov \\
Simulation Team & Argonne National Laboratory & \\
& Idaho National Laboratory & \\
& Pennsylvania State University & \\
\hline
\end{tabular}

Modeling and Simulation Functionality

Dynamic fluid flow and heat transfer behavior of primary and secondary side components

Inputs Required (as comprehensive as possible)

Components description; Core geometry; Multi-phase (liquid/solid/gas) flow models; System description; Definition of safety systems and components available for mitigation of accident events; Definition of components available for mitigation of accident events; Heat transfer correlations; Boundary conditions for accident progression, event sequence, and component failure; Compressibility of the salt; Decay heat distribution; Effective salt properties; Fuel temperatures; Gas bubble distribution; Heating rates; Liquid fuel property changes; Local power peaking; Pebble temperature distribution; Power distribution; Salt freezing location; Salt temperatures; Salt thermophysical properties; Solid structures temperatures; Steady-state flow distribution; Heat transfer through active and passive safety systems to the surrounding environment.

Definition and Phenomena

Thermal hydraulic aspects of increase or decrease in heat removal from the primary system, increase or decrease in reactor coolant system flow rate, and increase or decrease in reactor coolant inventory. This functionality models the fluid flow and heat transfer in the primary and secondary system during a power cooling mismatch.

\section{Outputs Obtained}

Time-dependent flow distribution and heat transfer. 


\section{Additional Comments (links to other functionalities) \\ Links to: Chapter 4 functionalities for reactor; Modeling of active and passive safety systems and components; Steady-state core neutronics; Liquid fuel performance; Demonstrate reactor startup procedure; Multiphase flow (gas bubbles); Heat conduction, convection, and radiation in core structure/moderator, heat transfer, and fluid flow; Pebble bed conduction, convection, and radiation; Salt freezing; Salt thermophysical properties; Modeling of control and protection system; Modeling of component failure and human factors; Mass transport; Predict radioactive release from a subsystem or component; Predict other possible design dependent events; Simulation of reactor kinetics feedback and coupled response; Predict behavior during power-cooling mismatch events. \\ Dynamic fluid flow and heat transfer is included as a functionality because there are unique issues related to flow and heat transfer transients, such as the transition from steady state forced circulation to natural circulation in a loss of flow accident. This functionality exists, but applications to molten salt reactors have been limited. Validation data are generally lacking. Fundamental data like cross sections, thermal neutron scattering, salt density and other constitutive relationships may also have high uncertainties. This includes three-phase coolant behavior, including potential salt freezing upon overcooling, liquid salt, and transport of fission product/transmutation product gases flowing throughout the primary loop. This also includes heat transfer, including transfer to decay heat removal heat exchangers (particularly in SCRAM scenarios), as well as through other components and to the surrounding environment, and heat transfer coefficients in the core, system, and heat exchangers. Fundamental thermophysical property data (density, coefficient of thermal expansion, viscosity, etc.) are important. Detailed analyses must be performed for the events that have been identified as limiting cases. Characteristics of pumps and other crucial flow components are necessary as part of the system description.}

For Internal Use Only

F-04.05 


\section{Behavior during power-cooling mismatch events}

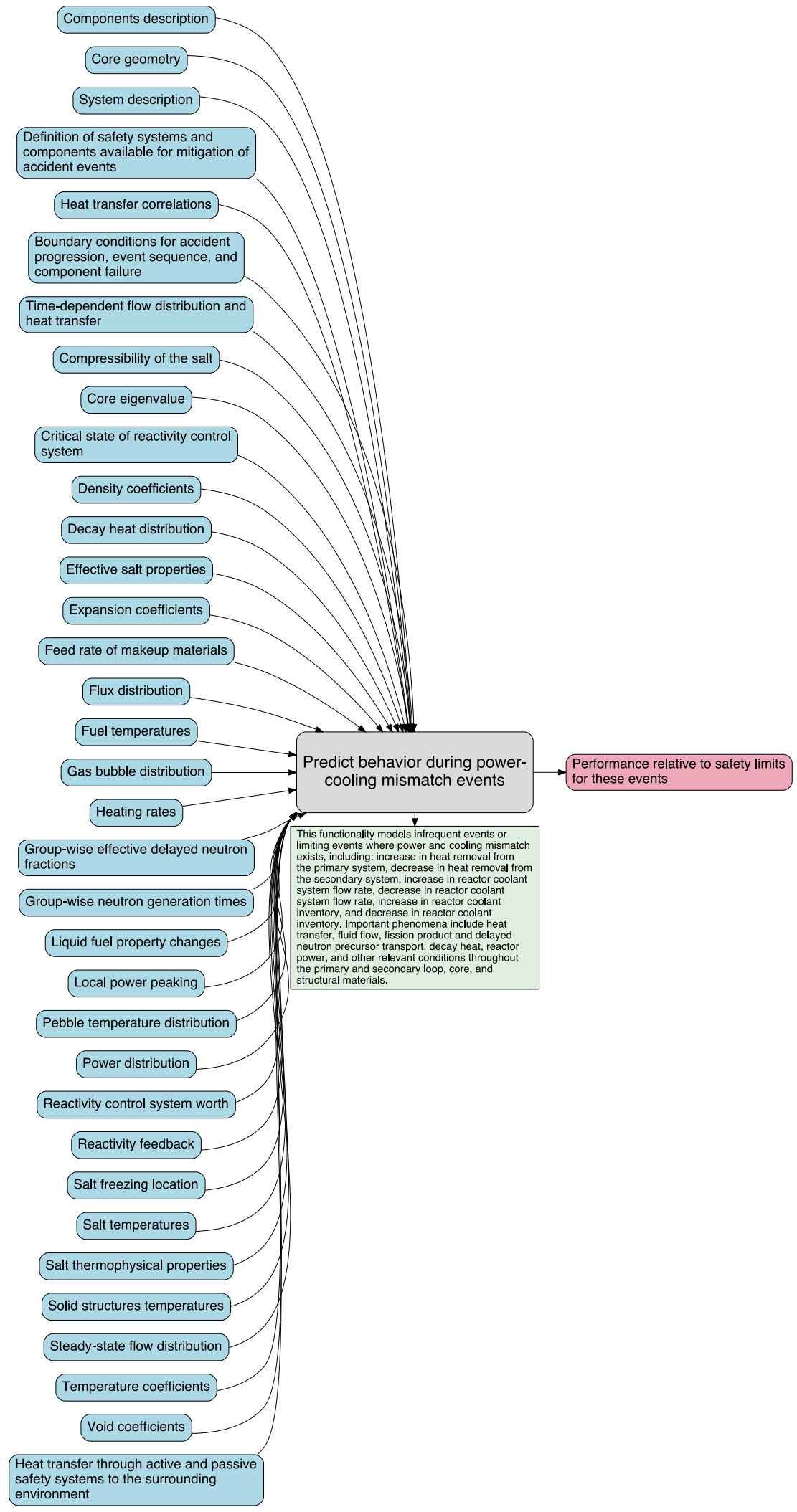




\section{MSR Modeling and Simulation Functionality Datasheet}

Version 0.0 - Feb. 28, 2018

Version 0.1 - Mar. 15, 2018

Date of Submission (mm/dd/yyyy)

$04 / 15 / 2018$

\begin{tabular}{|c|c|c|}
\hline Contributor Name(s) & Organization(s) & Email(s) \\
\hline MSR Campaign Modeling \& & Oak Ridge National Laboratory & betzlerbr@ornl.gov \\
Simulation Team & Argonne National Laboratory & \\
& Idaho National Laboratory & \\
& Pennsylvania State University & \\
\hline
\end{tabular}

Modeling and Simulation Functionality

Predict behavior during power-cooling mismatch events

Inputs Required (as comprehensive as possible)

Components description; Core geometry; System description; Definition of safety systems and components available for mitigation of accident events; Heat transfer correlations; Boundary conditions for accident progression, event sequence, and component failure; Time-dependent flow distribution and heat transfer; Compressibility of the salt; Core eigenvalue ; Critical state of reactivity control system; Density coefficients; Decay heat distribution; Effective salt properties; Expansion coefficients; Feed rate of makeup materials; Flux distribution; Fuel temperatures; Gas bubble distribution; Heating rates; Group-wise effective delayed neutron fractions; Group-wise neutron generation times; Liquid fuel property changes; Local power peaking; Pebble temperature distribution; Power distribution; Reactivity control system worth; Reactivity feedback; Salt freezing location; Salt temperatures; Salt thermophysical properties; Solid structures temperatures; Steadystate flow distribution; Temperature coefficients; Void coefficients; Heat transfer through active and passive safety systems to the surrounding environment.

\section{Definition and Phenomena}

This functionality models infrequent events or limiting events where power and cooling mismatch exists, including: increase in heat removal from the primary system, decrease in heat removal from the secondary system, increase in reactor coolant system flow rate, decrease in reactor coolant system flow rate, increase in reactor coolant inventory, and decrease in reactor coolant inventory. Important phenomena include heat transfer, fluid flow, fission product and delayed neutron precursor transport, decay heat, reactor power, and other relevant conditions throughout the primary and secondary loop, core, and structural materials.

\section{Outputs Obtained}

Performance relative to safety limits for these events. 


\section{Additional Comments (links to other functionalities)}

Links to: Modeling of active and passive safety systems and components; Steady-state core neutronics; Liquid fuel performance; Demonstrate reactor startup procedure; Kinetics parameters; Multiphase flow (gas bubbles); Heat conduction, convection, and radiation in core structure/moderator, heat transfer, and fluid flow; Dynamic fluid flow and heat transfer behavior of primary and secondary side components; Reactivity coefficients; Fuel depletion; Mass transport; Reactivity control behavior; Pebble bed conduction, convection, and radiation; Salt freezing; Salt thermophysical properties; Modeling of control and protection system; Modeling of component failure and human factors.

This functionality exists, but applications to molten salt reactors have been limited. Validation data are generally lacking. Fundamental data like cross sections, thermal neutron scattering, salt density and other constitutive relationships may also have high uncertainties. Characteristics of pumps and other crucial flow components are necessary as part of the system description.

\section{For Internal Use Only}

F-04.05 


\section{Reactor kinetics feedback and coupled response}

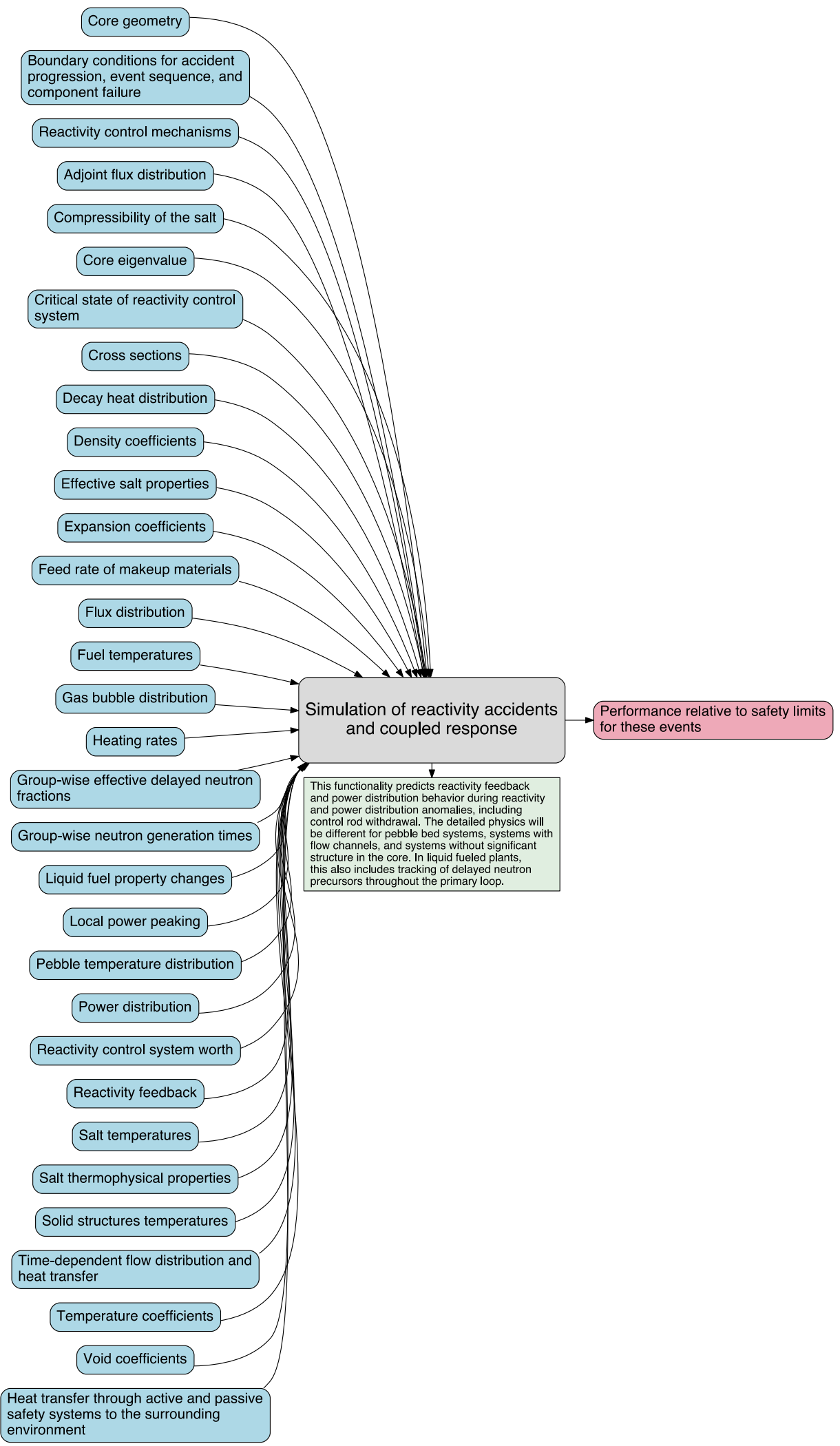




\section{MSR Modeling and Simulation Functionality Datasheet}

Version 0.0 - Feb. 28, 2018

Version 0.1 - Mar. 15, 2018

Date of Submission (mm/dd/yyyy)

$04 / 15 / 2018$

\begin{tabular}{|c|c|c|}
\hline Contributor Name(s) & Organization(s) & Email(s) \\
\hline MSR Campaign Modeling \& & Oak Ridge National Laboratory & betzlerbr@ornl.gov \\
Simulation Team & Argonne National Laboratory & \\
& Idaho National Laboratory & \\
& Pennsylvania State University & \\
\hline
\end{tabular}

Modeling and Simulation Functionality

Simulation of reactivity accidents and coupled response

Inputs Required (as comprehensive as possible)

Core geometry; Boundary conditions for accident progression, event sequence, and component failure; Reactivity control mechanisms; Adjoint flux distribution; Compressibility of the salt; Core eigenvalue ; Critical state of reactivity control system; Cross sections; Decay heat distribution; Density coefficients; Effective salt properties; Expansion coefficients; Feed rate of makeup materials; Flux distribution; Fuel temperatures; Gas bubble distribution; Heating rates; Group-wise effective delayed neutron fractions; Group-wise neutron generation times; Liquid fuel property changes; Local power peaking; Pebble temperature distribution; Power distribution; Reactivity control system worth; Reactivity feedback; Salt temperatures; Salt thermophysical properties; Solid structures temperatures; Time-dependent flow distribution and heat transfer; Temperature coefficients; Void coefficients; Heat transfer through active and passive safety systems to the surrounding environment.

\section{Definition and Phenomena}

This functionality predicts reactivity feedback and power distribution behavior during reactivity and power distribution anomalies, including control rod withdrawal. The detailed physics will be different for pebble bed systems, systems with flow channels, and systems without significant structure in the core. In liquid fueled plants, this also includes tracking of delayed neutron precursors throughout the primary loop.

\section{Outputs Obtained}

Performance relative to safety limits for these events. 


\section{Additional Comments (links to other functionalities)}

Links to: Modeling of active and passive safety systems and components; Steady-state core neutronics; Liquid fuel performance; Demonstrate reactor startup procedure; Kinetics parameters; Multiphase flow (gas bubbles); Heat conduction, convection, and radiation in core structure/moderator, heat transfer, and fluid flow; Dynamic fluid flow and heat transfer behavior of primary and secondary side components; Reactivity coefficients; Fuel depletion; Mass transport; Reactivity control behavior; Pebble bed conduction, convection, and radiation; Salt thermophysical properties; Modeling of control and protection system; Modeling of component failure and human factors.

This functionality exists, but applications to molten salt reactors have been limited. Validation data are generally lacking. Fundamental data like cross sections, thermal neutron scattering, salt density and other constitutive relationships may also have high uncertainties. Accurate cross section generation and parametrization methodologies are required. Fundamental nuclear cross section, fission and transmutation yield, and thermal neutron scattering data are needed to support this. This helps provide an understanding of reactivity, reactor power, and power peaking behavior during these events; response of control systems over a wide range of scenarios; reactor control in manual mode, including potential operator interventions or errors; and reactor control in automatic mode. Note that overcooling would be expected to insert positive reactivity, and therefore would represent a reactivity insertion event. Long-term anticipated transient without scram could result in reactor shutdown and potential recriticality after cooling and $\mathrm{Xe} / \mathrm{Sm}$ decay.

For Internal Use Only

F-04.05 


\section{Other possible design-dependent events}

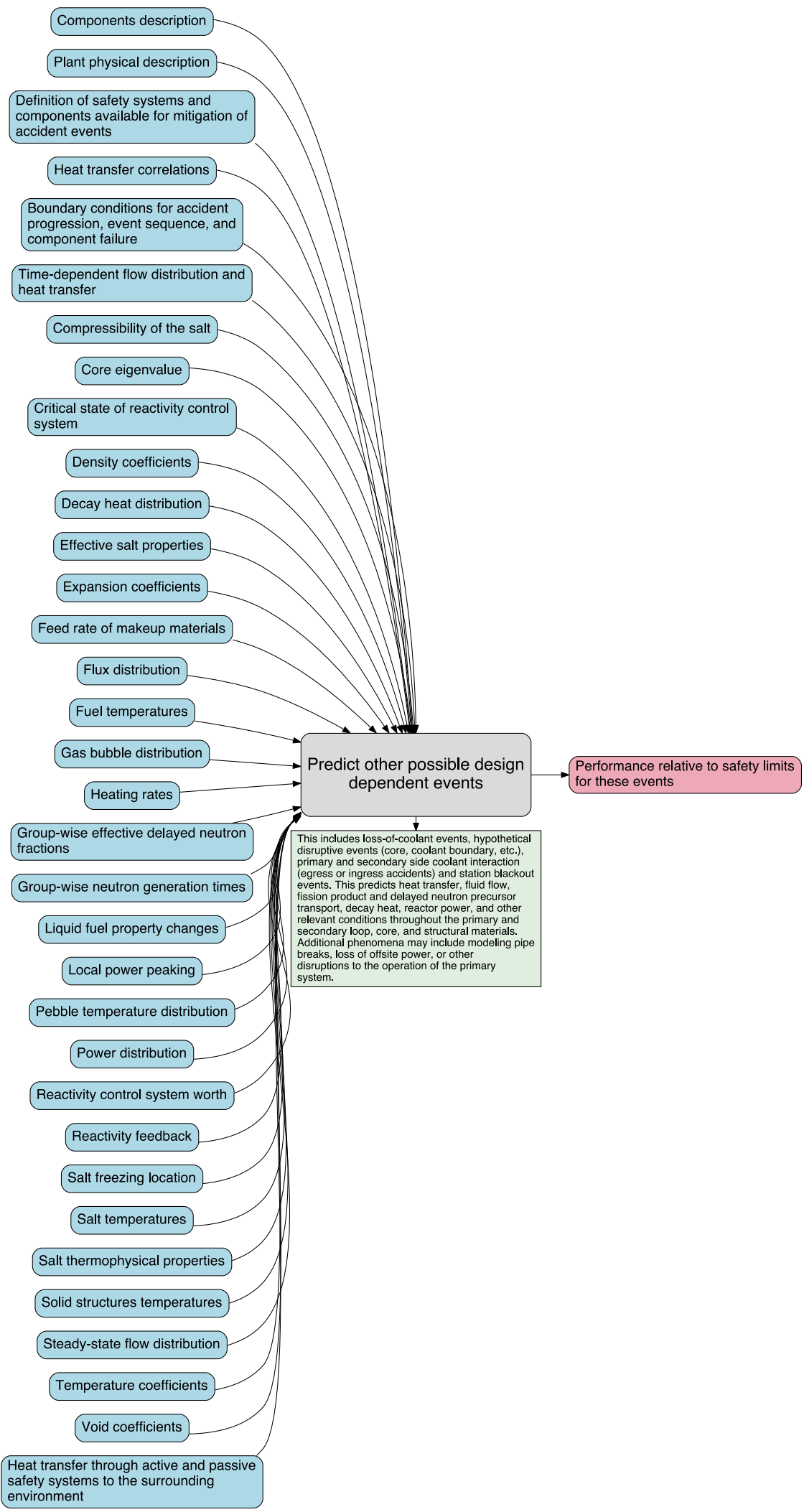




\section{MSR Modeling and Simulation Functionality Datasheet}

Version 0.0 - Feb. 28, 2018

Version 0.1 - Mar. 15, 2018

Date of Submission (mm/dd/yyyy)

$04 / 15 / 2018$

\begin{tabular}{|c|c|c|}
\hline Contributor Name(s) & Organization(s) & Email(s) \\
\hline MSR Campaign Modeling \& & Oak Ridge National Laboratory & betzlerbr@ornl.gov \\
Simulation Team & Argonne National Laboratory & \\
& Idaho National Laboratory & \\
& Pennsylvania State University & \\
\hline
\end{tabular}

Modeling and Simulation Functionality

Predict other possible design dependent events

Inputs Required (as comprehensive as possible)

Components description; Plant physical description; Definition of safety systems and components available for mitigation of accident events; Heat transfer correlations; Boundary conditions for accident progression, event sequence, and component failure; Time-dependent flow distribution and heat transfer; Compressibility of the salt; Core eigenvalue ; Critical state of reactivity control system; Density coefficients; Decay heat distribution; Effective salt properties; Expansion coefficients; Feed rate of makeup materials; Flux distribution; Fuel temperatures; Gas bubble distribution; Heating rates; Group-wise effective delayed neutron fractions; Group-wise neutron generation times; Liquid fuel property changes; Local power peaking; Pebble temperature distribution; Power distribution; Reactivity control system worth; Reactivity feedback; Salt freezing location; Salt temperatures; Salt thermophysical properties; Solid structures temperatures; Steady-state flow distribution; Temperature coefficients; Void coefficients; Heat transfer through active and passive safety systems to the surrounding environment.

\section{Definition and Phenomena}

This includes loss-of-coolant events, hypothetical disruptive events (core, coolant boundary, etc.), primary and secondary side coolant interaction (egress or ingress accidents) and station blackout events. This predicts heat transfer, fluid flow, fission product and delayed neutron precursor transport, decay heat, reactor power, and other relevant conditions throughout the primary and secondary loop, core, and structural materials. Additional phenomena may include modeling pipe breaks, loss of offsite power, or other disruptions to the operation of the primary system.

\section{Outputs Obtained}

Performance relative to safety limits for these events. 


\section{Additional Comments (links to other functionalities)}

Links to some functionalities are unclear because this is design dependent. Links to: Modeling of active and passive safety systems and components; Steady-state core neutronics; Liquid fuel performance; Demonstrate reactor startup procedure; Kinetics parameters; Multiphase flow (gas bubbles); Heat conduction, convection, and radiation in core structure/moderator, heat transfer, and fluid flow; Dynamic fluid flow and heat transfer behavior of primary and secondary side components; Reactivity coefficients; Fuel depletion; Mass transport; Reactivity control behavior; Pebble bed conduction, convection, and radiation; Salt freezing; Salt thermophysical properties; Modeling of control and protection system; Modeling of component failure and human factors.

Whether these potential accidents are credible limiting events is design dependent. Generally, molten salt reactors are designed to be inherently safe and are low pressure systems, so these events may not apply to all designs. These design-dependent hypothesized events may have similar requirements to power cooling mismatch events and reactivity events.

\section{For Internal Use Only}

F-04.05 


\section{Radioactive release from subsystem of component}

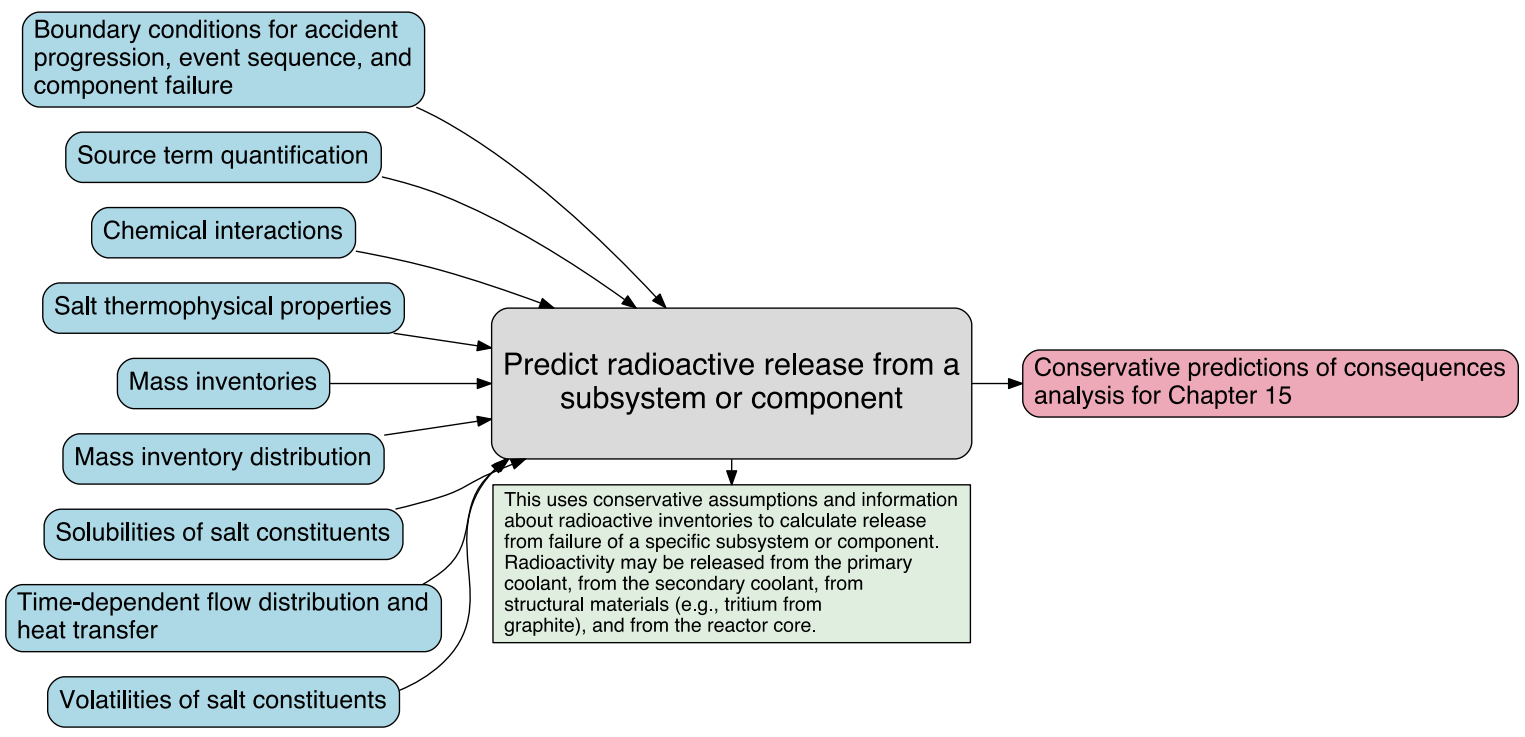

MSR Modeling and Simulation Functionality Datasheet

Version 0.0 - Feb. 28, 2018

Version 0.1 - Mar. 15, 2018

\section{Date of Submission (mm/dd/yyyy) \\ $04 / 15 / 2018$}

\begin{tabular}{|c|c|c|}
\hline Contributor Name(s) & Organization(s) & Email(s) \\
\hline MSR Campaign Modeling \& & Oak Ridge National Laboratory & betzlerbr@ornl.gov \\
Simulation Team & Argonne National Laboratory & \\
& Idaho National Laboratory & \\
& Pennsylvania State University & \\
\hline
\end{tabular}

Modeling and Simulation Functionality

Predict radioactive release from a subsystem or component

Inputs Required (as comprehensive as possible)

Boundary conditions for accident progression, event sequence, and component failure; Source term quantification; Chemical interactions; Salt thermophysical properties; Mass inventories; Mass inventory distribution; Solubilities of salt constituents; Time-dependent flow distribution and heat transfer; Volatilities of salt constituents. 


\section{Definition and Phenomena}

This uses conservative assumptions and information about radioactive inventories to calculate release from failure of a specific subsystem or component. Radioactivity may be released from the primary coolant, from the secondary coolant, from structural materials (e.g., tritium from graphite), and from the reactor core.

\section{Outputs Obtained}

Conservative predictions of consequences analysis for Chapter 15.

Additional Comments (links to other functionalities)

Links to: Chapter 19 functionalities for consequences analysis; Fuel depletion; Source term estimation; Dynamic fluid flow and heat transfer behavior of primary and secondary side components; Source term accountability; Salt thermochemistry; Salt thermophysical properties; Modeling of control and protection system; Modeling of component failure and human factors; Incore material performance; TRISO fuel performance.

This functionality does not exist, including accounting for volatility of fission and transmutation products within the salt. Validation data are generally lacking. Includes salt processing or tritium mitigation facilities. The sources of radioactivity for release are dependent on the specific accident. Conservative estimates of total effective dose equivalent in workers and the public. 


\section{Atmospheric transport of radioactive plume segments}

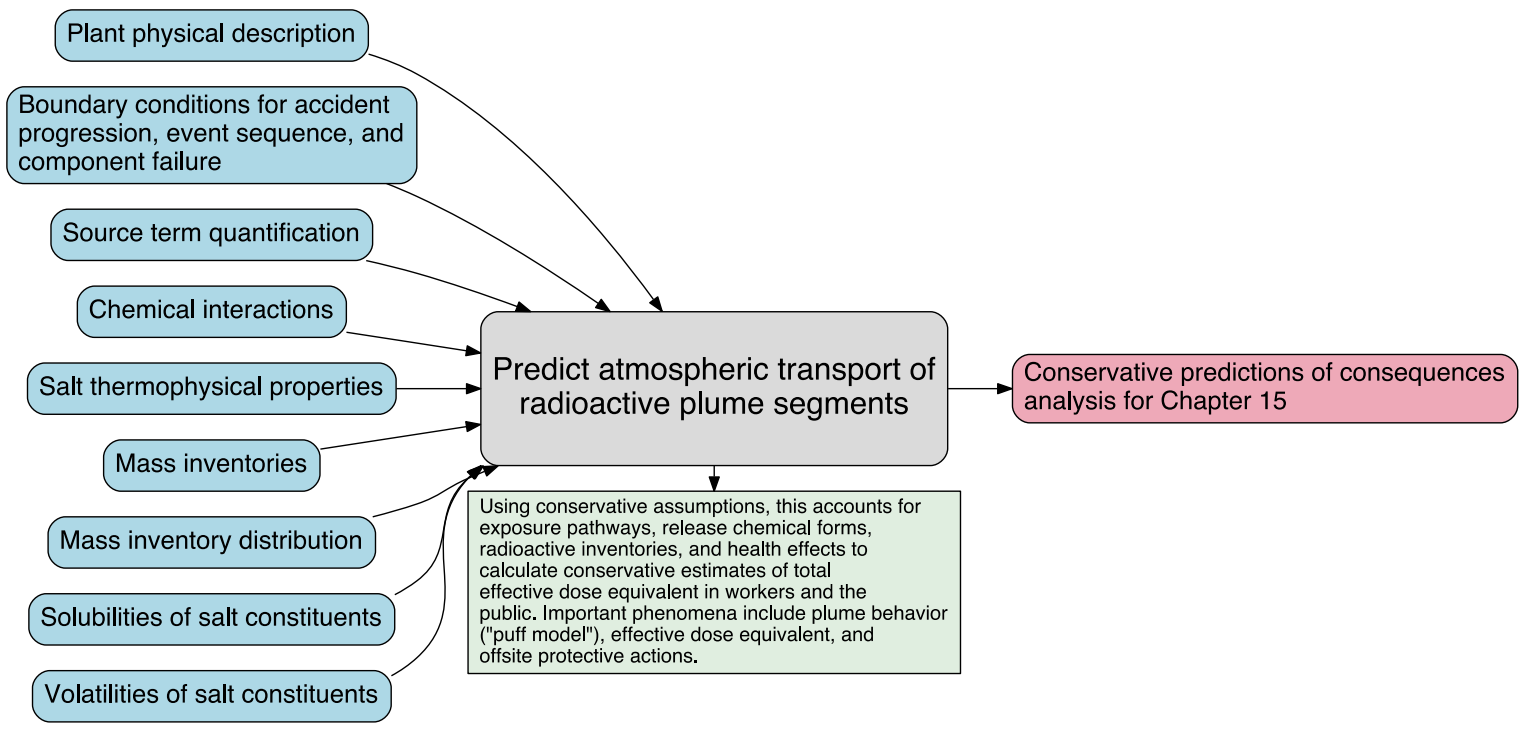

\section{MSR Modeling and Simulation Functionality Datasheet}

Version 0.0 - Feb. 28, 2018

Version 0.1 - Mar. 15, 2018

\section{Date of Submission (mm/dd/yyyy) \\ $04 / 15 / 2018$}

\begin{tabular}{|c|c|c|}
\hline Contributor Name(s) & Organization(s) & Email(s) \\
\hline MSR Campaign Modeling \& & Oak Ridge National Laboratory & betzlerbr@ornl.gov \\
Simulation Team & Argonne National Laboratory & \\
& Idaho National Laboratory & \\
& Pennsylvania State University & \\
\hline
\end{tabular}

Modeling and Simulation Functionality

Predict atmospheric transport of radioactive plume segments

Inputs Required (as comprehensive as possible)

Plant physical description; Boundary conditions for accident progression, event sequence, and component failure; Source term quantification; Chemical interactions; Salt thermophysical properties; Mass inventories; Mass inventory distribution; Solubilities of salt constituents; Volatilities of salt constituents. 


\section{Definition and Phenomena}

Using conservative assumptions, this accounts for exposure pathways, release chemical forms, radioactive inventories, and health effects to calculate conservative estimates of total effective dose equivalent in workers and the public. Important phenomena include plume behavior ("puff model"), effective dose equivalent, and offsite protective actions.

\section{Outputs Obtained}

Conservative predictions of consequences analysis for Chapter 15.

\section{Additional Comments (links to other functionalities)}

Links to: Chapter 19 functionalities for consequences analysis; Fuel depletion; Source term estimation; Source term accountability; Salt thermochemistry; Salt thermophysical properties; Modeling of control and protection system; Modeling of component failure and human factors; Incore material performance; TRISO fuel performance.

Some functionalities exist, others do not because environmental release pathways are different for molten salt reactors than for other reactors. Validation data are generally lacking. The sources of radioactivity for release are dependent on the specific accident. Radioactivity may be released from the primary coolant, from the secondary coolant, from structural materials (e.g., tritium from graphite), and from the reactor core. Failure in the salt processing facilities of the plant is important to consider.

\section{For Internal Use Only}




\section{Structural seismic response}

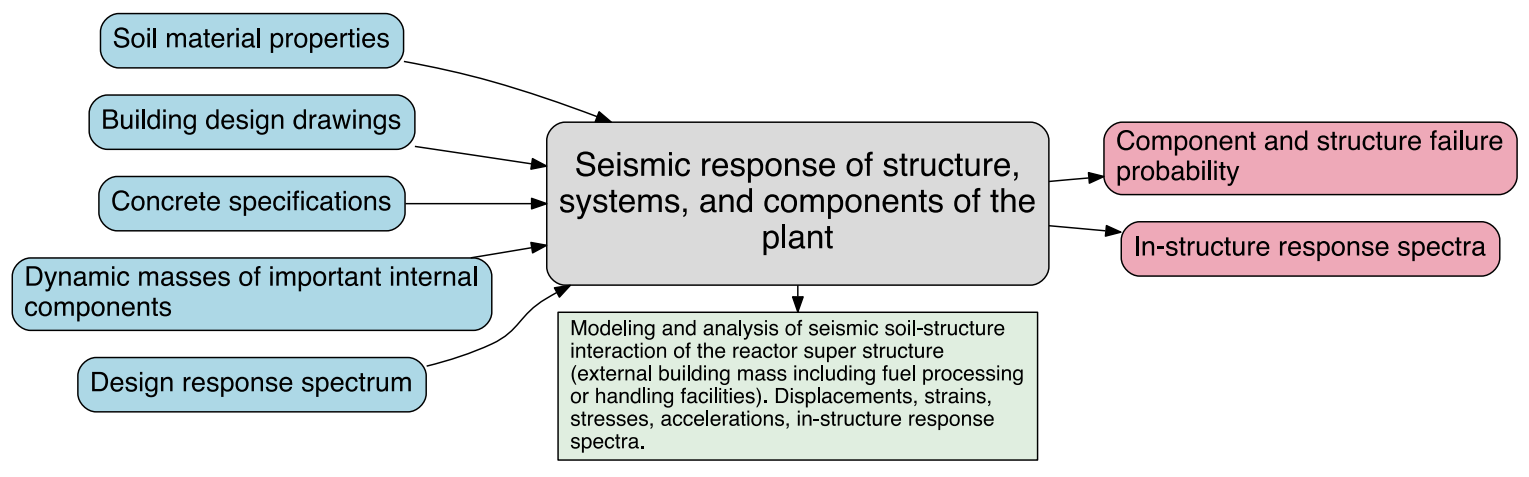

MSR Modeling and Simulation Functionality Datasheet

Version 0.0 - Feb. 28, 2018

Version 0.1 - Mar. 15, 2018

Date of Submission (mm/dd/yyyy)

$04 / 15 / 2018$

\begin{tabular}{|c|c|c|}
\hline Contributor Name(s) & Organization(s) & Email(s) \\
\hline MSR Campaign Modeling \& & Oak Ridge National Laboratory & betzlerbr@ornl.gov \\
Simulation Team & Argonne National Laboratory & \\
& Idaho National Laboratory & \\
& Pennsylvania State University & \\
\hline
\end{tabular}

Modeling and Simulation Functionality

Seismic response of structure, systems, and components of the plant

Inputs Required (as comprehensive as possible)

Soil material properties; Building design drawings; Concrete specifications; Dynamic masses of important internal components; Design response spectrum.

Definition and Phenomena

Modeling and analysis of seismic soil-structure interaction of the reactor super structure (external building mass including fuel processing or handling facilities). Displacements, strains, stresses, accelerations, in-structure response spectra.

Outputs Obtained

Component and structure failure probability; In-structure response spectra. 
Additional Comments (links to other functionalities)

Links to: Plant PRA (Ch. 19); Liquid fuel seismic response; Pebble bed seismic response; Seismic response of safety significant reactor vessel and related systems of the plant.

Currently, seismic soil-structure interaction validation of advanced reactors (deeply embedded) does not exist. There is a need for tools that can perform sensitivity studies to quantify the effect of nonvertically propagating seismic waves.

For Internal Use Only

F-04.05 


\section{Reactor vessel and safety system seismic response}

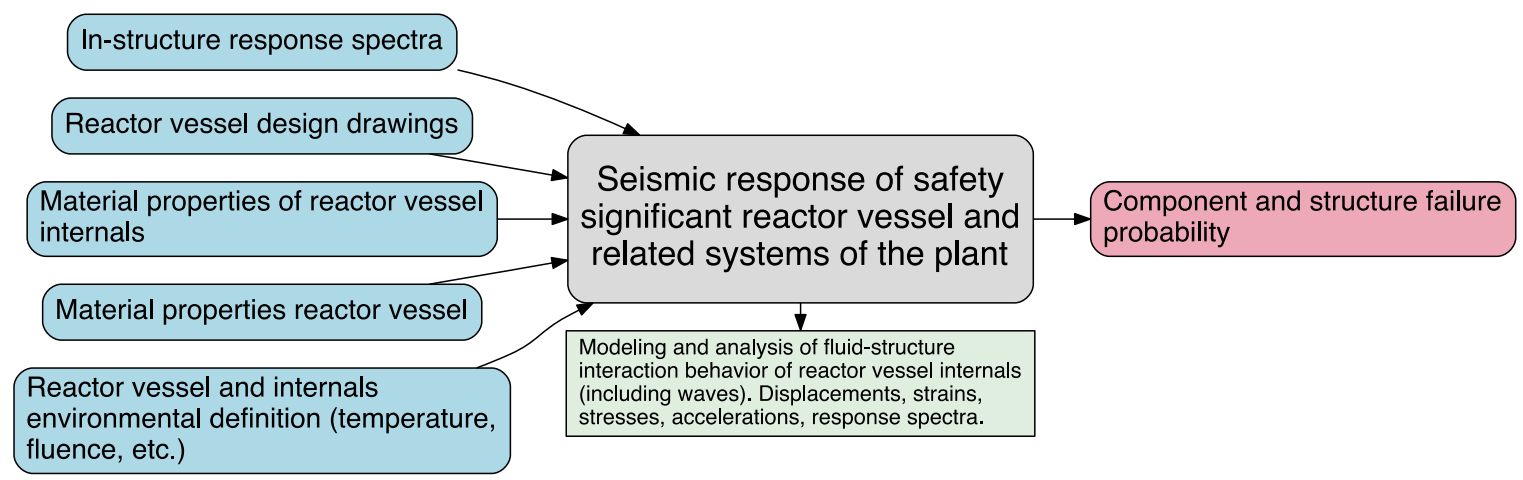

MSR Modeling and Simulation Functionality Datasheet

Version 0.0 - Feb. 28, 2018

Version 0.1 - Mar. 15, 2018

Date of Submission (mm/dd/yyyy)

$04 / 15 / 2018$

\begin{tabular}{|c|c|c|}
\hline Contributor Name(s) & Organization(s) & Email(s) \\
\hline MSR Campaign Modeling \& & Oak Ridge National Laboratory & betzlerbr@ornl.gov \\
Simulation Team & Argonne National Laboratory & \\
& Idaho National Laboratory & \\
& Pennsylvania State University & \\
\hline
\end{tabular}

Modeling and Simulation Functionality

Seismic response of safety significant reactor vessel and related systems of the plant

Inputs Required (as comprehensive as possible)

In-structure response spectra; Reactor vessel design drawings; Material properties of reactor vessel internals; Material properties reactor vessel; Reactor vessel and internals environmental definition (temperature, fluence, etc.).

Definition and Phenomena

Modeling and analysis of fluid-structure interaction behavior of reactor vessel internals (including waves). Displacements, strains, stresses, accelerations, response spectra.

\section{Outputs Obtained}

Component and structure failure probability. 
Additional Comments (links to other functionalities)

Links to: Plant PRA (Ch. 19); Seismic response of structure, systems, and components of the plant.

Need validated fluid-structure interaction tools to quantify seismic performance, including both experimental tests and numerical calculations and tools.

For Internal Use Only

F-04.05 


\section{Pebble bed seismic response}

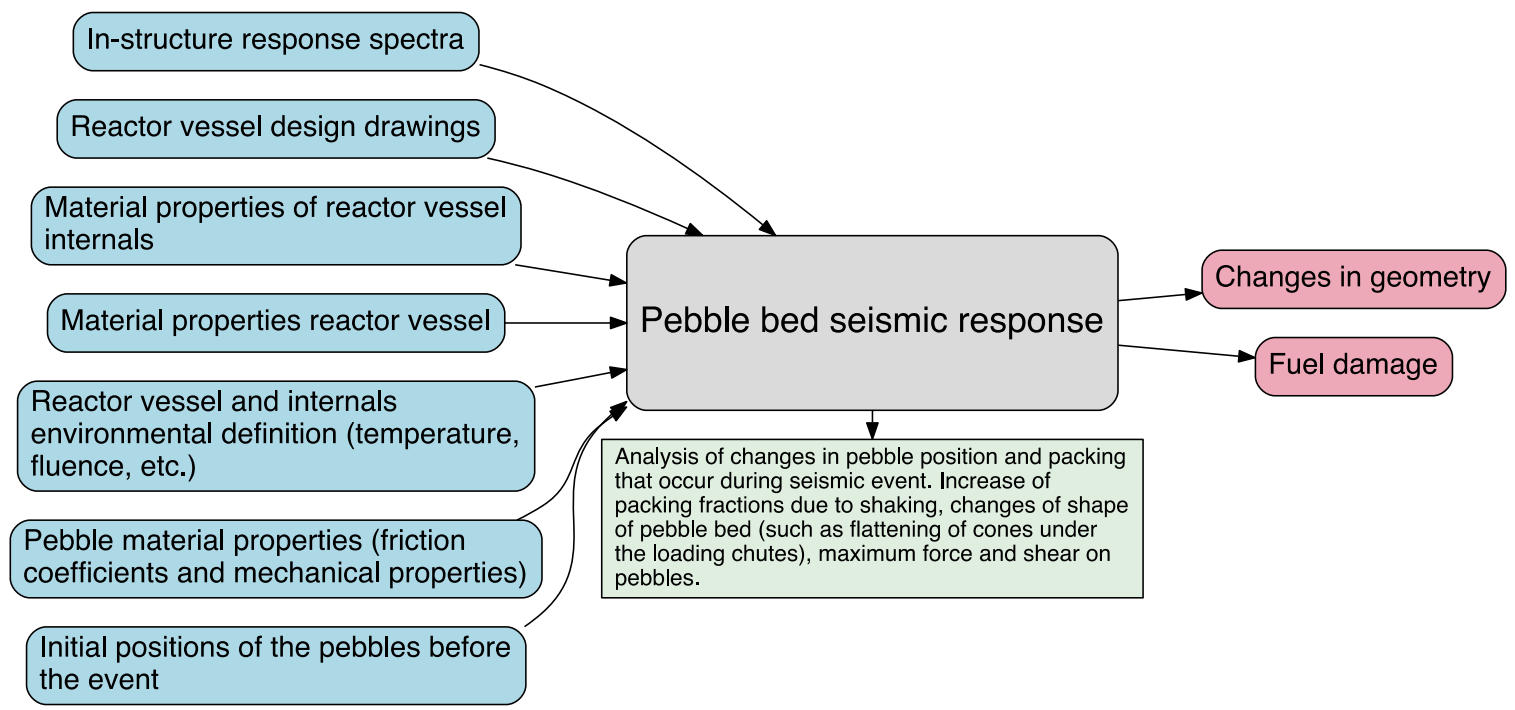

\section{MSR Modeling and Simulation Functionality Datasheet}

Version 0.0 - Feb. 28, 2018

Version 0.1 - Mar. 15, 2018

Date of Submission (mm/dd/yyyy)

$04 / 15 / 2018$

\begin{tabular}{|c|c|c|}
\hline Contributor Name(s) & Organization(s) & Email(s) \\
\hline MSR Campaign Modeling \& & Oak Ridge National Laboratory & betzlerbr@ornl.gov \\
Simulation Team & Argonne National Laboratory & \\
& Idaho National Laboratory & \\
& Pennsylvania State University & \\
\hline
\end{tabular}

Modeling and Simulation Functionality

Pebble bed seismic response

Inputs Required (as comprehensive as possible)

In-structure response spectra; Reactor vessel design drawings; Material properties of reactor vessel internals; Material properties reactor vessel; Reactor vessel and internals environmental definition (temperature, fluence, etc.); Pebble material properties (friction coefficients and mechanical properties); Initial positions of the pebbles before the event. 


\section{Definition and Phenomena}

Analysis of changes in pebble position and packing that occur during seismic event. Increase of packing fractions due to shaking, changes of shape of pebble bed (such as flattening of cones under the loading chutes), maximum force and shear on pebbles.

\section{Outputs Obtained}

Changes in geometry; Fuel damage.

Additional Comments (links to other functionalities)

Links to: Plant PRA (Ch. 19); Modeling of active and passive safety systems and components;

Modeling of component failure and human factors; Seismic response of structure, systems, and components of the plant; Pebble bed granular flow.

Bounding calculations should be performed to determine if more detailed simulations and experiments are needed (the bounding calculations may be sufficient for safety analysis). Tools may not exist to do these simulations due to the combination of moving solid objects in a fluid, so shake table experiments may be needed for either determining effects and/or provide validation data.

For Internal Use Only

F-04.05 


\section{Liquid fuel seismic response}

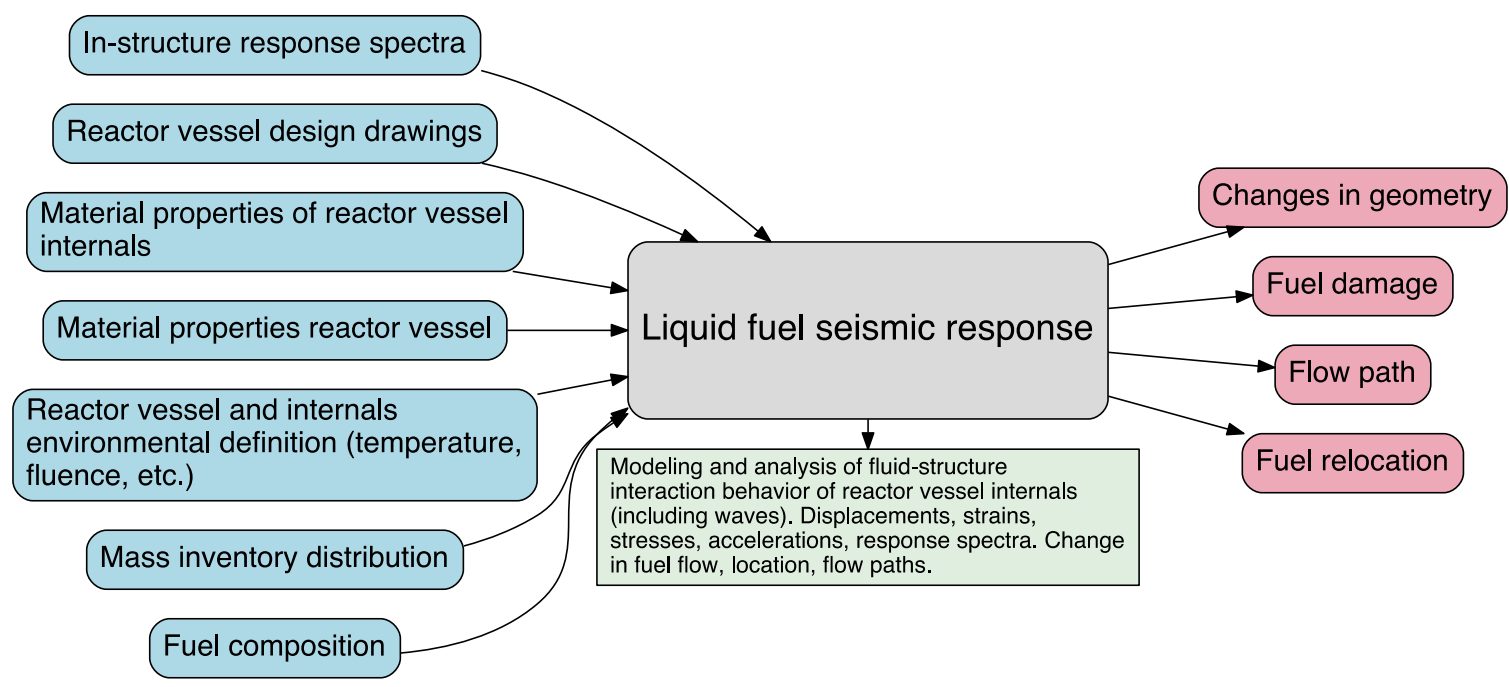

\section{MSR Modeling and Simulation Functionality Datasheet}

Version 0.0 - Feb. 28, 2018

Version 0.1 - Mar. 15, 2018

\begin{tabular}{|c|c|c|}
\hline & Date of Submission (mm/dd/yyyy) & \\
\hline Contributor Name(s) & Organization(s) & Email(s) \\
\hline $\begin{array}{c}\text { MSR Campaign Modeling \& } \\
\text { Simulation Team }\end{array}$ & $\begin{array}{l}\text { Oak Ridge National Laboratory } \\
\text { Argonne National Laboratory } \\
\text { Idaho National Laboratory } \\
\text { Pennsylvania State University }\end{array}$ & betzlerbr@ornl.gov \\
\hline
\end{tabular}

Modeling and Simulation Functionality

Liquid fuel seismic response

Inputs Required (as comprehensive as possible)

In-structure response spectra; Reactor vessel design drawings; Material properties of reactor vessel internals; Material properties reactor vessel; Reactor vessel and internals environmental definition (temperature, fluence, etc.); Mass inventory distribution; Fuel composition.

\section{Definition and Phenomena}

Modeling and analysis of fluid-structure interaction behavior of reactor vessel internals (including waves). Displacements, strains, stresses, accelerations, response spectra. Change in fuel flow, location, flow paths. 


\section{Outputs Obtained}

Changes in geometry; Fuel damage; Flow path; Fuel relocation.

Additional Comments (links to other functionalities)

Links to: Plant PRA (Ch. 19); Modeling of active and passive safety systems and components;

Modeling of component failure and human factors; Seismic response of structure, systems, and components of the plant; Fuel depletion; Source term accountability.

Bounding calculations should be performed to determine if more detailed simulations and experiments are needed (the bounding calculations may be sufficient for safety analysis).

For Internal Use Only

F-04.05 